Portland State University

PDXScholar

Spring 6-1-2015

\title{
Experimental Investigation of Fiber Reinforced Concrete Beams
}

\author{
Karrar Ali Al-lami \\ Portland State University
}

Follow this and additional works at: https://pdxscholar.library.pdx.edu/open_access_etds

Part of the Structural Engineering Commons

Let us know how access to this document benefits you.

\section{Recommended Citation}

Al-lami, Karrar Ali, "Experimental Investigation of Fiber Reinforced Concrete Beams" (2015). Dissertations and Theses. Paper 2296.

https://doi.org/10.15760/etd.2293

This Thesis is brought to you for free and open access. It has been accepted for inclusion in Dissertations and Theses by an authorized administrator of PDXScholar. For more information, please contact pdxscholar@pdx.edu. 
Experimental Investigation of Fiber Reinforced Concrete Beams

by

Karrar Ali Al-lami

A thesis submitted in partial fulfillment of the requirements for degree of

Master of Science

in

Civil and Environmental Engineering

Thesis Committee:

Franz Rad, Chair

Peter Dusicka

Evan Kristof

Portland State University

2015 


\begin{abstract}
Shear strength of fiber reinforced concrete beams was studied in this research project. Three types of fibers were examined: hooked-end steel fiber, crimped-steel fiber, and crimped-monofilament polypropylene fibers. The experimental program included five beam specimens. Two of the beams were control specimens in which one was reinforced with minimum shear reinforcement according to ACI 318, while the other one did not have any shear reinforcement. Each one of the other three specimens was reinforced with one of the above mentioned fibers by $1 \%$ volumetric ratio. In addition to the beam specimens, three prisms were also made for each type fiber to determine their toughness.

The aim of this research was to investigate the following questions for medium-high concrete strength 1) to evaluate the effectiveness of each type of fibers on the shear strength, 2) to investigate the shear strength, toughness, crack patterns and near ultimate load crack width of each beam, and 3) to determine if using $1 \%$ volumetric ratio of fibers as shear reinforcement in beams would provide adequate strength and stiffness properties comparable to reinforcing steel used as minimum shear reinforcement.

The results showed that all three types of fibers increased the shear capacity of the beam specimens more than the beam reinforced with minimum shear reinforcement. Moreover, some of the fibers used could shift the type of failure from a pure shear failure to a combined flexural-shear or pure flexural failure.
\end{abstract}




\begin{abstract}
AKNOWLEDGEMENTS
This research was submitted by the author to Portland State University in partial fulfillment the requirements of Masters of Science in Civil Engineering. First, the author wants to thank God for blessing him while he finished this research. The author would like to acknowledge the support provided by High Committee of Education Development in Iraq (HCED), which granted and funded the author's education and research.

The author would like also to show his gratitude for Professor Franz Rad, for his guidance, feedback, and valuable notes. The author would like to extend his appreciation to the other members of his graduate committee, Professors Peter Dusicka and Evan Kristof, for their review of the thesis and their helpful suggestions.

The author also would like to show his sincere gratitude to his friends and Mr. Tom Bennett who helped with the experimental part of this research. Finally, the author wants to thank his family for all the support and advice that they gave him during his graduate studies and research.
\end{abstract}




\section{Table of Contents}

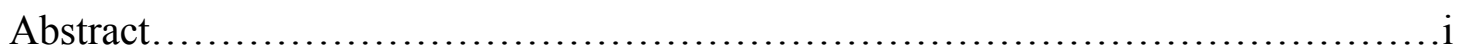

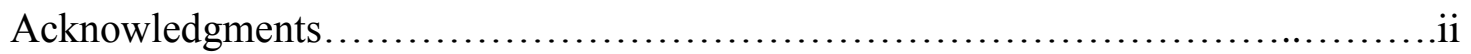

List of Tables.........................................................................

List of Figures...............................................................

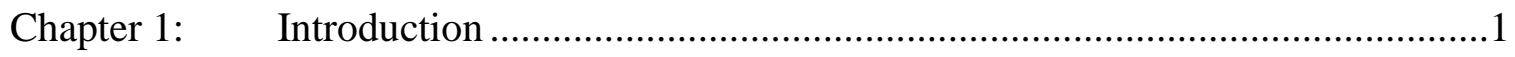

1.1. Historical Background and Development of Fibers ............................................1

1.2. Potential Uses of Fiber Reinforced Concrete FRC ..................................................

1.3. Motivation for the Research ........................................................................

1.4. Objective and Scope of the Research ...............................................................

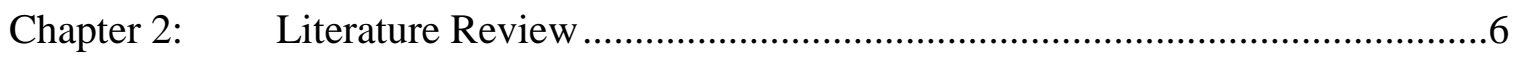

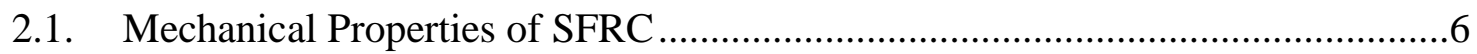

2.1.1. Bond Behavior of Steel Fiber Reinforced Concrete ......................................6

2.1.2. Tensile Strength of Steel Fiber Reinforced Concrete (SFRC) ......................10

2.1.3. Flexural Strength and Flexural Toughness of SFRC ..................................15

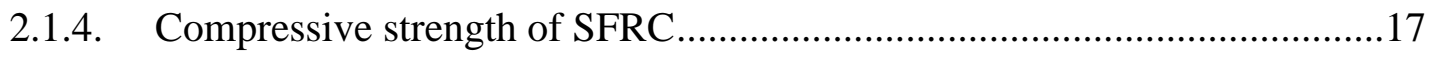

2.2. Mechanical Properties of Polypropylene Fiber Reinforced Concrete PPFRC....18

2.2.1. Tensile-Flexural and Compression Strength of PPFRC ...............................18

2.2.2. Flexural Strength and Flexural Toughness of PPFRC .................................19

2.2.3. Cracking and Shrinkage of PPFRC.........................................................20 
2.2.4. Shear Strength of PPFRC.

2.3. Shear Failure Mechanism of FRC

2.3.1. Failure of Plain Concrete Beams

2.3.2. Failure of Longitudinally Reinforced Beams without Diagonal Tension

Reinforcement

2.3.3. Modes of Failure of Beams Without Diagonal Tension Reinforcements ....24

2.3.4. Web Steel Reinforcement in Beams

2.3.5. Failure of SFRC Beams without Stirrups Reinforcement.........................28

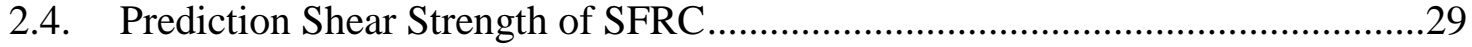

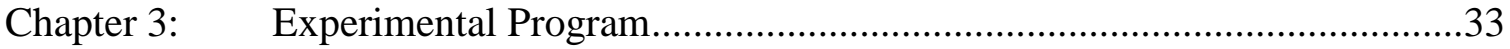

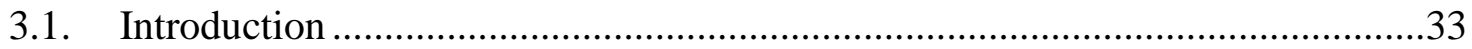

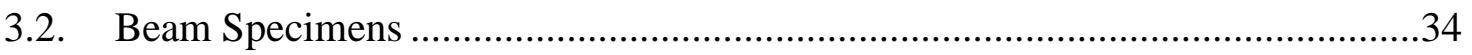

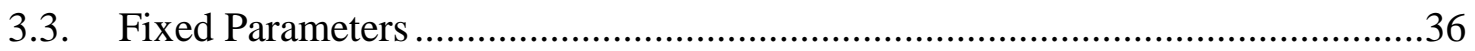

3.3.1. Shear Span-to-Effective Depth Ratio.......................................................

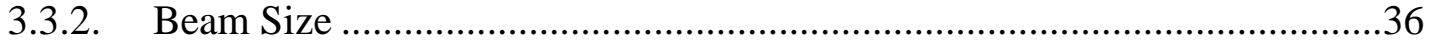

3.3.3. Longitudinal and Transverse Reinforcement for the Control Beam.............38

3.3.4. Fiber Volume Fraction ...................................................................... 41

3.3.5. Concrete Compressive Strength.......................................................... 42

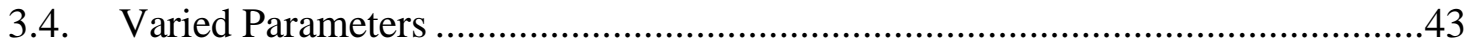


3.4.1. Fiber Types

3.5. Fabrication of Reinforcement Cages and Formwork …….................................44

3.6. Proportioning, Mixing and Curing of FRC ......................................................

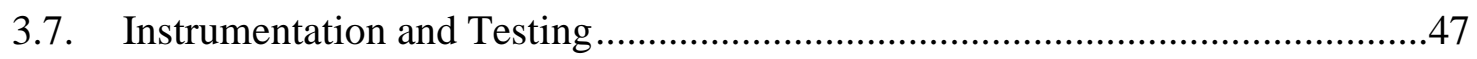

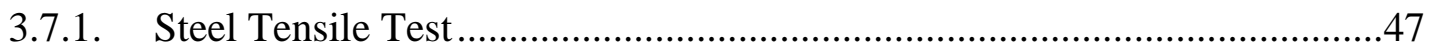

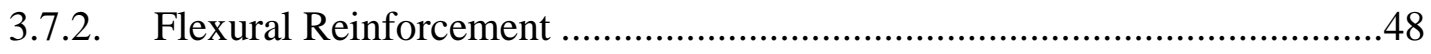

3.7.3. Concrete Compressive Test ........................................................................49

3.7.4. Splitting Tensile Strength ....................................................................50

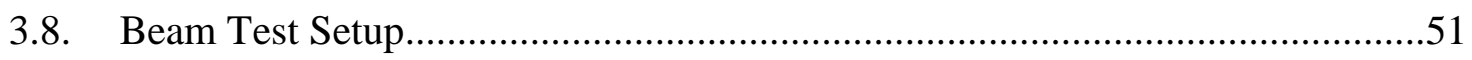

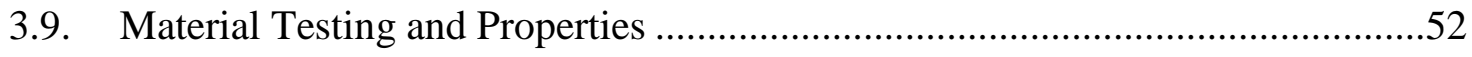

3.9.1. Shear Reinforcement..............................................................................52

Chapter 4: $\quad$ Result of the Experimental Program .........................................................53

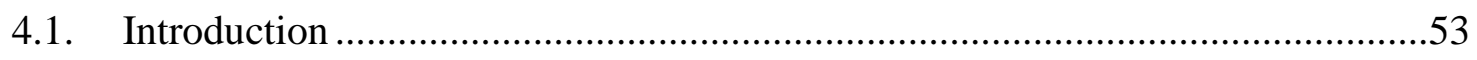

4.2. Mechanical Properties of Fiber Reinforced Concrete …………….....................53

4.2.1. Compressive Strength of Fiber Reinforced Concrete ..................................53

4.2.2. Splitting Tensile Strength .........................................................................58

4.2.3. Flexural Strength...............................................................................62

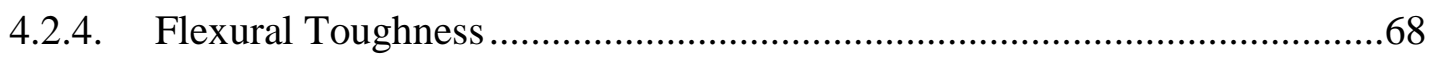

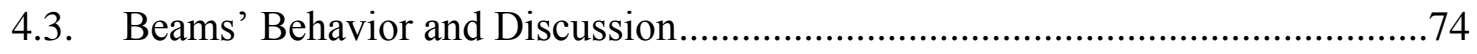


4.3.1. Beam Without Any Shear Reinforcement (B5-NS)

4.3.2. Beam Reinforced with Minimum Shear Steel Reinforcement (B1-MS) .....77

4.3.3. Beam Reinforced with Hooked-End Steel Fiber (B2-HS) ..........................81

4.3.1. Beam Reinforced with Crimped-Steel Fiber (B3-CS) ..............................84

4.3.2. Beam Reinforced with Monofilament-Crimped Polypropylene Fiber (B4CPP) $\quad 87$

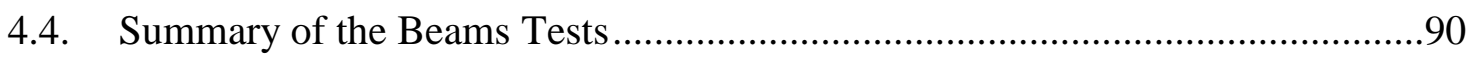

4.4.1. Ultimate Shear Stress and Normalize Shear Stress..................................90

4.4.2. Crack Width, Pattern and Failure Mode ................................................93

4.4.3. Prediction of Shear Strength Based on Previous Research.........................94

4.4.4. Replacement of Minimum Shear Reinforcement ...................................95

Chapter 5: $\quad$ Summary, Conclusions and Recommendations for Further Research .....97

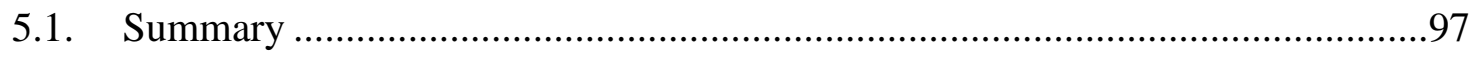

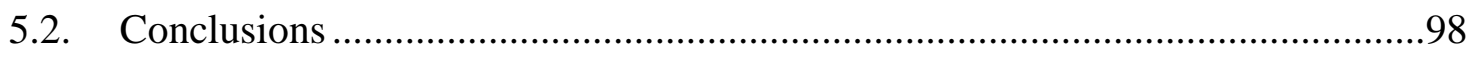

5.3. Recommendations for Further Research ................................................99

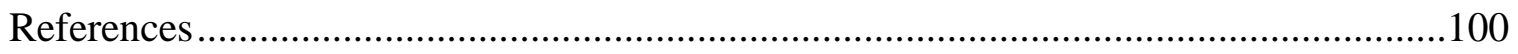




\section{List of Tables}

Table 2-1 Pullout test pertinent to hooked steel fibers and deformed fibers .....................7

Table 2-2 Test results for hooked and cimped steel fibers embedded in a concrete matrix 8

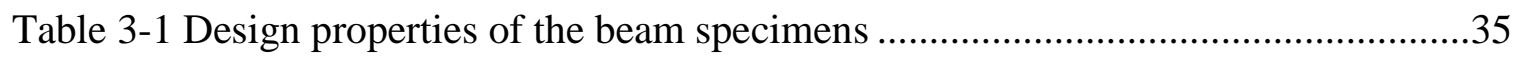

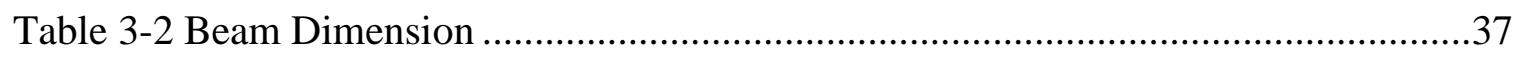

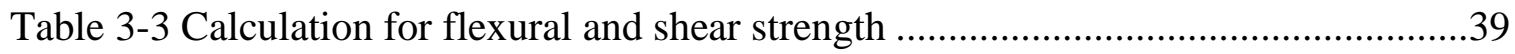

Table 3-4 Mix proportion for each type of fiber..................................................42

Table 3-5 Type and Characteristics of the used fibers................................................43

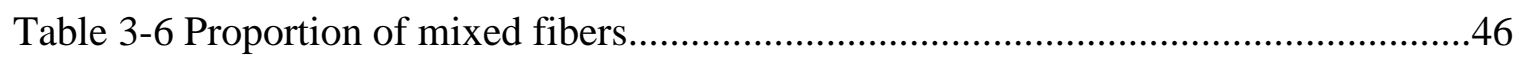

Table 3-7 Diagonal shear reinforcement properties.................................................52

Table 4-1 Compressive strength and modulus of elasticity ........................................54

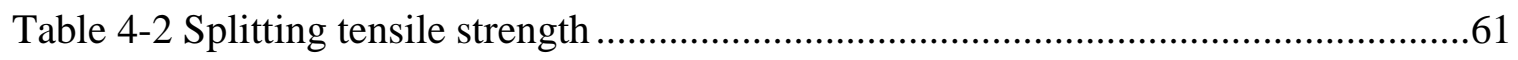

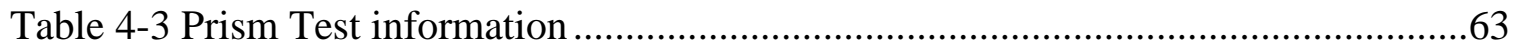

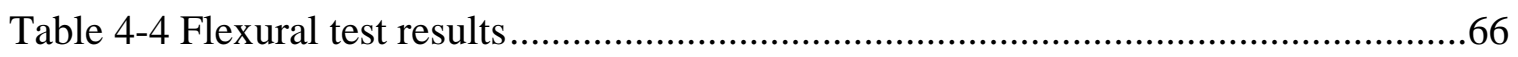

Table 4-5 Flexural toughness index of fiber reinforced concrete .................................71

Table 4-6 Normalized ultimate shear stress in term of f'c ......................................91

Table 4-7 Normalized shear strength of the beams to the one with min shear

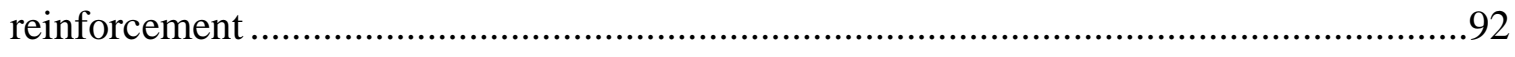

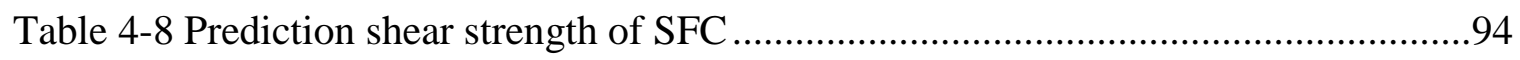




\section{List of Figures}

Figure 1-1 Type of fibers; (a) Steel fibers; (b) polypropylene fibers reinforced concrete ..2 Figure 2-1 Effect of compressive strength on pullout (from Naaman and Najim, 1991)....7

Figure 2-2 Effect of fiber inclination for hooked steel fiber in Concrete .9

Figure 2-3 Direct tensile stress-strain curves for different type of SFRC ......................12

Figure 2-4 Tensile stress-crack opening relationship for different SFRC mixes..............12

Figure 2-5 Dinh Direct tensile strength; (a) dog-bone specimen; (b) result ....................13

Figure 2-6 Important characteristics of the load-deflection curve (ASTM C 1018) ........15

Figure 2-7 Effect of hooked and straight steel fibers on flexural performance of

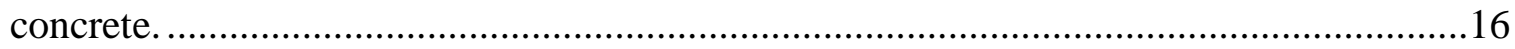

Figure 2-8 Effect of the volume of fibers on the compressive stress-strain curve ............17

Figure 2-9 The effect of Fiber content on the modules of rapture (From ACI 544).........19

Figure 2-10 Average Cracks width Versus Fiber content (From ACI 544) ....................21

Figure 2-11 Plain concrete beam subjected to concentrated load ...................................23

Figure 2-12 Crack pattern and principal stresses in longitudinally reinforced concrete

beam.

Figure 2-13 Failure modes (a) Flexural failure; (b) Diagonal tension (c) Shear

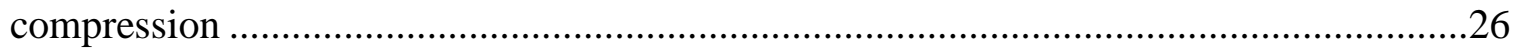

Figure 2-14 Shear resistant component (From Dinh, 2009) .....................................27

Figure 3-1 Load, Dimension and cross section for the tested beams..............................37

Figure 3-2 Reinforcement details and beams dimension .......................................40

Figure 3-3 Fibers used in the experimental program ..............................................44

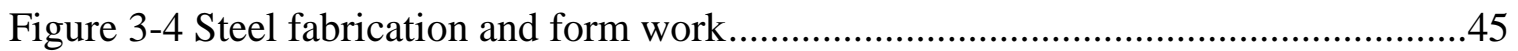


Figure 3-5 Direct tensile testing machine "Instorn"

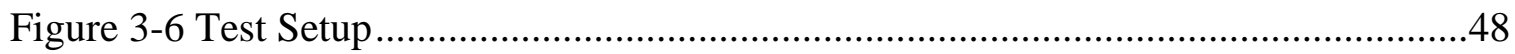

Figure 3-7 Stress-strain curve for longitudinal reinforcement...................................48

Figure 3-8 Concrete compressive machine ..........................................................49

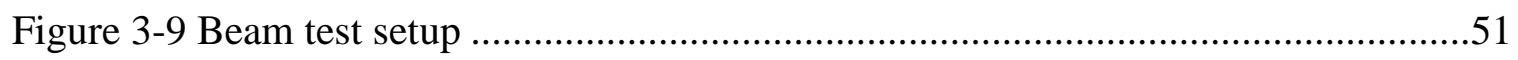

Figure 3-10 Stress-Strain relationship for diagonal shear reinforcement wire .................52

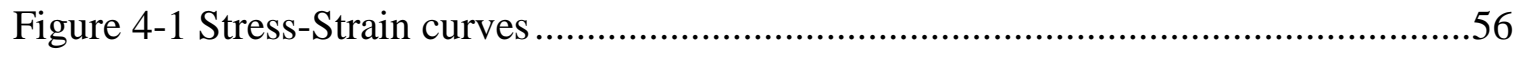

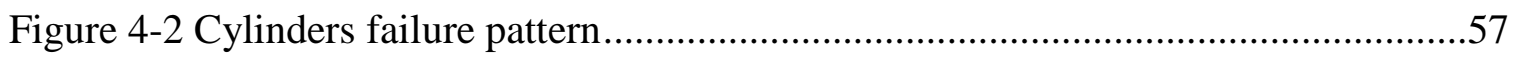

Figure 4-3 Tensile stress Vs Strain for splitting test...............................................59

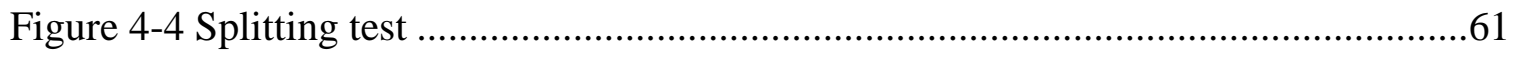

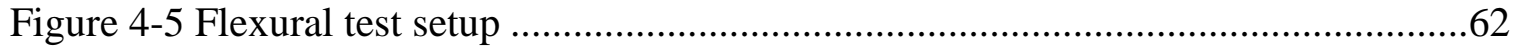

Figure 4-6 Flexural Stress Versus Deflection at midspan ........................................65

Figure 4-7 Flexural toughness of concrete prism ...................................................

Figure 4-8 Comparison of the average flexural toughness index for the three used fiber.72

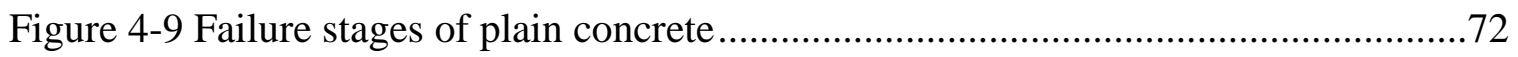

Figure 4-10 Areas used to determine flexural toughness index.................................73

Figure 4-11 Experimental load versus deflection ................................................. 74

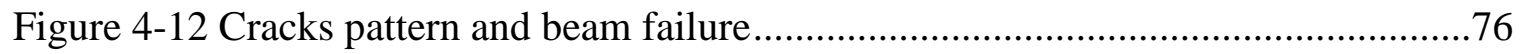

Figure 4-13 Load versus deflection for minimum shear reinforcement beam.................77

Figure 4-14 Cracks propagation for minimum shear reinforcement specimen ................80

Figure 4-15 Load Vs deflection for hooked end steel fiber ......................................81

Figure 4-16 Cracks propagation and failure pattern for hooked end steel fiber ...............83 
Figure 4-17 Load vs deflection for crimped steel fiber

Figure 4-18 Cracks propagation and failure pattern for crimped steel fiber....................86

Figure 4-19 Load vs deflection for crimped monofilament polypropylene fiber .............87

Figure 4-20 Cracks propagation and failure pattern for crimped polypropylene fiber......89

Figure 4-21 Shear forces in the tested beams ...................................................... 90

Figure 4-22 comparison load versus deflection for the tested beam specimens...............95

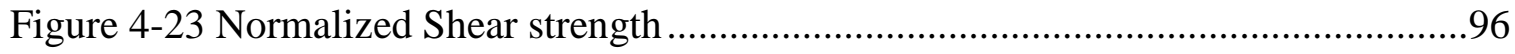




\section{Chapter 1: Introduction}

\subsection{Historical Background and Development of Fibers}

Historically, much effort has been spent improving the behavior of concrete structures. Flexural, compressive, shear strength, ductility, and other properties have been the focus of many researchers who have tested concretes with added steel and other materials to improve the behavior of concrete. The concept of adding fibers to improve brittle material behavior is ancient. For example, Mesopotamians used straw to reinforce sunbaked bricks. This ancient technology is still used to improve concrete characteristics.

Nowadays, fibers are produced from different materials such as steel, glass, carbon, and synthetic material. Each one of these fibers has it specific benefits. However, steel fiber is the most common one. It has been reported [1] that the first experimental trial to improve concrete characteristics using discontinues steel reinforcing elements, such as nails segments, was done in 1910. However, it was not until 1963 [1] when major experiments were done to improve concrete characteristics using a real steel fibers. A typical length of steel fibers ranges from 0.25 to 2.5 in ( 6 to $64 \mathrm{~mm}$ ), and its diameter ranges from 0.02 to 0.04 in $(0.5$ to $1.0 \mathrm{~mm})$. Steel fibers are produced in different forms as shown in figure11. This type of fiber is available commercially in tensile strength up to $300 \mathrm{ksi}$ (2068 $\mathrm{MPa})$.

In order to overcome problems with steel fibers such rusting, researchers have studied other types of fibers. Synthetic fibers (polypropylene and nylon) are some of these fibers. Polypropylene fibers were used for the first time in 1965 in the construction of blast 
resisting building for the United States Army Corps of Engineers (USACE). Earlier studies [1] showed that these fibers were not successful like steel and glass. However, a better understanding of fiber behavior, new types of fibers, and other factors led to successful synthetic fiber.
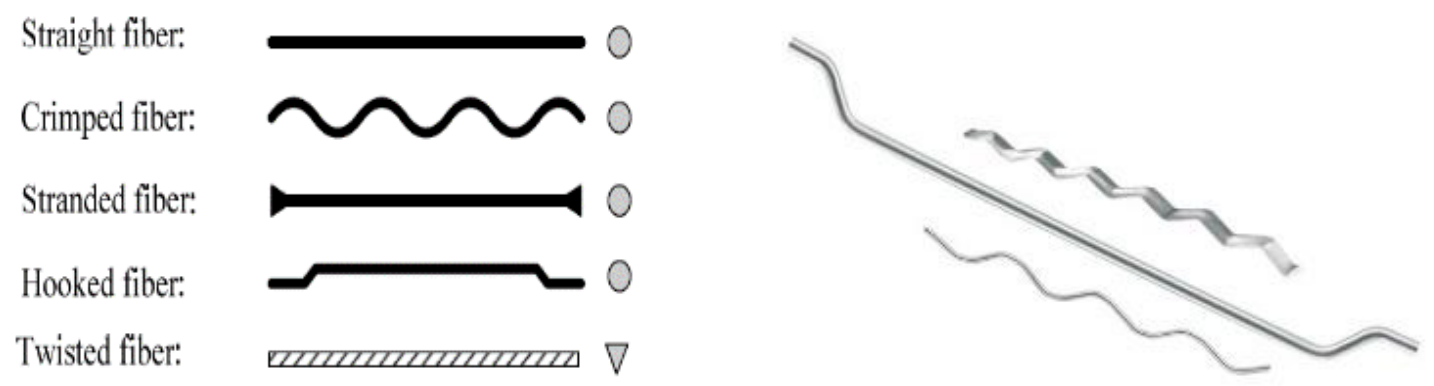

(a)

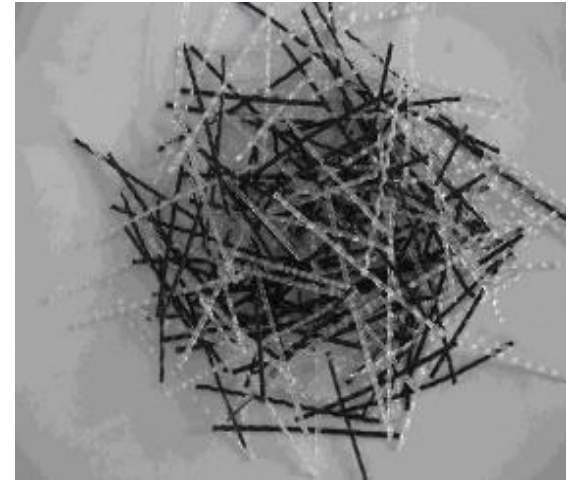

Monofilament

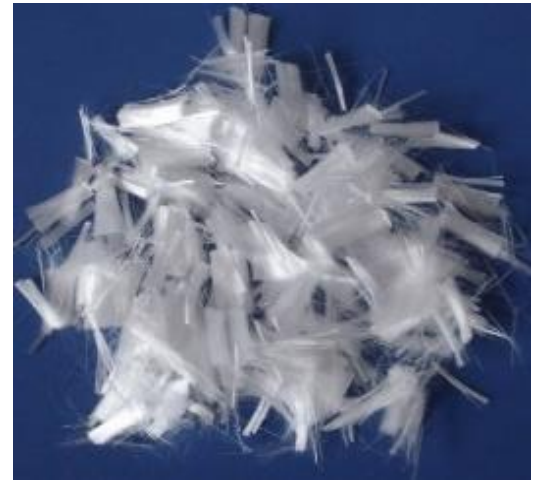

Fibrillated fiber

(b)

Figure 1-1 Type of fibers; (a) Steel fibers; (b) polypropylene fibers reinforced concrete 


\subsection{Potential Uses of Fiber Reinforced Concrete FRC}

Steel fiber is used to improve the mechanical properties of concrete, especially the postcracking tensile resistant. Moreover, it has recently been used as an alternative engineering material instead of steel bars/steel stirrups in short-span concrete slabs. Steel fibers reinforced concrete (SFRC) construction is more economical than conventional construction. In addition to cost reduction, SFRC has other beneficial properties such as higher stiffness, higher ductility, lightweight, low repair costs, and better post-cracking and dynamic behavior.

SFRC has been used extensively in construction of industrial floors, bridge deck overlays, airport runways, highway pavements, tunnel linings, spillways, dams, slope stabilizations, and many precast products. An example of recent use of steel fiber is the Gotthard Base Tunnel. Nevertheless, relatively little use of SFRC in the building structure is mainly due to the lack of design provisions in building codes.

Steel fibers can improve the characteristics of hardened concrete, and polypropylene fibers can have a significant effects on the fresh concrete. Polypropylene fibers significantly reduce the slump of the fresh concrete resulting in an increase in the adhesion and cohesion of the concrete. Polypropylene fibers also reduce the plastic shrinkage cracks. Polypropylene fibers can increase concrete durability against fire, freezing, and chemical attacks. Due to its benefits, polypropylene fiber reinforced concrete (PPFRC) is used in pile foundations, piers, highways, industrial floors, bridge decking and others. 


\subsection{Motivation for the Research}

The guidelines that deal with SFRC is "Design Consideration for Steel Fiber Reinforced Concrete" (ACI Committee 544, 2009). It contains test results and equations to predict shear strength. This provision does not have any design equations for two possible reasons. First, the most available research has been done with older types of fibers such as chopped-straight wire. These types of fibers do not enhance concrete characteristics as much as modern fibers. Second, the working mechanisms of steel fibers in RC beams to enhance flexure, shear and other characteristics are not fully understood.

These reasons were the motivation to study STFRC in this research project.

\subsection{Objective and Scope of the Research}

The objective of this research was to investigate the following aspects of fiber reinforced beams made of medium-high concrete capacity. 1) to evaluate the effectiveness of each type of fibers (hooked-end steel fibers, crimped-steel fibers and polypropylene fibers) on the shear strength of beams, 2) to investigate the shear strength, toughness, crack patterns and near ultimate load crack width of each beam, and 3) to determine if using $1 \%$ volumetric ratio of fibers as shear reinforcement in beams would provide adequate strength and stiffness properties comparable to reinforcing steel used as minimum shear reinforcement.

The experimental program included five beam specimens. Two beams were control specimens, one was reinforced with minimum shear reinforcement using reinforcing steel 
according to ACI 318, while the other one had no shear reinforcement. Each one of the other three specimens was reinforced with one type of fibers (hooked-end steel fibers, crimped-steel fibers and polypropylene fibers) by $1 \%$ volumetric ratio. In addition to the beam specimens, three prisms were made using each type of fiber to determine their toughness. This research is limited to testing approximately one-third scale simply supported beams. In this research test specimens were approximately one-third scale simply supported beams, suitable for laboratory experiments.

Each specimen is reinforced with $1 \%$ volumetric ratio of fiber. These fibers are hookedend steel fibers, crimped-steel fibers and polypropylene fibers. The main objectives of this research were: 1) to investigate the possibility of using $1 \%$ volumetric ratio of fibers to replace minimum shear reinforcement required by ACI 318; 2) to study the behavior of fiber reinforced concrete beams without reinforcing steel shear reinforcement; 3) and to evaluate the effectiveness of each type of fibers. 


\section{Chapter 2: $\quad$ Literature Review}

\subsection{Mechanical Properties of SFRC}

\subsubsection{Bond Behavior of Steel Fiber Reinforced Concrete}

As it mentioned before, the utilization of fibers to enhance the characteristics of brittle material is very old. In the early 1960s [1], steel fiber was introduced as a new a version of fiber. Straight fiber was the first type of that fiber. The bond of that fiber depended on the friction between the concrete and fiber. Consequently, a rectangular section with higher aspect ratio was more efficient.

The role of steel fiber is to inhabit the propagation of micro-cracks. There are two possible scenarios of failure of fibers. The first is the fracture of fiber and the second $\mathrm{s}$ the pull-out of fibers from the concrete. The second scenario is more preferable because it is more ductile, and acts as an energy absorber. In other words in order for the fiber to be pulled out, hooked-end fiber and crimped-fiber should bend significantly and yield. Consequently, this process will absorb a great amount of energy. One of the factors that affect the failure type is the bond between steel fiber and concrete.

A relationship was derived [2] to determine critical fiber length, after which fiber undergoes fracture instead of pullout, when a crack intersects the fiber at midpoint.

$l_{c}=\frac{d_{f}}{2 v_{b}} \sigma_{f}$

Where $d_{f}, v_{b}$, and $\sigma_{f}$, are respectively fiber diameter, interfacial bond strength, and fiber strength. 
Studies [3] have shown that an increase in the compressive strength of concrete could increase the bond between steel fiber concrete itself as shown in table 2.1. Furthermore, hooked-end steel fibers and deformed steel fibers required a load that was four times the load required to pullout smooth fiber figure 2-1. However, volume fraction of steel fibers did not have that significant effect for less than $3 \%$ content. The content increased peak pullout load by $10 \%$ and slightly affected the post-peak load resistance.

Table 2-1 Pullout test pertinent to hooked steel fibers and deformed fibers embedment in cement based matrix (from Naaman and Najam, 1991)

\begin{tabular}{|c|c|c|c|c|c|}
\hline $\begin{array}{c}\text { Diameter } \\
\text { (in.) }\end{array}$ & $\begin{array}{l}\text { Embedment } \\
\text { length } \\
\text { (in.) }\end{array}$ & Fiber type & $\begin{array}{c}\text { Matrix } \\
\text { strength } \\
\text { (psi) }\end{array}$ & $\begin{array}{c}\text { Ppeak } \\
\text { (lb) }\end{array}$ & $\begin{array}{c}\Delta p e a k \\
\text { (in.) }\end{array}$ \\
\hline \multirow{5}{*}{$\begin{array}{c}0.0295 \\
(0.75 \mathrm{~mm})\end{array}$} & \multirow{5}{*}{$(25.4 \mathrm{~mm})$} & Hooked & 8650 & 102.8 & 0.029 \\
\hline & & Hooked & 7400 & 80.3 & 0.035 \\
\hline & & Hooked & 4850 & 58.9 & 0.031 \\
\hline & & Deformed & 7400 & 35.4 & 0.051 \\
\hline & & Deformed & 4850 & 21.6 & 0.067 \\
\hline
\end{tabular}

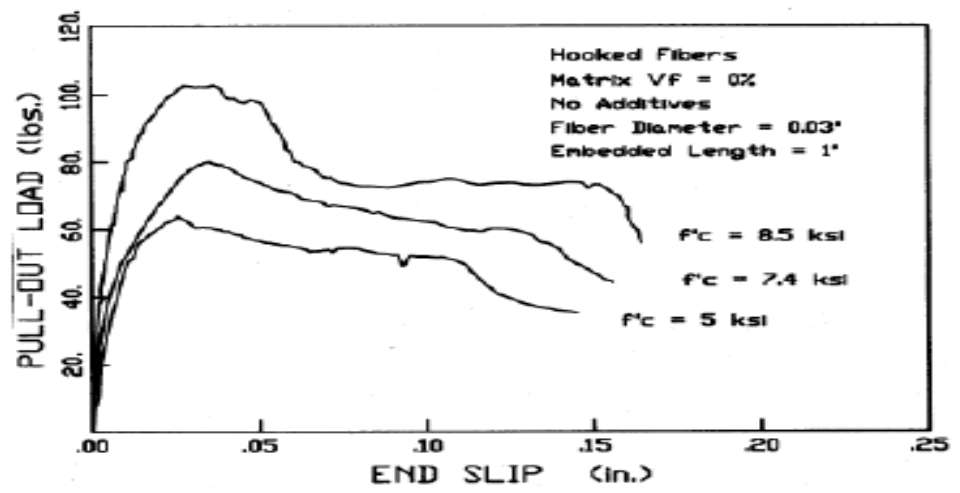

Figure 2-1 Effect of compressive strength on pullout (from Naaman and Najim, 1991) 
Other researchers [4] studied bond behavior of hooked, crimped, and standard steel fibers that had fibers that were inclined toward a degree that ranged from (0-90) with respect to the load direction. The conclusion was that increasing concrete compressive strength would enhance the bond between fibers and concrete as shown in table 2-2.

Table 2-2 Test results for hooked and cimped steel fibers embedded in a concrete matrix (from Banthia and Trottier, 1994)

\begin{tabular}{|c|c|c|c|c|}
\hline Fiber Type & Diameter & $\begin{array}{l}\text { Matrix } \\
\text { strength }\end{array}$ & Ppeak & $\Delta$ average \\
\hline \multirow[t]{3}{*}{ Hooked end } & \multirow[t]{3}{*}{$\begin{array}{l}0.0315 \mathrm{in} \\
(0.8 \mathrm{~mm})\end{array}$} & $\begin{array}{l}5802 \mathrm{psi} \\
(40 \mathrm{MPa})\end{array}$ & $\begin{array}{c}61 \mathrm{lb} \\
(272.9 \mathrm{~N})\end{array}$ & $\begin{array}{c}0.06 \mathrm{in} \\
(1.55 \mathrm{~mm})\end{array}$ \\
\hline & & $\begin{array}{l}7542 \mathrm{psi} \\
(52 \mathrm{MPa})\end{array}$ & $\begin{array}{c}65 \mathrm{lb} \\
(287.2 \mathrm{~N})\end{array}$ & $\begin{array}{l}0.039 \mathrm{in} \\
(0.98 \mathrm{~mm}\end{array}$ \\
\hline & & $\begin{array}{l}12382 \mathrm{psi} \\
(85 \mathrm{MPa})\end{array}$ & $\begin{array}{c}67 \mathrm{lb} \\
(296.5 \mathrm{~N})\end{array}$ & $\begin{array}{l}0.047 \mathrm{in} \\
(1.19 \mathrm{~mm})\end{array}$ \\
\hline \multirow[t]{3}{*}{ Crimped } & \multirow[t]{3}{*}{$\begin{array}{l}0.039 \text { in } \\
(1.0 \mathrm{~mm})\end{array}$} & $\begin{array}{l}5802 \mathrm{psi} \\
(40 \mathrm{MPa})\end{array}$ & $\begin{array}{c}152 \mathrm{lb} \\
(676.5 \mathrm{~N})\end{array}$ & $\begin{array}{c}0.100 \mathrm{in} \\
(2.56 \mathrm{~mm})\end{array}$ \\
\hline & & $\begin{array}{l}7542 \mathrm{psi} \\
(52 \mathrm{MPa}\end{array}$ & $\begin{array}{c}153 \mathrm{lb} \\
(680.0 \mathrm{~N})\end{array}$ & $\begin{array}{c}0.096 \text { in } \\
(2.44 \mathrm{~mm})\end{array}$ \\
\hline & & $\begin{array}{l}12382 \mathrm{psi} \\
(85 \mathrm{MPa})\end{array}$ & $\begin{array}{c}151 \mathrm{lb} \\
(670.9 \mathrm{~N})\end{array}$ & $\begin{array}{c}0.082 \mathrm{in} \\
(2.09 \mathrm{~mm})\end{array}$ \\
\hline
\end{tabular}


(a) Normal-strength concrete

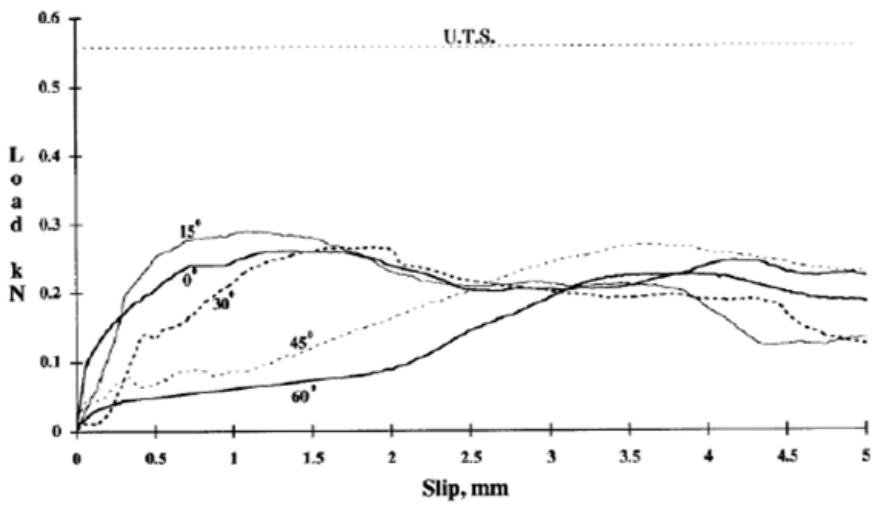

(b) Mid-strength concrete

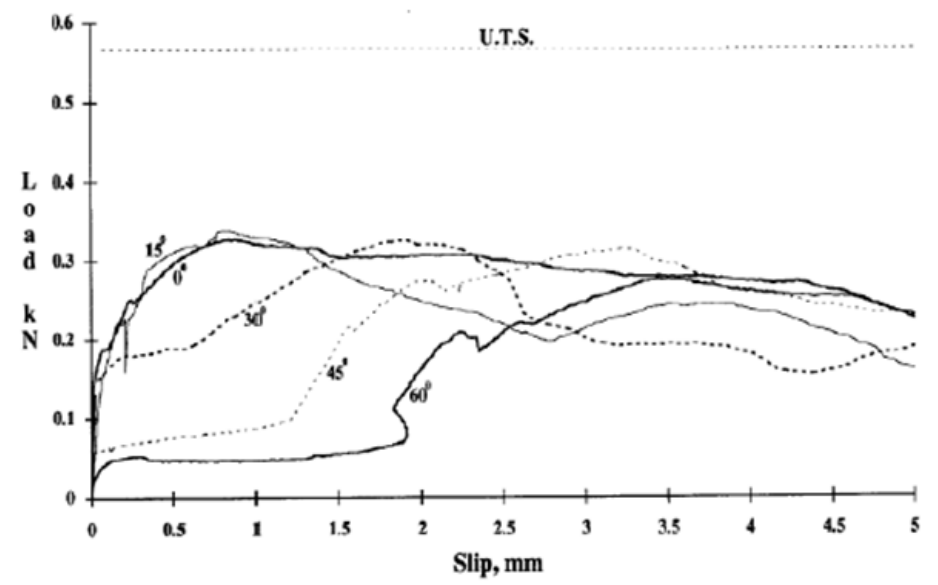

(c) High-strength concrete

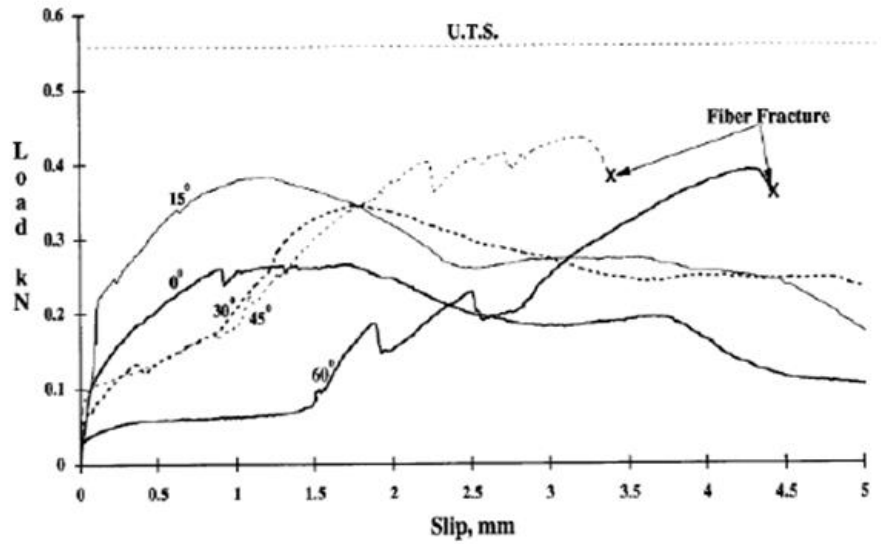

Figure 2-2 Effect of fiber inclination for hooked steel fiber in Concrete (from Banthia and Trottier, 1994) 


\subsubsection{Tensile Strength of Steel Fiber Reinforced Concrete (SFRC)}

Concrete is a brittle material with very low tensile strength in comparison with its compressive strength. It is estimated that its tensile strength about $10 \%$ of its compressive strength. The tensile failure of plain concrete starts with cracks. Consequently, one of these cracks will extend along the member leading to its structural failure. However in fiber reinforced concrete, tensile failure can be divided into two stages. The first stage is up to the first crack. Previous studies [5], [6] provided equations to determine the tensile strength, $\sigma_{c}$ and stiffness $E_{c}$ of the composite at this stage.

$\sigma_{c}=\sigma_{f} V_{f}+\sigma_{m u}\left(1-V_{f}\right)$

$E_{c}=E_{f} V_{f}+E_{m}\left(1-V_{f}\right)$

Where $\sigma_{\mathrm{mu}}, \mathrm{E}_{\mathrm{m}}, \mathrm{E}_{f}$, and $\mathrm{V}_{f}$, are, respectively, the matrix tensile strength at first-crack, the matrix modulus, the fiber modulus, and the fiber volume fraction. These equations show that composite strength and stiffness are the function volumetric ratio of steel fibers. Since this ratio is so small, less than $2 \%$ in most cases, first-crack strength and stiffness of the composite are almost equal to the plain concrete. In order to account for fiber alignment in two or three dimensions, two factors were introduced to the previous equations. First one is fiber length factor, $\eta 1$. Second one is fiber orientation factor, $\eta_{2}$.

$$
\begin{aligned}
& \sigma_{c}=\eta_{1} \eta_{2} \sigma_{f} V_{f}+\sigma_{m u}\left(1-V_{f}\right) \\
& E_{c}=\eta_{1} \eta_{2} E_{f} V_{f}+E_{m}\left(1-V_{f}\right)
\end{aligned}
$$

The second stage of tension cracks is post-cracking. In this stage, fibers bridge the cracks. They debond and pull out before fiber fracture occurs. Therefore, fibers play a significant 
role in this stage. The post-cracking strength depends on the bond between fibers and concrete, fibers orientation, and number of fibers that across the crack. Naaman and Reinhardt [7] provided an equation to determine post-cracking strength

$\sigma_{p c}=\left(\lambda_{1} L_{f} \cdot \pi D_{f} \cdot \lambda_{2} \tau\right) \cdot\left[\lambda_{3} \frac{V_{f}}{\pi D_{f}^{2}}\right]=\lambda_{1} \lambda_{2} \lambda_{3} \tau V_{f} \frac{L_{f}}{D_{f}}$

Where $\lambda_{1}$ and $\lambda_{2}$ are, respectively, the fiber length and orientation factors for a post-

cracking state, while $\lambda 3$ is the group factor associated with the number of fibers crossing a unit area.

Experimentally, there are two methods to assess tensile strength of concrete. The first one is direct tensile test. This test needs a large cross section specimen such that it can simulate steel fiber distribution in real beams. The problem with such a section is the mechanism used to grip beam's ends for testing. Moreover, one of the studies [8] mentioned that a large cross section specimen will prevent uniform cracks from forming, causing the sample to twist sideways. Therefore, the load condition at failure is not purely uniaxial anymore. Nonetheless, in a small size specimen, the fractural failure will be hindered by the boundary conditions. Moreover, it is difficult to rely on strain values to determine direct tension strength of SFRC, especially after cracking, because they are the result of local cracks opening. However, researchers tend to report deformation in the form of the cracks' width to determine direct tensile strength of steel fiber reinforced concrete.

Other studies [9] focused on the effect of different types of steel fibers on tensile stress of fiber-reinforced mortar indirect tension as shown in figure 2-3. 


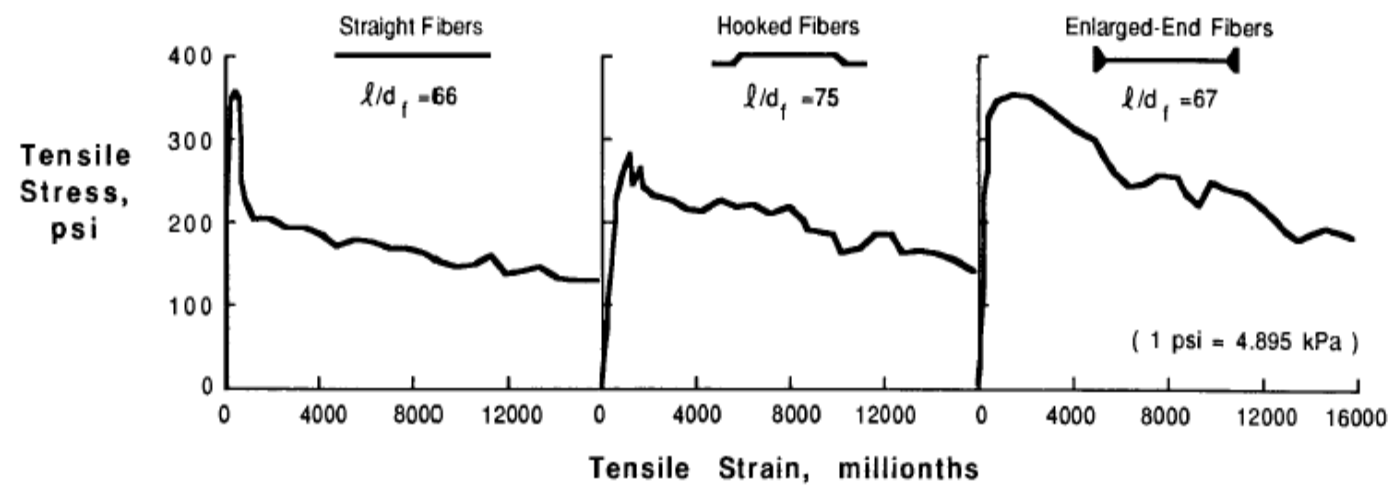

Figure 2-3 Direct tensile stress-strain curves for different type of SFRC (from Hai H. Dinh, 2009)

Other tests [10] on concrete cylinder specimens of 2.76 in $(70 \mathrm{~mm})$ diameter and with a height of 3.35 in $(85 \mathrm{~mm})$, as shown in figure. 2-4, used hooked-steel fibers, highstrength concrete, and aggregate size ranging from 0.315 in $(8 \mathrm{~mm})$ to 0.63 in $(16 \mathrm{~mm})$. The test result showed that high strength concrete could increase both first-cracking and post-cracking strength of steel fiber reinforced concrete.

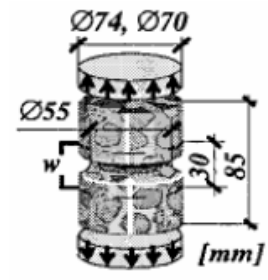

(a): Test set-up

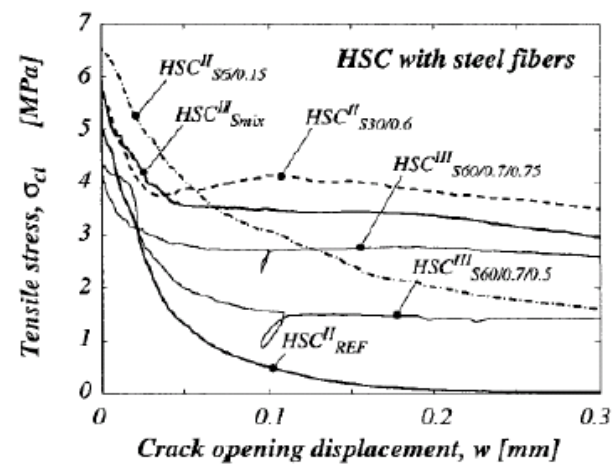

(b) Tensile stress-crack opening relationship

Figure 2-4 Tensile stress-crack opening relationship for different SFRC mixes 
One of the studies [6] used a dog-bone specimen to investigated direct tensile strength of steel fiber reinforced concrete. This research investigated hooked-end steel fibers with different aspect ratio. The result varied from one specimen to another even for those made from the same material. The varied result was attributed to size of the specimen, which prevented a uniform distribution of the fibers. Figure 2-5 shows the specimen that was used, and some of the results that were obtained.
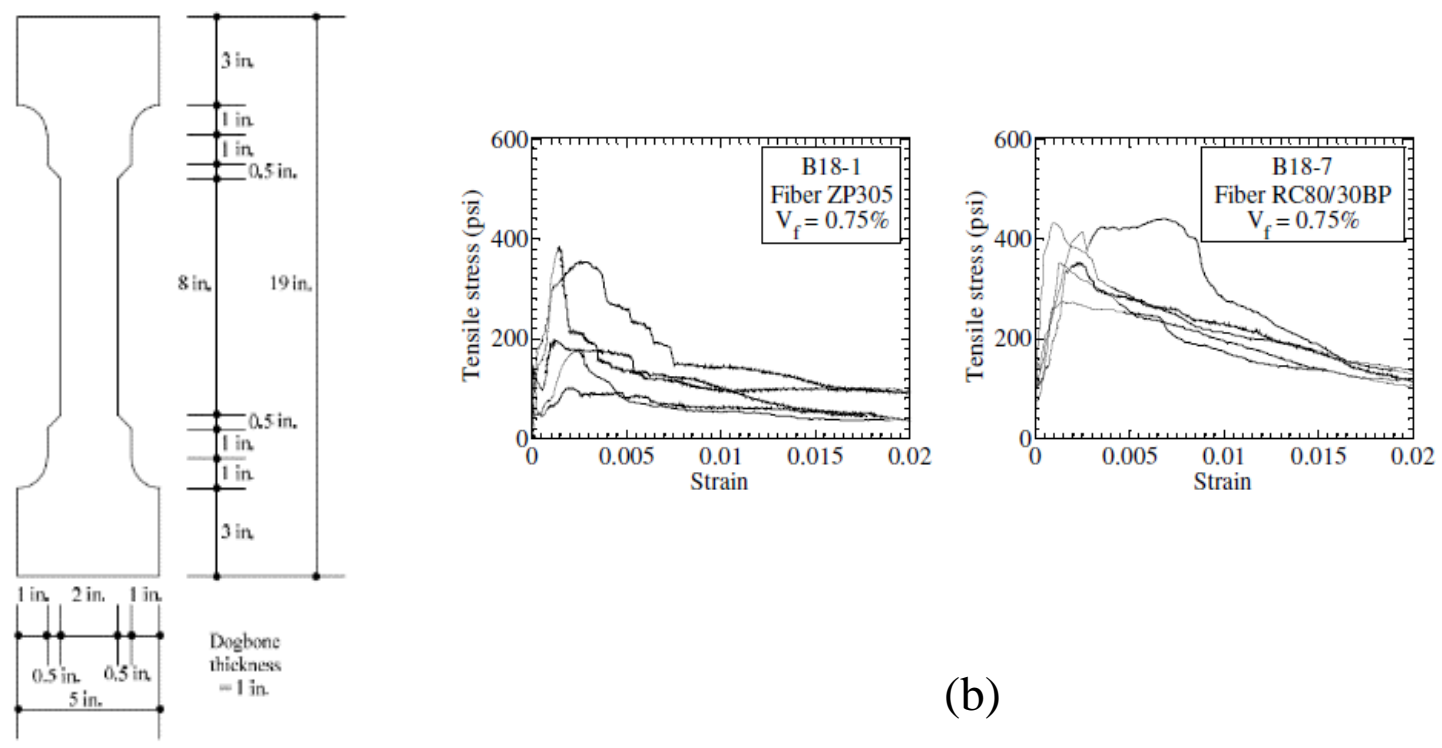

(a)

Figure 2-5 Dinh Direct tensile strength; (a) dog-bone specimen; (b) result

The second testing method is the splitting tensile test also referred to as the Brazilian test, which was first introduced in 1953 [11]. In this test, the specimen and testing equipment are the same as compression test. Thus, the test can be conducted in most facilities. This test has been used in production application for quality control purposes. Like the previous test, it has disadvantages also. Compared with direct tensile test, splitting tensile test does not provide convenient data for post-cracking behavior. Another major concern 
is that the loading condition does not represent a realistic situation for most application. Researchers [12] mentioned that the normal test configurations could not be used to obtain tensile strength for FRC. Nevertheless, other studies [11] presented a methodology that can be used to obtain rough estimation of tensile strength of FRC using splitting test. One of the studies by Tang [13] included the effect of the loading strip lying between the actuator and the specimen, which cause non-uniform stress distribution along the loading axis. The old equation used to determine tensile strength is $f_{t}=\frac{2 p}{\pi D}$

Where $p$ is the applied load, and $D$ is the specimen diameter. With the Tang modification the equation will be:

$f_{t}=\frac{2 p}{\pi D}\left[1-\left(\frac{b}{D}\right)^{2}\right]^{\frac{2}{3}}$

In order to include the quasi-brittle behavior of the concrete material and the related fracture mechanics size effect, the reason for the big differences between the splitting tensile strength and true tensile strength, studies [14] suggested using a strip not more than $8 \%$ of the specimen's diameter and the loading speed not more $1.0 \mathrm{MPa}$ per minute. 


\subsubsection{Flexural Strength and Flexural Toughness of SFRC}

There are two types of flexural strength [1] for SFRC. The first one is first-crack flexural strength, which shows a linear behavior as shown in figure2-7 (point A). From studies [9], it was found out that this flexural strength could be increased by almost $100 \%$ for concrete reinforced with $1 \%$ of straight steel fibers. Another study [15] reported that $2 \%$ of hooked steel fiber with aspect ratio of 64 could increase first-crack flexural strength of high strength concrete up to $127 \%$. In another research [16], it was reported that hooked fiber ranging from $0.5 \%$ to $1.5 \%$ with aspect ratio of 60 could increase first-crack flexural strength of 5000 psi to 12500 psi concrete up to $40 \%$. The second one is ultimate flexural strength shown in figure 2-6 (point $\mathrm{C}$ ), which is related to maximum load achieved, and therefore is more important for design considerations. Flexural strength can be increased by increasing fiber volume fraction and fibers' aspect ratio (1/d). Another researcher [17] reported that hooked-end fibers or enlarge-end fibers can increase ultimate flexural strength by $100 \%$.

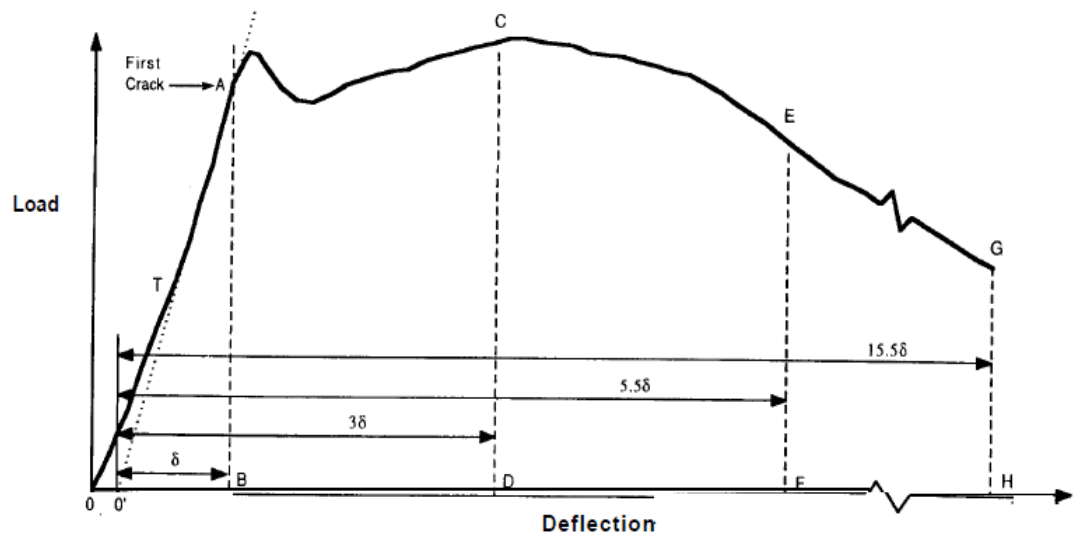

Figure 2-6 Important characteristics of the load-deflection curve (ASTM C 1018) 
Another important characteristic that should be determined for SFRC is flexural toughness. American concrete institute (ACI 544) defines flexural toughness under static loading as the area under load-deflection curve. In other words, it is the total energy observed before separation. Flexural toughness is represented by flexural toughness index. The flexural toughness index [18] [19] is the area under load-deflection curve of steel fibers to specified end-point to the area up to first- crack. Studies [20] [21]found that flexural toughness depends on type, and concentration of fibers as shown in figure 2-7. It is important to mention that flexural toughness refers to the toughening effect of the fibers distinct from other effects like strengthening of first-crack occurrence.

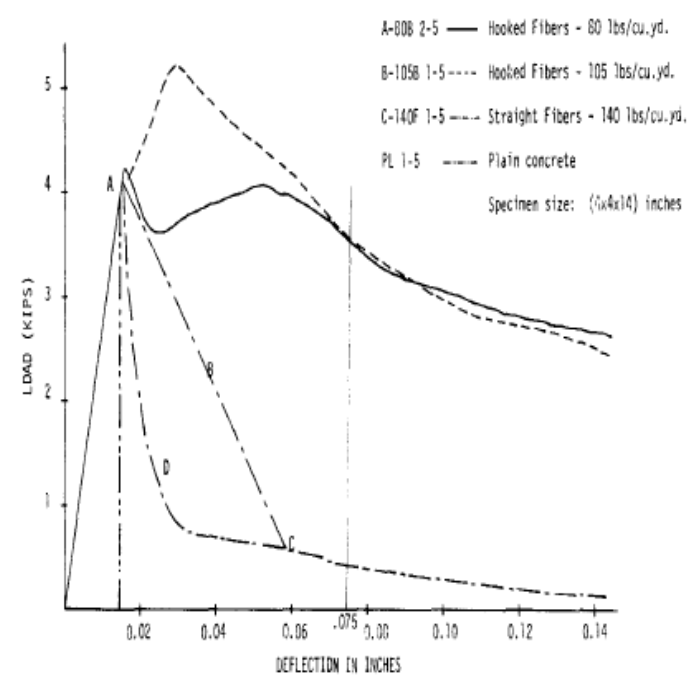

(a) from Ramakrishnan et al., 1980

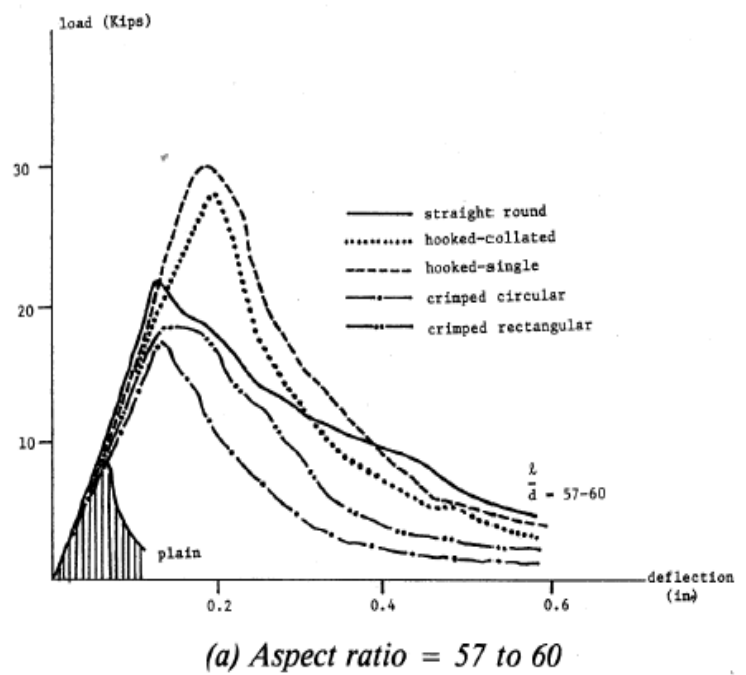

(b) from Soroushian and Bayasi, 1991

Figure 2-7 Effect of hooked and straight steel fibers on flexural performance of concrete. (From Hai $\mathrm{H}$. Dinh, 2009) 


\subsubsection{Compressive strength of SFRC}

According to ACI 544, the effect of steel fiber on the compressive of concrete is variable. The increasing in compressive strength ranges from 0 to $23 \%$ with $2 \%$ volumetric ratio of steel fiber with $\mathrm{l} / \mathrm{d}=100$. It was showed in one of the studies [22] that using $1.5 \%$ volumetric ratio of steel fiber could increase the compressive strength by $37 \%$. On the other hand, another study [16] reported that using the same previous ratio of steel fibers increased the peak compressive strength by less $10 \%$.

What is certain is that steel fiber can improve the post-peak compressive strength of concrete. It can be seen from figure 2-8 that the descending part of stress-strain curve is less steep when fiber is used. In other words, using steel fiber increases the toughness and energy observation. This feature is useful to prevent a sudden explosive failure of concrete, and therefore is successfully used to improve high strength concrete.

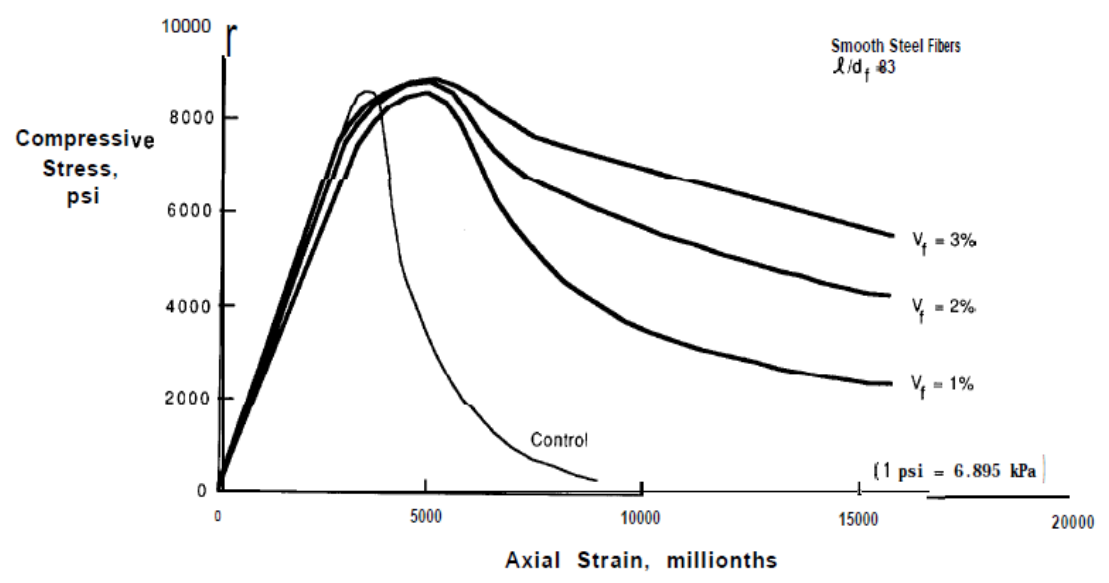

Figure 2-8 Effect of the volume of fibers on the compressive stress-strain curve (From ACI 544) 


\subsection{Mechanical Properties of Polypropylene Fiber Reinforced Concrete PPFRC}

Polypropylene fiber is a synthetic hydrocarbon polymer. According to ACI 544R-2003, synthetic fibers are fibers made and developed by man using petrochemical and textile industries. Monofilament form of polypropylene fibers are made through an extrusion process. Like any other type of fibers, polypropylene fibers are used to enhancing tensile and flexural strength of concrete. In addition, polypropylene fiber inhabits and controls plastic shrinkage cracks.

\subsubsection{Tensile-Flexural and Compression Strength of PPFRC}

From one of the studies [23], it was inferred that a linear increasing in tensile-flexural strength of PPFRC up to $70 \%$ with fiber volumetric ratio $0.40 \%$. Nonetheless, any further increasing in the fiber ratio would decrease the tensile-flexural strength. Polypropylene fiber has a significant effect on the tensile-flexural strength, but it barely has an effect on compression strength. From the same study, it was concluded that by adding a volumetric ratio of polypropylene fiber up to $0.40 \%$ can increase concrete compressive by $5 \%$. Nevertheless, $0.55 \%$ to $0.60 \%$ volumetric ratio will decrease the compressive strength by $3 \%$ and $5 \%$ respectively. 


\subsubsection{Flexural Strength and Flexural Toughness of PPFRC}

It has been reported that for the flexural strength and modules of rapture, polypropylene fibers do not have a significant effect. According to one of the studies [24] adding $0.1 \%$ volumetric ratio of fibrillated polypropylene fiber would slightly increase pre-cracking flexural strength. However, a fiber content ranging from 0.2 to 0.3 by volume will decrease the pre-flexural strength. From another study [25], it was concluded that modules of rapture for fibrillated concrete is slightly increased than plain concrete by using 0.1 to 0.3 volumetric ratio of polypropylene fiber. Figure 2-9 illustrated the effect of fiber on the modals of rapture.

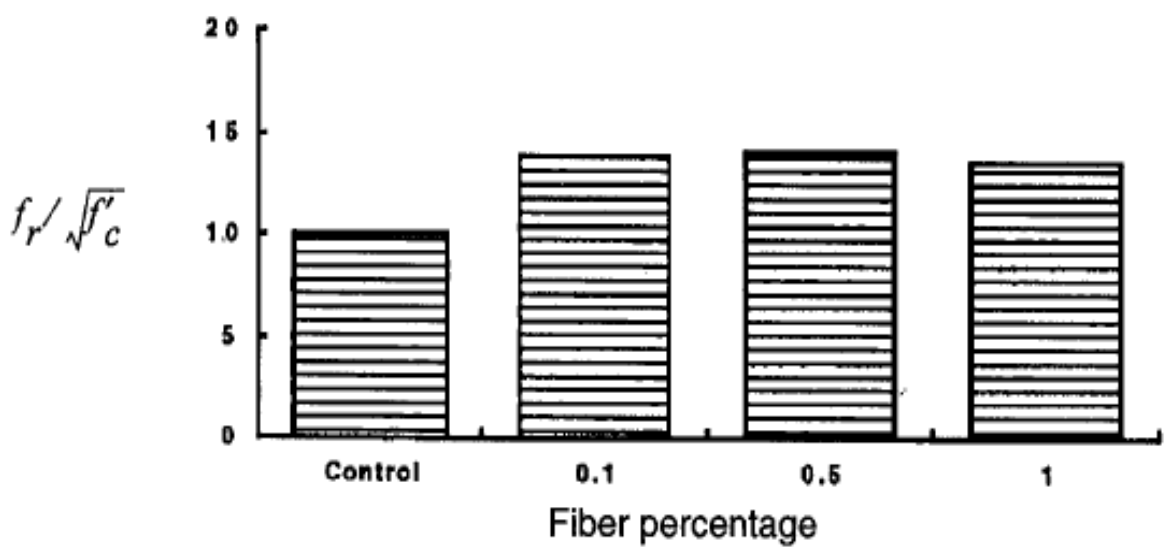

Figure 2-9 The effect of Fiber content on the modules of rapture (From ACI 544)

Flexural strength is influenced by many factors such as fiber material, length, geometry and bonding. Polypropylene fibers have been used to enhance it. Using load-controlled machines [25] $0.1 \%$ by volume, the polypropylene fiber did not have an effect on the concrete, which experienced a sudden failure. In contrast, beams with $0.2 \%$ and $0.3 \%$ 
volumetric ration showed a significant increase in the flexural toughness. It was reported by another study [26] that even beams with $0.1 \%$ by volume can give toughness index of 3 or more by using deflection-controlled machine or closed-loop testing machine specified by ASTM 1018.

\subsubsection{Cracking and Shrinkage of PPFRC}

There are several types of cracks in concrete. However, they can be classified into two types based on the age of the concrete. The first is hardening concrete cracks. The second type is plastic shrinkage cracks. Polypropylene fiber has a greater influence on the second type rather than the first one. In order to determine the influence of polypropylene fiber on concrete, rectangular square slabs have been used. Ring specimen [27] was used to simulate restrained shrinkage cracks. From the study, it was concluded that PPFRC could control drying shrinkage cracks. In addition, it can reduce crack width. Another study [28] focused on unrestrained PPFRC. They inferred that fiber of $0.1 \%, 0.2 \%$ and $0.3 \%$ by volume reduced drying shrinkage cracks by $18 \%, 59 \%$ and $10 \%$, respectively. They also concluded a shrinkage reduction for fiber content ranging from $0.1 \%$ to $0.3 \%$ by volume. Moreover, it was found that polypropylene fiber reduced surface water bleeding. Therefore, it can increase concrete life. Figure 2-10 shows the relation between average crack width and fiber content. 


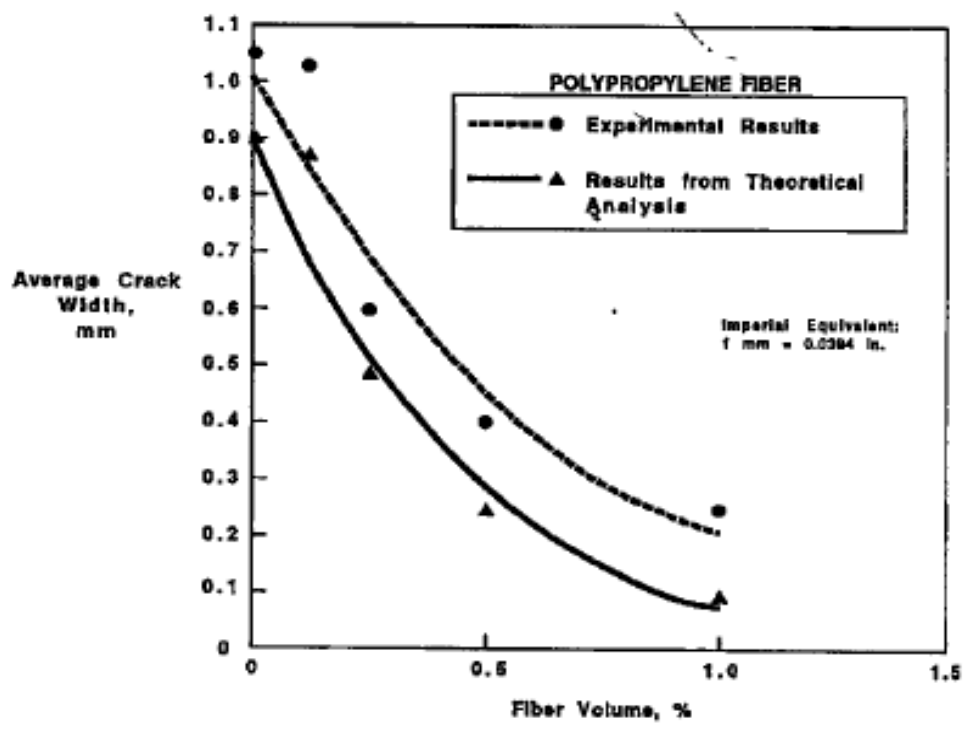

Figure 2-10 Average Cracks width Versus Fiber content (From ACI 544)

\subsubsection{Shear Strength of PPFRC}

As was mentioned previously, polypropylene increases concrete first-crack resistant.

Whereas, once cracks are developed, polypropylene fiber cannot sustain them as well as steel fibers. It was concluded [23] for $0.2 \%$ to $0.4 \%$ by volume fiber that polypropylene fiber can increase the load carrying capacity of concrete beams up to first-crack. Once the crack develops, failure will occur with load less than the one obtained beam without any fiber. When fiber content is increased to $0.6 \%$ by volume, there is an increase in the failure load. One study [29] used the monofilament fiber type. It was concluded that $1 \%$ of polypropylene fiber could increase shear strength by $80 \%$ to $85 \%$. 


\subsection{Shear Failure Mechanism of FRC}

Concrete is a brittle material. Its tensile strength is considerably lower than its compressive strength. Reinforced concrete fails suddenly in shear without any previous warning [30]. The failure mechanism starts with diagonal cracks, which can be wider than flexural cracks.

\subsubsection{Failure of Plain Concrete Beams}

In any flexural member subjected to a concentrated load at distance "a" from one support, all elements of that member experience shear and moment as shown in figure 2-11. From beam theory, these stresses can be determined by the equations:

$$
\begin{aligned}
& f(x, y)=\frac{M y}{I}=\frac{12 V x y}{b h^{3}} \\
& v(y)=\frac{V Q}{I b}=\frac{6 V}{b h^{3}}\left(\frac{h^{2}}{4}-y^{2}\right)
\end{aligned}
$$

On one hand, it can be seen from fig. 2-8 that the top and the bottom fibers at distance " $\mathrm{x}$ " from the left support are subjected to tension and compression-bending stress, respectively. On the other hand, the mid-depth is subjected to a pure-shear stress. Elements located between mid-depth and extreme fibers experience accompanied bending-shear stress. The maximum tensile normal stress is located at the extreme bottom fiber. At that location, flexural cracks will develop. For plain concrete, complete failure will occur due to the development of flexural cracks. 


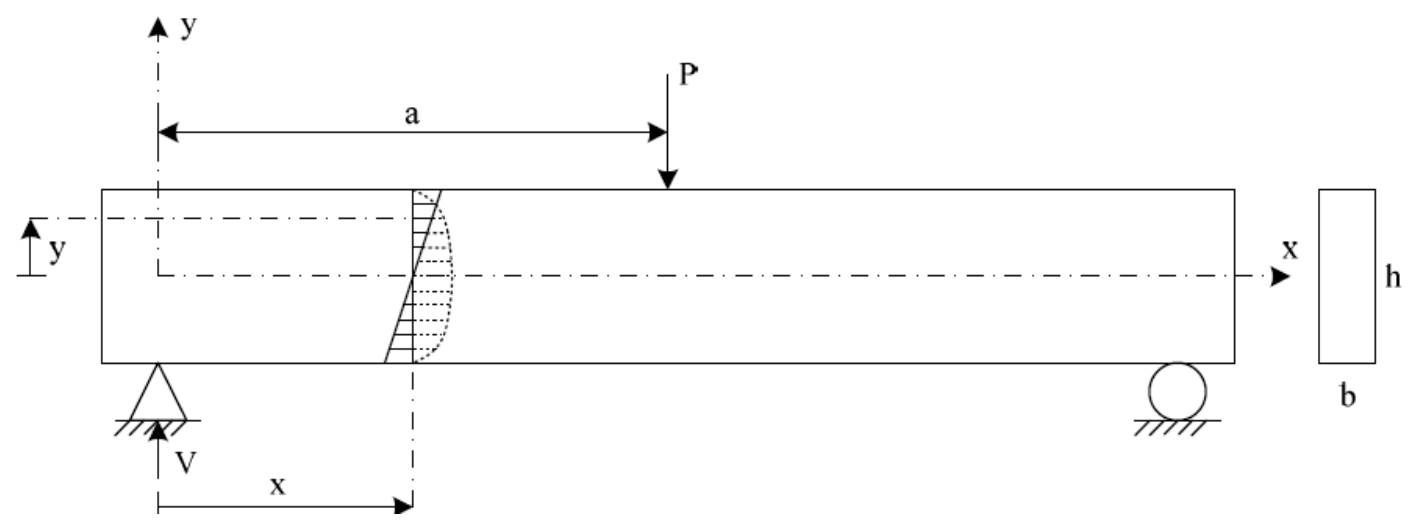

Figure 2-11 Plain concrete beam subjected to concentrated load

\subsubsection{Failure of Longitudinally Reinforced Beams without Diagonal Tension Reinforcement}

Adding longitudinal reinforcement to concrete will enhance its flexural characteristics. This reinforcement will bridge cracks allowing stress transfer through cracks.

Consequently, the failure mechanism of longitudinally reinforced concrete may be shifted to shear failure depending on factors such as shear span, longitudinal reinforcement ratio, and concrete strength.

Shear failure of longitudinally reinforced concrete is explained in many references [30]. As it was mentioned previously, adding rebar to a beam allows it to exhibit more flexural cracks. At the same time, shear cracks will develop in the elements located between section mid-depth and bottom fibers. 
Elements located between mid-depth and top fiber are subjected to accompanied shearcompressive bending stress as shown in figure. 2-12. Cracks are inhibited in these elements because the maximum principal stress in these elements is

compression. However, elements located between mid-depth and bottom fiber are subjected to companied shear-tensile bending stress. It is known that tensile strength of concrete is very low compared with its compressive strength. Therefore, tension cracks will develop at these elements because maximum principle stress is tensile.

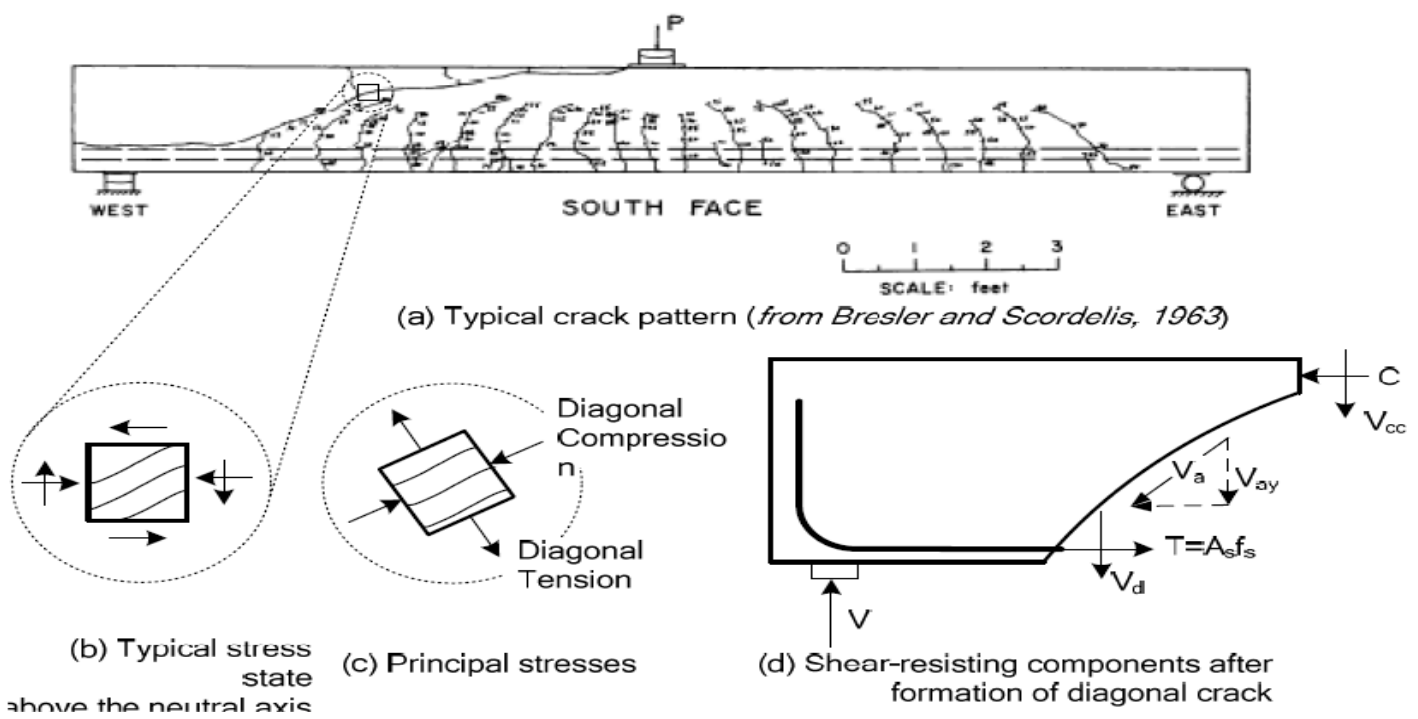

Figure 2-12 Crack pattern and principal stresses in longitudinally reinforced concrete beam

\subsubsection{Modes of Failure of Beams Without Diagonal Tension Reinforcements}

Shear span/depth ratio is an important factor in determining the failure mode of beams without diagonal tension reinforcements. Shear span/ depth ratio is the distance from the 
load application point to the support in the case of a concentrated load. However, it is the clear span in the case of a uniformly distributed load. Based on this ratio, there are three possible failure modes.

The first mode of failure is the flexural failure mode. This mode occurs in slender beams whose shear span/depth $(\mathrm{a} / \mathrm{d})$ ratio is more than 5.5 in the case of a concentrated load. This failure mode starts with flexural cracks in the middle third of the beam span. This type of beam fails either due to yielding longitudinal reinforcements, which fractures the beam providing ample warning in case of low amount of reinforcement, or the crashing of concrete around the load application point without any ample warning as in the case of a high amount of reinforcement. This type of failure can be seen in figure 2-13a

The second type of failure is called a diagonal tension failure. The shear span/depth $(\mathrm{a} / \mathrm{d})$ ratio for normal strength concrete ranges from 2.5 to 5.5 in the case of a concentrated load. For this mode, both flexural and diagonal cracks developed. Without any previous warning, two or three cracks developed at a distance of (1.5d to $2 \mathrm{~d})$ from the support. One of these cracks widen and split the beam into two sections as shown in figure 2-13b The last mode of failure is called shear compression failure. The shear span/depth $(\mathrm{a} / \mathrm{d})$ ratio for a concentrated loaded beam ranges from 1 to 2.5 . This mode is almost similar to the previous one. At first, a few flexural cracks appeared, and then diagonal cracks, which are steeper than cracks of the previous case, appeared. These cracks progressed toward the top fiber. Failure occurred when the crack met with crashed concrete around the concentrated load as shown in figure $2-13 \mathrm{C}$. 


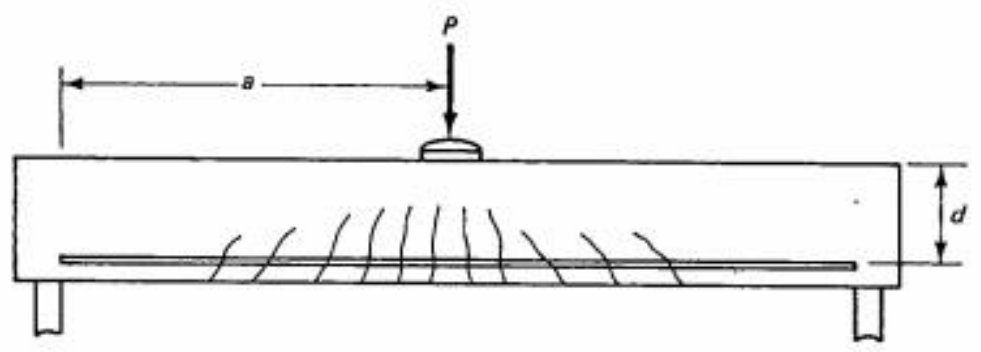

(a)

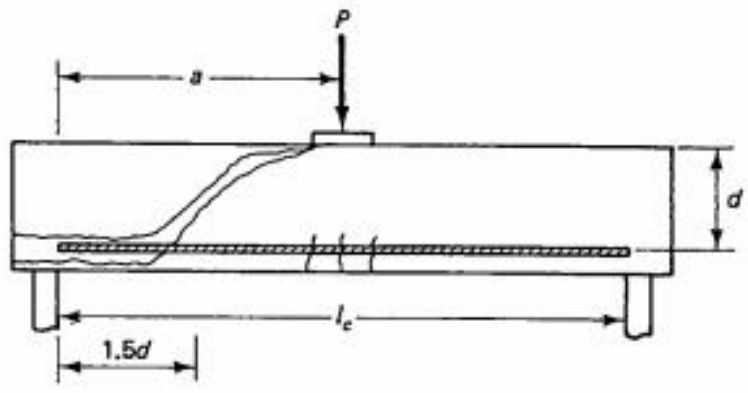

(b)

2

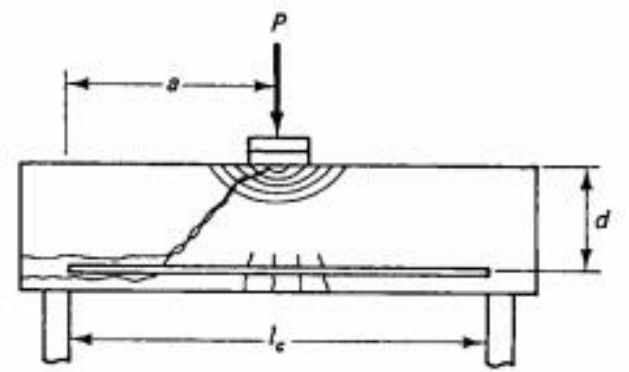

(c)

Figure 2-13 Failure modes(from Nawy, 2009) (a) Flexural failure; (b) Diagonal tension failure; (c) Shear compression failure 


\subsubsection{Web Steel Reinforcement in Beams}

Adding transfer reinforcement in form of stirrups enhances the shear characteristics of concrete in addition to improving shear resistance. Stirrups play a significant role in carrying part of the external factored load, holding longitudinal reinforcements in place by maintaining the required dowel capacity, and restricting the growth of diagonal cracks.

According to some research [31], [32], stirrups were effective after crack formation. They redistribute shear stresses after the formation of diagonal cracks. They take this tension stress back to the concrete leading to more cracks.

$V_{s}=\left\{\begin{array}{ll}\frac{A_{v} f_{y t} d}{S} & \text { for Vertical stirrups } \\ \frac{A_{v} f_{y t} d}{S}(\sin \alpha+\cos \alpha) & \text { for inclined stirrups }\end{array}\right\}$

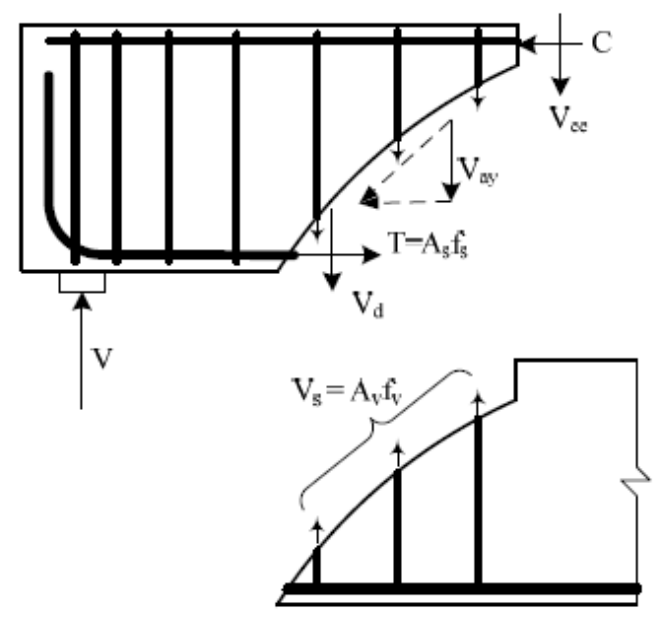

Figure 2-14 Shear resistant component (From Dinh,, 2009) 


\subsubsection{Failure of SFRC Beams without Stirrups Reinforcement}

The behavior of a longitudinally reinforced SFRC beam without any stirrups is similar to a RC beam with stirrups reinforcement. Both steel fibers and stirrups contribute to shear resistance after cracks occur. They carry redistributed tensile stress and prevent crack propagation. However, steel fibers have a better control on crack width and promote multiply cracks thereby creating better stress distribution. Another similarity is that steel fibers prevent concrete splitting around the longitudinal reinforcement.

Challenges with SFRC emerge in shear strength analysis for two reasons. First, distribution of steel fibers in concrete, which insures developing uniform mechanical properties, is somewhat uncertain. Second, the increase in cracks opening is the result of fibers pulling out rather than yielding. Therefore, it is bond failure, which makes it more complicated problem.

It has been observed [33] that in terms of ultimate strength a similar performance is obtained by using steel fibers instead of stirrups for shear reinforcement. In addition, it was inferred [6] that using hooked-steel fibers in a volume fraction equal or greater than $0.75 \%$ can improve shear strength up to $4 \sqrt{f^{\prime} c}$. Furthermore, the same hooked-steel fibers if used by the same volume fraction can replace stirrups as minimum shear reinforcement specified by ACI 318. The same conclusion was also supported by Kranti Jain (2013) [34]. 


\subsection{Prediction Shear Strength of SFRC}

Since the behavior of steel fiber reinforced concrete (SFRC) is relatively complicated, most of the predictive methods depend on regression analysis. A number of factors effeet. such as span-to-effective depth ratio; longitudinal reinforcement; and tensile strength of fiber reinforced concrete, which are concrete matrix properties; fiber aspect ratio; fiber ratio; fiber shape, can affect shear strength of FRC

- Sharma (1986) [35] proposed an empirical formula to estimate the shear strength of fiber reinforced concrete depending on the splitting tensile strength, $f_{c t}$, and span-to-effective-depth ratio $(\mathrm{a} / \mathrm{d})$

$$
v_{u}=\left(k f_{c t}\right)\left(\frac{d}{a}\right)^{1 / 4}
$$

Where $\mathrm{k}=2 / 3$ was determined from tests

- Narayanan and Darwish (1987) [36] proposed an equation to determine the shear strength of FRC that considers splitting tensile strength, $f_{c t}$, dowel action (as function of longitudinal reinforcement), fiber pullout forces along inclined crack, and shear span-to-effective depth ratio $(\mathrm{a} / \mathrm{d})$

$v_{u}=e A^{\prime} f_{c t}+e B^{\prime} \rho \frac{d}{a}+v_{b}$

Where $e$ coefficient accounts for beam/ach action which value is approximately 1 for slender beam $(\mathrm{a} / \mathrm{d}>2.8)$ and is $2.8 \mathrm{~d} / \mathrm{a}$ for $(\mathrm{a} / \mathrm{d} \leq 2.8) . A^{\prime}$, and $B^{\prime}$ were estimated based on regression analysis of 91 tests, which gave these value $A^{\prime}=0.24, B^{\prime}=80 \mathrm{MPa} . \mathrm{V}_{b}$ is the bond stress based on all fibers crossing 45-degree diagonal. The fiber bond stress, $\tau$, was 
assumed to be along $1 / 4$ of the fiber length. The number of the fibers over unit area, $n_{w}$, was estimated based on Romualdi et al. (1963) [37] as follows.

$n_{w}=\frac{1.64 V_{f}}{\pi D_{f}^{2}}$

The above equation reflects the number of fibers crossing the diagonal crack that have a vertical projection from the top center of the longitudinal reinforcement to the lower tip of the compression reign. In order to avoid all these calculations the author derived an equation to determine $v_{b}$

$v_{b}=0.41 \tau V_{f} \frac{L_{f}}{D_{f}}$

Fiber geometry was considered using a factor $\beta$

$v_{b}=0.41 \tau V_{f} \frac{L_{f}}{D_{f}} \beta=0.41 \tau F$

Where $\beta$ is 0.5 for the rounded fiber, 0.75 for the crimped and 1 for the indented fiber.

The bond stress, $\tau$, is equal to 4.1 MPa based on Swamy et al. (1974) [38]. The author did include the effect of the compression and aggregates interlock.

- Al-Ta'an and Al-Feel (1990) [39]proposed an expression to determine shear strength based on the shear-resisting component. The first component included the influence of compression region, aggregate interlock and dowel action which is

$v_{c}=\left(10 \rho f^{\prime} c \frac{d}{a}\right)^{1 / 3} \quad(M P a)$ for $\frac{a}{d}>2.5$ 
$v_{c}=\left(160 \rho f^{\prime} c\right)^{1 / 3}\left(\frac{d}{a}\right)^{4 / 3} \quad(M P a)$ for $\frac{a}{d}<2.5$

The other component considered the effect of the fiber that is accounted using postcracking tensile stress along the diagonal crack. However, in their research they excluded the depth of the compression region from the crack height. The fiber effect can be determined using $\sigma_{p c}=0.5 \tau F$

- Khuntia, Stojadinovic and Goel (1999) [40]proposed an expression that consider two terms also. The first contribution is based on dowel action, aggregate interlock, and compression region. They are presented in one term

$v_{c}=0.167 \sqrt{f^{\prime} c}(\mathrm{MPa})$

The second contribution is the post-cracking effect of fiber which is $0.41 \tau F$. By assuming is $\tau=0.68 \sqrt{f^{\prime} c}$ and the vertical projection of the diagonal crack equals to $0.9 \mathrm{~d}$

$v_{f r}=0.41 \tau F(\mathrm{MPa})$

$F=V_{f} \frac{L_{f}}{D_{f}} \beta$,

$\tau=0.68 \sqrt{f^{\prime} c}$

$\therefore v_{f r}=0.41 * 0.68 \sqrt{f^{\prime} c} * 0.9 * F=0.25 F \sqrt{f^{\prime} c} \mathrm{MPa}$

By including the arch action $\alpha$, which is equal to $2.5 \mathrm{~d} / \mathrm{a}$, to the term $v_{c}$, the term will be

$v_{u}=(0.167 \propto+0.25 F) \sqrt{f^{\prime} c}(\mathrm{MPa})$ 
- Hai H. Dinh (2009) [6]proposed an expression to estimate shear strength SFRC without stirrups. In his research, he considered shear force due to compression and tensile force due to steel fiber. He neglected the effect of the aggregate interlock and dowel action because the widening of crack at failure will diminish the effect of aggregate interlock. In addition, the dowel action was ignored because it was believed to be small.

$$
\begin{aligned}
& V_{u}=V_{c c}+V_{f} \\
& V_{c c}=0.11 \beta_{1} f^{\prime} c \cdot b \cdot c \\
& V_{f}=\sigma_{f u}\left(1-\frac{c}{d}\right) \cot \alpha \\
& \sigma_{f u}=K \frac{L_{f}}{D_{f}} \sqrt{0.0075 V_{f}}
\end{aligned}
$$

Where $\beta=\left\{\begin{array}{cl}0.85 & \text { if } f^{\prime} c<4000 p s i \\ 1.05-\frac{0.05 f^{\prime} c}{1000} & \text { if } 4000 p s i<f^{\prime} c<8000 p s i, \alpha \operatorname{ranging}(37.5 \text { to } 40), \\ 0.65 & \text { if } f^{\prime} c>8000 p s i\end{array}\right.$ $\mathrm{K}=400 \mathrm{psi}$

This expression is limited to the hooked-end steel fiber, $\rho \leq 2 \%$, with a volumetric ration of more than 0.5 and concrete compressive strength ranging from 3000 to 8000 psi. 


\section{Chapter 3: Experimental Program}

\subsection{Introduction}

As mentioned in chapters 1 and 2, fibers are used to enhance both plastic and harden concrete characteristics. The experimental program of this research provides further understanding of using steel fiber, hybrid steel and fibrillated polypropylene fiber, and hybrid monofilament and fibrillated polypropylene fiber to enhance concrete characteristics.

The experimental program aimed to answer the following questions:

(1) What are the shear strength, cracks patterns, cracks width, and flexural toughness of fiber reinforced concrete?

(2) How do these results change if the fiber type is changed?

(3) Can $1 \%$ fiber be used to substitute minimum shear reinforcement as specified by ACI Committee 318 for RC beams?

The concrete strength for the experimental beams was selected as a "medium-high" capacity of $6000 \mathrm{psi}$. This capacity was selected in order to reflect the expected capacities of the future concretes, possibly in the next one or two decades.

The experimental program involved designing, manufacturing, and testing about onethird scale simply supported beam specimens subjected to two concentrated symmetrical loads. In addition, a fiber bond test, a trial mix test, cylinder tests, and a rebar test were conducted 


\subsection{Beam Specimens}

The experimental program consisted of five beam specimens of the same size. Each specimen had a different shear resisting system. The first three specimens were reinforced with $1 \%$ volumetric ratio of hooked-end steel, crimped-steel and crimpedmonofilament polypropylene. The fourth specimen was reinforced with minimum shear steel reinforcement specified by ACI 318 [41]. The last one did not have shear steel reinforcement or fiber. Table 3-1 shows the detail of these specimens.

The system used to identify the specimens was based on two parts. The first part of the specimen name refers to its number in the sequence. The second part refers to the shear resisting system that was used such as HS which refers to hooked-end steel fiber. 
Table 3-1 Design properties of the beam specimens

\begin{tabular}{|c|c|c|c|c|c|}
\hline Beams(*) & $\boldsymbol{\rho}$ & Fiber type & Shear resisting system & V ff & Targeted $\boldsymbol{f}^{\prime} \boldsymbol{c}$ \\
& & & & & \\
\hline B1-MS & $2.42 \%$ & No fiber & Conventional Minimum Steel & $0 \%$ & 6000 \\
& & & reinforcement & & \\
\hline B2-HS & $2.42 \%$ & Novocon 1050 & Hooked-end Steel fiber & $1.0 \%$ & 6000 \\
\hline B3-CS & $2.42 \%$ & Novomesh & Crimped-Steel fiber & $1.0 \%$ & 6000 \\
\hline B4-CPP & $2.42 \%$ & Novomesh & Crimped monofilament & $1.0 \%$ & 6000 \\
& & $950^{* *}$ & Polypropylene fiber & & \\
\hline B5-NS & $2.42 \%$ & No fiber & No Shear & Zero & 6000 \\
\hline
\end{tabular}

(*) All beams dimensions bxhxl=4"x6”x 72"

(**) For Novomesh 850 , Novomesh 950, only crimped steel fiber and crimped monofilament polypropylene fiber were used. 


\subsection{Fixed Parameters}

\subsubsection{Shear Span-to-Effective Depth Ratio}

Shear span-to-effective depth ratio (a/d) of all beam specimens was fixed at 4 in order to obtain diagonal tension (shear) failure. It is noted for $(\mathrm{a} / \mathrm{b})$ less than 2.5 , a direct strut from the loading point to the support is formed leading to increase beam strength compared to slender beams. However, for slender beams with (a/d) approximately more than 5.5, flexural failure is expected.

\subsubsection{Beam Size}

The tested specimen beams were a one-third scale model. In other words, the dimensions of the model were determined by dividing the dimensions of an assumed prototype beam by 3 . The depth of the model beam was chosen based on the ease of handling. In addition, increasing the beam height significantly affected the total length of the model, as it was seen in the beam length determination. Therefore, 7 inches depth met the mentioned criteria. The width of the beam was chosen to maintain adequate room for longitudinal reinforcement and provide 0.75 inches cover.

It can be seen from figure 3-1 that the test set up is a four-point test. Therefore, there are two possible locations for shear failure, which are the left and right span. These spans were designed to have span-effective depth ratio (a/d) of 3.6. In order to keep consistency, the length of the middle span was kept equal to the other two spans, as shown in table 3-2. 

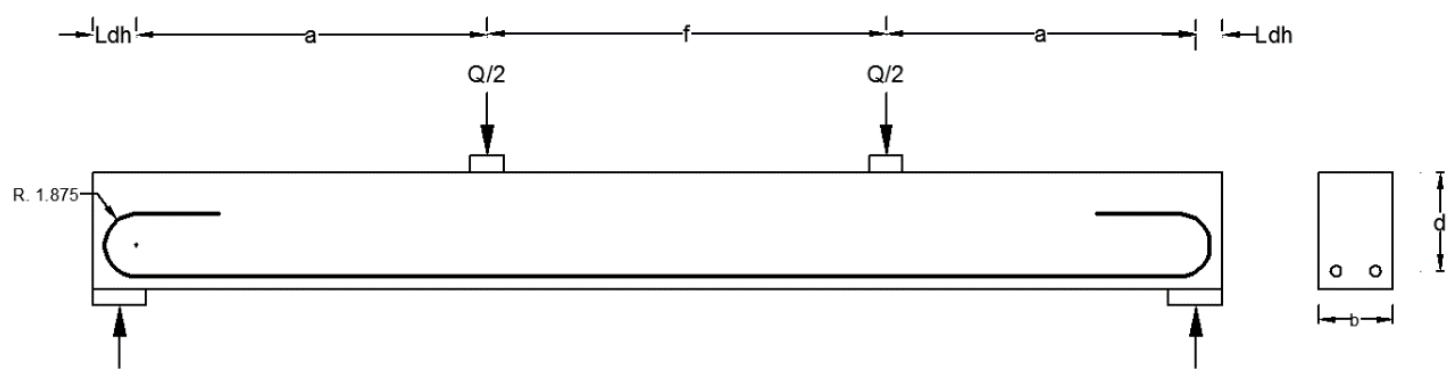

Figure 3-1 Load, Dimension and cross section for the tested beams

Table 3-2 Beam Dimension

\begin{tabular}{|c|c|}
\hline Beam & Dimension \\
\hline $\mathrm{b}$ & 4.5 in \\
\hline $\mathrm{d}$ & 5.9 \\
\hline $\mathrm{a} / \mathrm{d}$ & 3.6 \\
\hline $\mathrm{a}$ & $3.6(5.8)=21 \mathrm{in}$ \\
\hline $\mathrm{f}$ & 21 \\
\hline $\mathrm{L}_{\mathrm{dh}}$ & 3.25 \\
\hline Total length & 69 in \\
\hline
\end{tabular}




\subsubsection{Longitudinal and Transverse Reinforcement for the Control Beam}

The longitudinal reinforcement ratio was selected based on ensuring shear failure control. In other words, the goal was to ensure that the beam would not fail by flexure, but by shear. Therefore, a relatively high reinforcement ratio of $2.42 \%$ was chosen for longitudinal reinforcement.

Allowable applied load failure $\left(\mathrm{Q}_{\mathrm{sp}}\right)$ required for plain concrete was determined by using the equation $2.0 \sqrt{f^{\prime} c} b_{w} d$. However, depending on propesal according to past research [42], allowable load failure $\left(\mathrm{Q}_{\mathrm{sf}}\right)$ required for fiber reinforced concrete was determined

using $3.5 \sqrt{f^{\prime} c} b_{w} d$ as shown below. Table 3-3 shows calculations for shear and flexural strength of beam specimens.

The control beam was designed without any fibers but it had transverse reinforcement for comparison purposes. As mentioned before, the beams were approximately third scale model, and no. 7 wires were used as transverse reinforcement.

$$
\begin{aligned}
& V_{c}=2 \sqrt{f^{\prime} c} b_{w} d=\frac{2 \sqrt{6000}}{1000} * 4.5 * 5.8=4.04 \text { kips } \\
& V_{s}=f_{y} A_{s} \frac{d}{s}=32 * 2(0.0165) * \frac{5.8}{2.9}=2.1 \mathrm{kips} \\
& \mathrm{V}_{\mathrm{u}}=\mathrm{V}_{\mathrm{c}}+\mathrm{Vs}_{\mathrm{s}}=4.04+2.1=6.14 \mathrm{kip} \\
& Q_{s}=2 V_{u}=2(6.14)=\mathbf{1 2 . 2 8} \text { kips }
\end{aligned}
$$

For the fiber reinforced concrete:

$$
V_{c f}=3.5 \sqrt{f^{\prime} c} b_{w} d=\frac{3.5 \sqrt{6000}}{1000} * 4.5 * 5.8=7.08 \text { kips }
$$




$$
Q_{s}=2 V_{c p}=14.15 \text { kips }
$$

The calculation of beam flexural strength was done using the traditional method of reinforced concrete as shown below.

$$
\begin{gathered}
a=\frac{f y A s}{0.85 f^{\prime} c . b}=\frac{68(0.62)}{0.85(6)(4.5)}=1.84 \\
M_{u}=f y A s\left[d-\frac{a}{2}\right]=\frac{68(0.62)}{12}\left[5.8-\frac{1.84}{2}\right]=17.2 \mathrm{kip}-f t \\
Q_{m}=1.1 M_{u}=\mathbf{1 8 . 7} \text { kips }
\end{gathered}
$$

\begin{tabular}{|c|c|c|c|c|c|c|c|c|c|}
\hline $\operatorname{Beams}(*)$ & $\begin{array}{l}f^{\prime} c \\
(p s i)\end{array}$ & $\begin{array}{l}\text { b } \\
\text { in }\end{array}$ & $\begin{array}{l}\text { d } \\
\text { in }\end{array}$ & $\begin{array}{l}\mathbf{Q}_{\mathrm{s}} \\
\text { kips }\end{array}$ & $\begin{array}{l}A_{s} \\
\text { in }^{2}\end{array}$ & $\begin{array}{l}M_{u} \\
\text { k-1 }\end{array}$ & $\begin{array}{r}\mathbf{Q m} \\
\mathbf{k}\end{array}$ & $\begin{array}{c}\text { Failure } \\
\text { type }\end{array}$ & $\begin{array}{l}\text { Beam } \\
\text { type }\end{array}$ \\
\hline B1-MS & 6000 & 4.5 & 5.8 & 12.28 & 0.62 & 14.96 & 18.7 & Shear & $\begin{array}{l}\underline{\text { Minimum Steel }} \\
\text { reinforcement }\end{array}$ \\
\hline B2-HS & 6000 & 4.5 & 5.8 & 14.15 & 0.62 & 14.96 & 18.7 & Shear & $\begin{array}{l}\text { Hooked-end } \\
\text { Steel fiber }\end{array}$ \\
\hline B3-CS & 6000 & 4.5 & 5.8 & 14.15 & 0.62 & 14.96 & 18.7 & Shear & $\begin{array}{c}\text { Crimped-Steel } \\
\text { fiber }\end{array}$ \\
\hline B4-CPP & 6000 & 4.5 & 5.8 & 14.15 & 0.62 & 14.96 & 18.7 & Shear & $\begin{array}{c}\text { Crimped } \\
\text { Polypropylene } \\
\text { fiber }\end{array}$ \\
\hline B5-NS & 6000 & 4.5 & 5.8 & 8.08 & 0.62 & 14.96 & 18.7 & Shear & $\begin{array}{c}\text { No Shear } \\
\text { reinforcement }\end{array}$ \\
\hline
\end{tabular}

Table 3-3 Calculation for flexural and shear strength 
Figure 3-2 shows the reinforcement details for test beams. There were two types of beams. One was designed with shear reinforcement, which was the control with minimum steel shear reinforcement. The other was designed without steel shear reinforcement. This detail was used for a second control beam and for beams with fiber reinforcement.

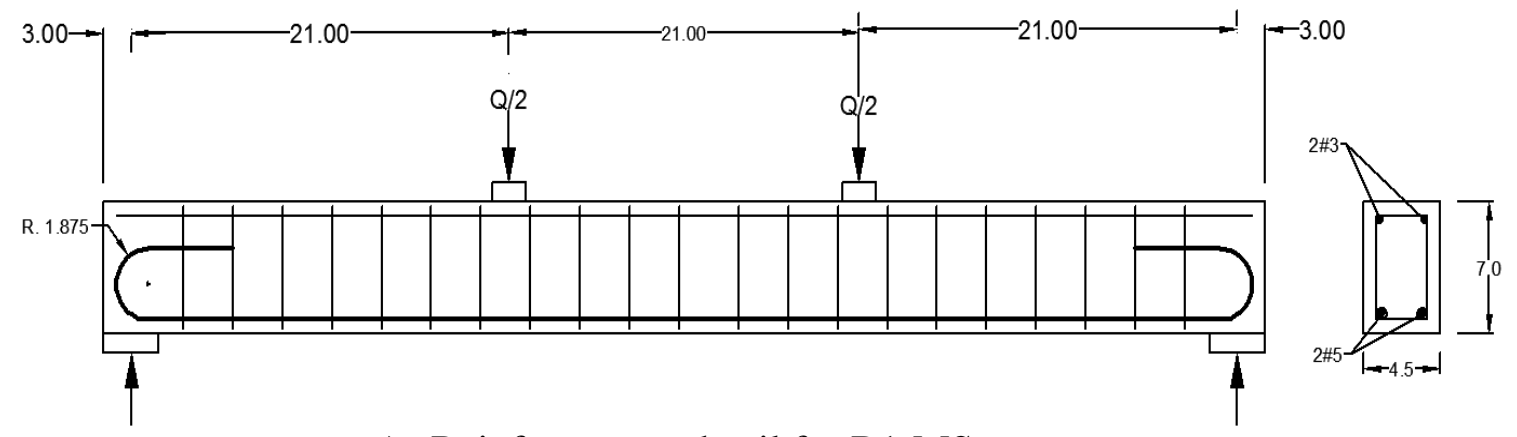

a) Reinforcement detail for B1-MS

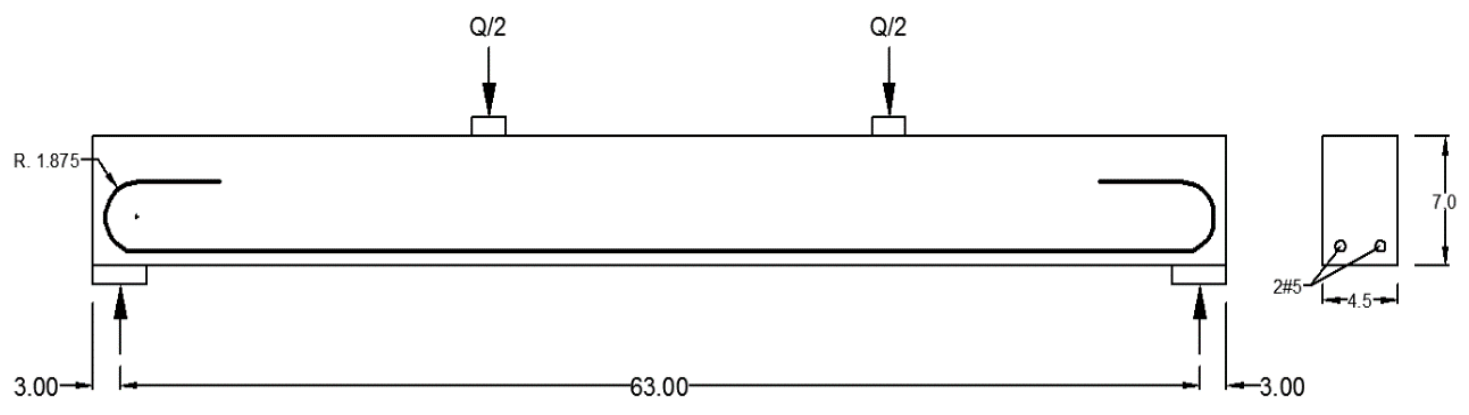

b) Reinforcement detail for other specimens

Figure 3-2 Reinforcement details and beams dimension 


\subsubsection{Fiber Volume Fraction}

Reviewing the literature shows that a volumetric ratio of $1.0 \%$ of steel fibers can satisfy the minimum shear reinforcement specified by ACI-318. In addition, using a volumetric ratio more than $1 \%$, and up $2.0 \%$ can slightly increase shear strength . In other words, the enhancement in shear characteristics when fiber content increase from $0.5 \%$ to $1.0 \%$ volumetric ratio is more than when fiber content increases from 1.05 to $2.0 \%$ volumetric ratio. Therefore, $1.0 \%$ volumetric ratio was considered as a reasonable ratio for test specimens. 


\subsubsection{Concrete Compressive Strength}

The targeted compressive strength was $6000 \mathrm{psi}$. Three trial mixes were made in order to obtain a compressive strength close to 6000 psi. One of the mixes was designed using Design and Controlling of Concrete Mixture. However, the other two were designed based on the literature. For each mix, four cylinders were prepared. Two of the cylinders were tested at the age of twenty-eight days while the other two were tested at the age of seven and fourteen days. The mix that was utilized gave a compressive strength of 6200 psi, as shown in the table 3-4.

Table 3-4 Mix proportion for each type of fiber

\begin{tabular}{|c|c|c|c|}
\hline \multirow{2}{*}{ Material } & \multicolumn{3}{|c|}{ Proportion by weight for $\mathbf{1} \mathbf{f t}^{\mathbf{3}}$} \\
\cline { 2 - 4 } & Mix 1 & Mix 2 & Mix 3 \\
\hline Cement & 25 & 25 & 25 \\
\hline Sand & 45 & 45 & 45 \\
\hline Coarse aggregate & 75 & 75 & 75 \\
\hline Water & 14.5 & 14.5 & 14.5 \\
\hline W/C & 0.58 & 0.58 & 0.58 \\
\hline $\begin{array}{c}\text { Hooked end steel } \\
\text { fiber }\end{array}$ & 5.2 & - & - \\
\hline $\begin{array}{c}\text { Crimped steel fiber } \\
\text { Crimped } \\
\text { polypropylene fiber }\end{array}$ & - & 5.2 & - \\
\hline $\begin{array}{c}\text { Slump after adding } \\
\text { fiber }\end{array}$ & - & - & 0.6 \\
\hline
\end{tabular}




\subsection{Varied Parameters}

\subsubsection{Fiber Types}

There are three types of fibers used in this experimental program. These fibers are manufactured by Propex. The first type of fiber is Novocon 1050, which is hooked-end steel fiber. The second type is Novomesh 850. This type is a hybrid of two fibers, which are crimped-steel fibers and fibrillated-polypropylene fiber. The last one is Novomesh 950. Similar to the previous one, this type is also is a hybrid fiber of two types. However, both of them are made of polypropylene. These fibers are monofilament fibers of sinusoidal deformations and fibrillated polypropylene fibers. All these fibers can be seen in figure 3-3. In addition, their properties are listed in table 3-5, where aspect ratio is the approximate ratio of length to diameter.

Table 3-5 Type and Characteristics of the used fibers

\begin{tabular}{|l|c|c|c|}
\hline \multicolumn{1}{|c|}{ Fiber type } & Diameter & Length & Aspect ratio \\
\hline Novocon 1050 & 0.039 in $(1.0 \mathrm{~mm})$ & 2 in $(50 \mathrm{~mm})$ & 50 \\
\hline Novomesh 850 $(*)$ & - & 1.5 in $(38 \mathrm{~mm})$ & 34 \\
\hline Novomesh 950 $\left.{ }^{*}\right)$ & 0.033 in $(0.83 \mathrm{~mm})$ & 1.8 in $(45 \mathrm{~mm})$ & 55 \\
\hline
\end{tabular}

* Only crimped steel fiber and monofilament polypropylene fiber were used. 

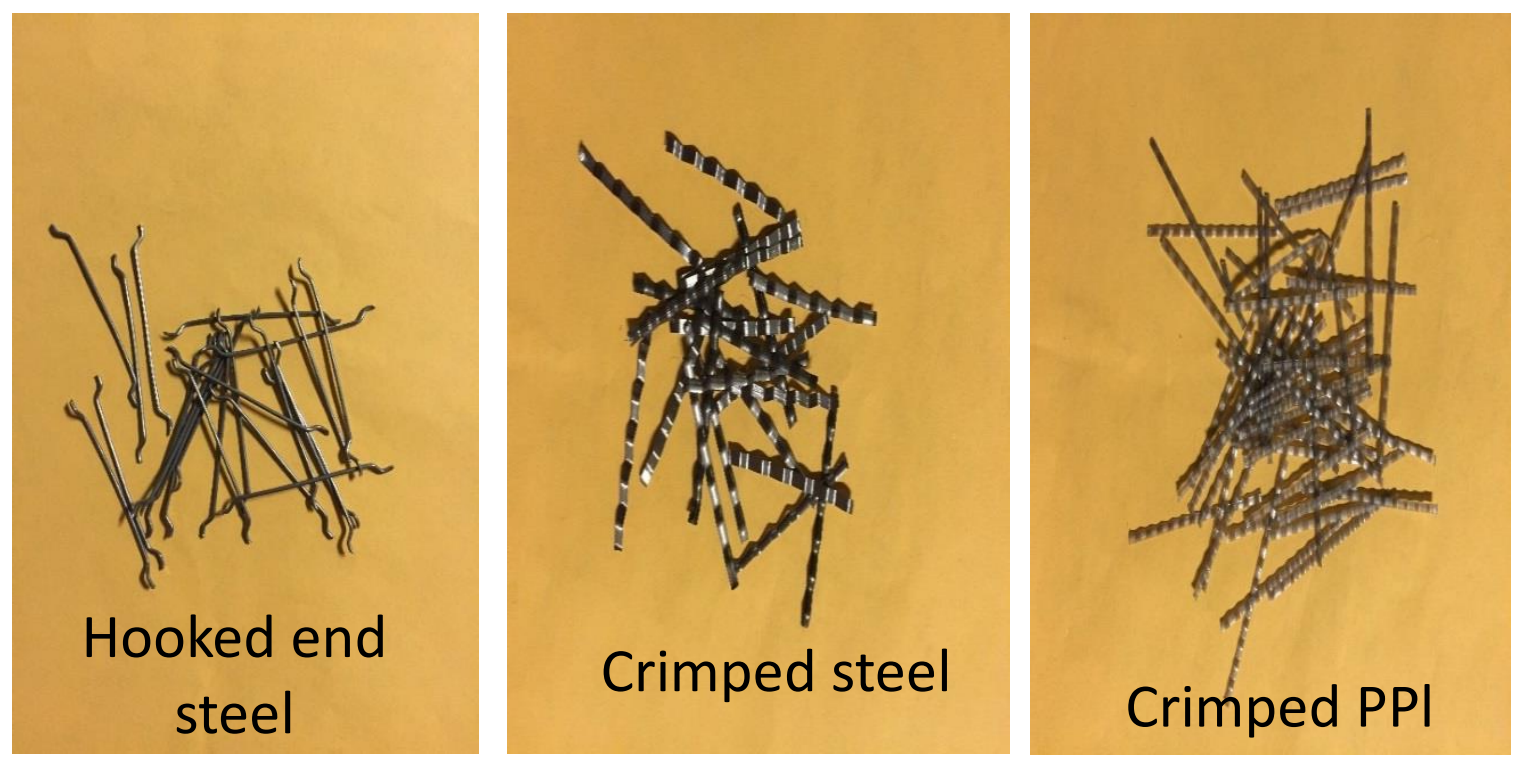

Figure 3-3 Fibers used in the experimental program

\subsection{Fabrication of Reinforcement Cages and Formwork}

Reinforcement cages were constructed at Portland State University "Hoophouse” Lab.

First, they were cut to the required length. The longitudinal reinforcement was hooked by 180 " to prevent any bond failure. Second, formwork was constructed using plywood and the interior faces of the formwork were oiled before concrete placement. Figure 3-4 shows some examples of the laboratory site preparation. 

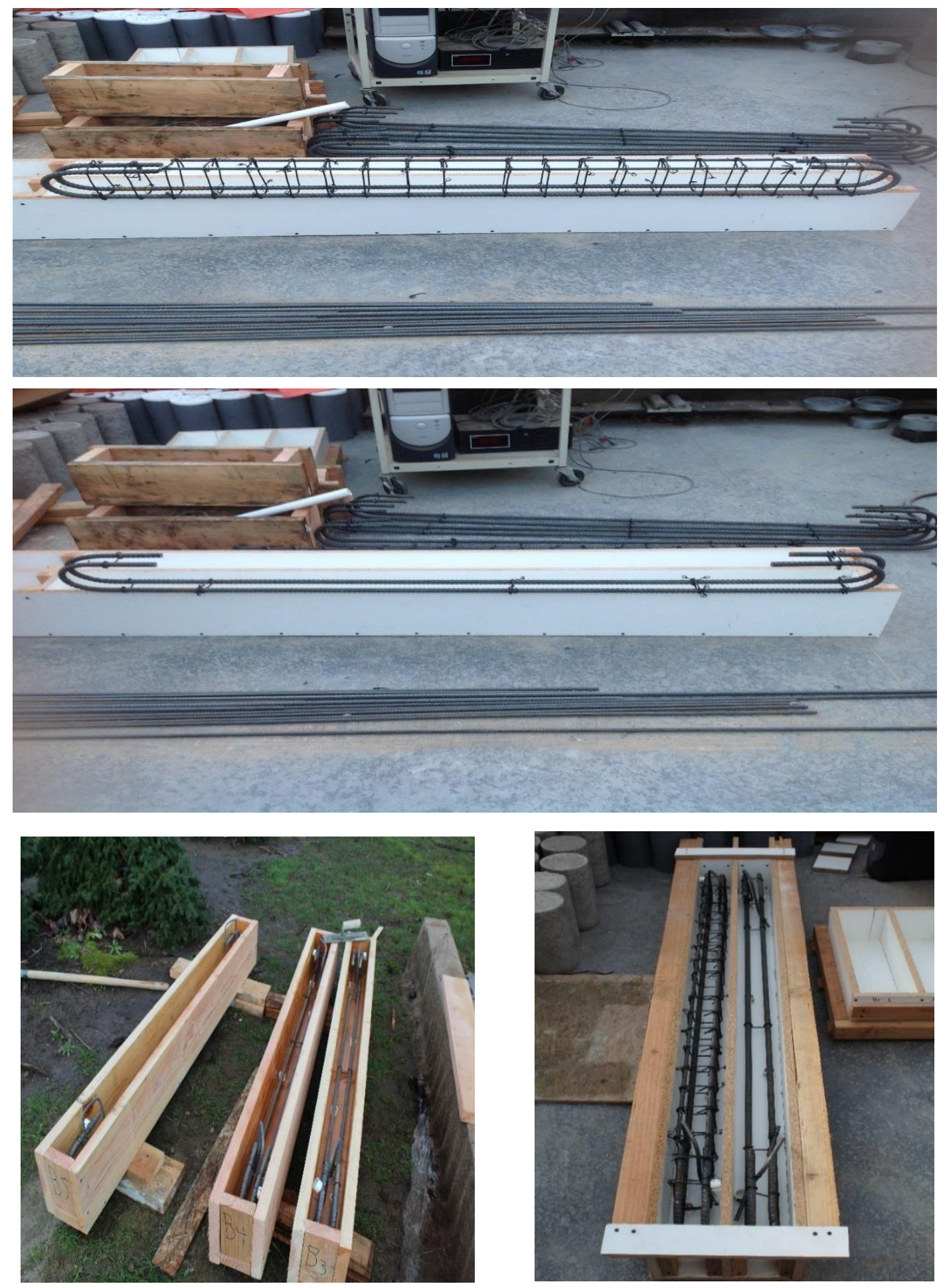

Figure 3-4 Steel fabrication and form work 


\subsection{Proportioning, Mixing and Curing of FRC}

The amounts of cement, fine aggregate and coarse aggregate, were determined depending on the targeted compressive strength using trial mixes. However, the required amount of each type of fibers was determined depending on the specific gravity, which was determined in the lab or provided by a producer. Table 3-6 shows the specific gravity and the amount of fiber used one cubic foot.

Table 3-6 Proportion of mixed fibers

\begin{tabular}{|c|c|c|}
\hline Fiber type & Specific gravity & Amount in lb for every $\mathbf{~ f t}^{\mathbf{3}}$ \\
\hline Novocon 1050 & 7.84 & 5.1 \\
\hline Novomesh 850* & 7.84 & 5.1 \\
\hline Novomesh 950* & 0.91 & 0.6 \\
\hline
\end{tabular}

* For Novomesh 850 and Novomesh 950, only crimped steel fibers and crimped monofilament

The mixing of the materials was done at Portland State University's Hoophouse Lab using $2.5 \mathrm{ft}^{3}$ mixer. Fine and coarse aggregates were first mixed for two minutes. Then cement was added and left to be mixed for another two minutes, then water was added to the mix. Fibers were the last ingredient to be added. In order to ensure a sufficient mixing and distributing of fibers, the concrete was mixed for five minutes.

The curing of the beam specimens started on the second day. The beams were covered with burlap sheets and kept moist for twenty-eight days. For the cylinders, concrete was 
cast in plastic test cylinders. On the seventh day, they were opened and moved to the curing room.

\subsection{Instrumentation and Testing}

\subsubsection{Steel Tensile Test}

The Instron, a direct tensile stress machine housed in the Department of Mechanical and Materials Lab at Portland State University was used to determine the tensile capacity of steel. This machine is shown in figure 3-5. The strain was determined using two methods. The first one used strain gages fixed on the rebar. The second used a "laser extensometer". The second method was done by fixing two reflectors on the surface of the steel rebar. The laser extensometer determined the length of the rebar surrounded by the two reflectors. After applying the load, the laser extensometer recoded the length increase. From knowing the original length and increment in the length, strain can be determined.

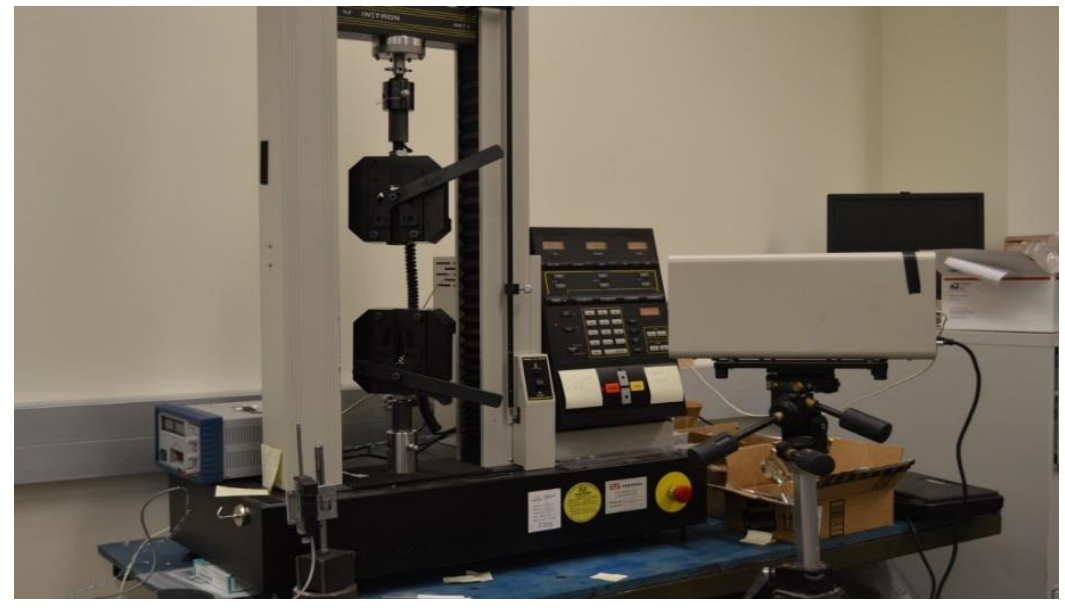

Figure 3-5 Direct tensile testing machine "Instorn" 


\subsubsection{Flexural Reinforcement}

For longitudinal reinforcement, No. 5 rebars were used as the main flexural reinforcement. The direct tensile test was conducted for three samples. A pre-stressing frame was used to test the specimens. Two splicers were placed at the end of the rebar to hold them. The axial tensile load was applied using hydraulic ramp. The test setup is shown in Figure 3-6. The load was monitored using a load cell that was connected to a computer (data acquisition system). The strain was determined using a strain gage. The obtained stress-strain relationship is showing in figure.3-7.
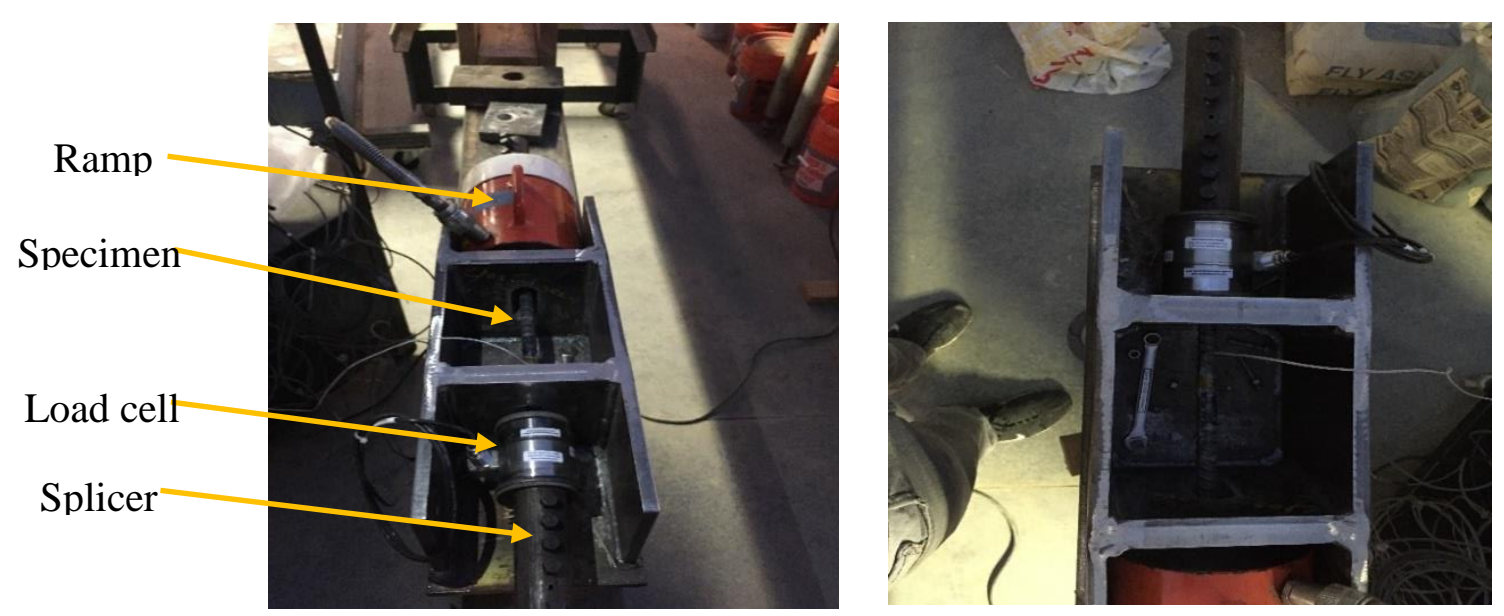

Figure 3-6 Test Setup

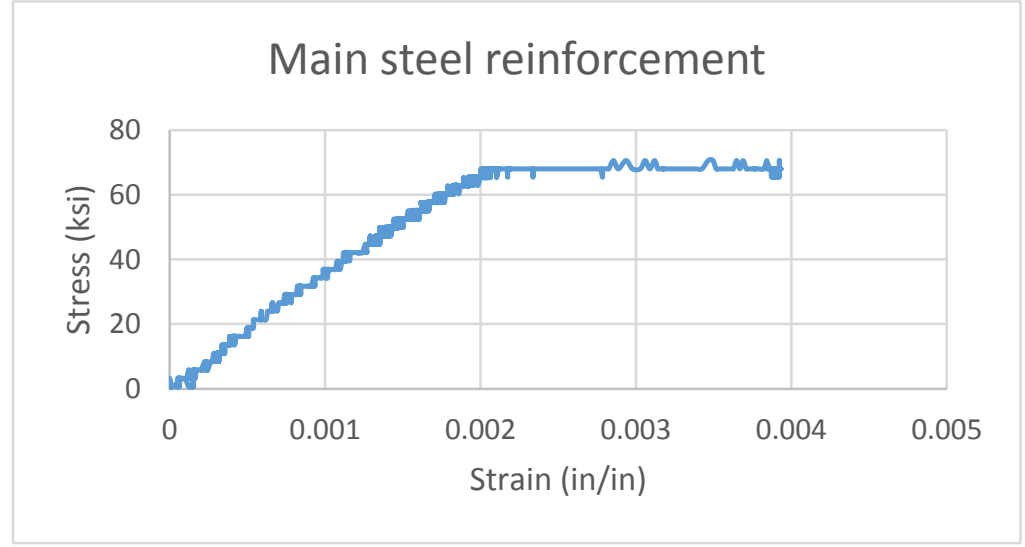

Figure 3-7 Stress-strain curve for longitudinal reinforcement 


\subsubsection{Concrete Compressive Test}

Two cylindrical specimens were molded for each beam specimen. Another two fiber reinforced concrete cylindrical specimens were molded for beam specimens with fiber. Therefore, each fiber reinforced concrete beam specimen had at least four cylindrical specimens. In order to ensure a fiber distribution similar to the one in the beams, 6" diameter by 12 " height cylinders were used. Cylinders were sampled, compacted and cured following the ASTM specification [43] [44] [45]. A plastic cylindrical mold that can be covered with a plastic lid was used in order to keep the moisture for more than one day. After three to five days the plastic molds were opened and the cylinders were moved to the curing room until the testing day. An ACCU-TEK 250 digital series compression tester, which is shown in figure 3-8, was used to determine the compressive strength.
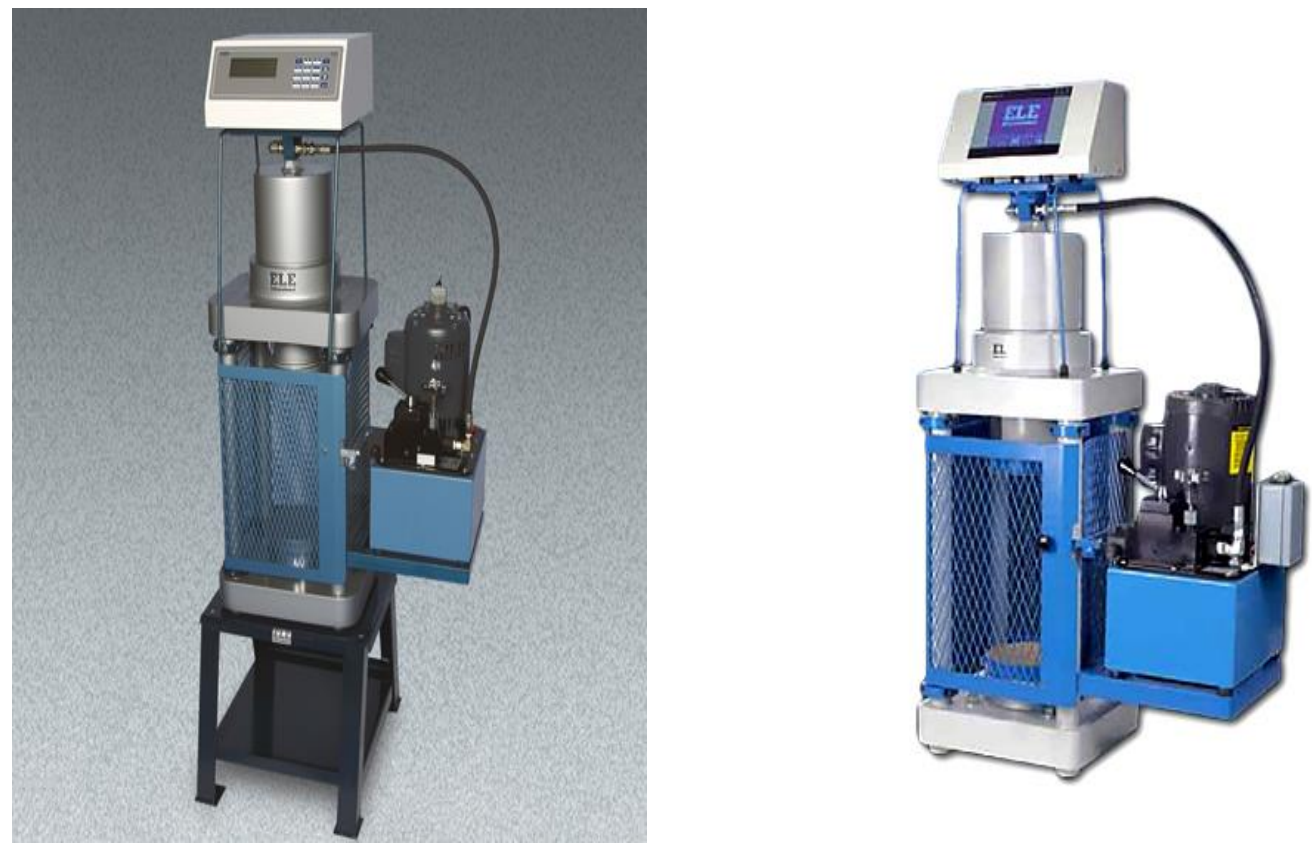

Figure 3-8 Concrete compressive machine (from http://www.hoskin.ca/catalog/index.php?main_page=index\&manufacturers_id=89) 


\subsubsection{Splitting Tensile Strength}

For each type of beam, two cylinders were sampled following ASTM C172 (2007). Then they were cured based on ASTM C31/C31M. The cylinders were taken out of the curing room after twenty-eight days. Then, two concrete strain gages, PL-60-11-1L, were attached on two end faces of the cylinders in a way that the applied load (vertical) would be perpendicular to the horizontal axis of the strain gages. The splitting tensile test was conducted following ASTM C496 [46] as shown in figure4-4. A concrete compressive tester was used to apply the load. 


\subsection{Beam Test Setup}

A load contain system was used to test the beam specimens. This system consist of a hydraulic actuator with 40-kip load capacity in which each stroke applies 1 kip. The applied load on the beam specimens was measured by a load cell while a linear variable differential transformer (LVDT) determined the defection of the specimens. Figure 3-9 shows the beam test setup.

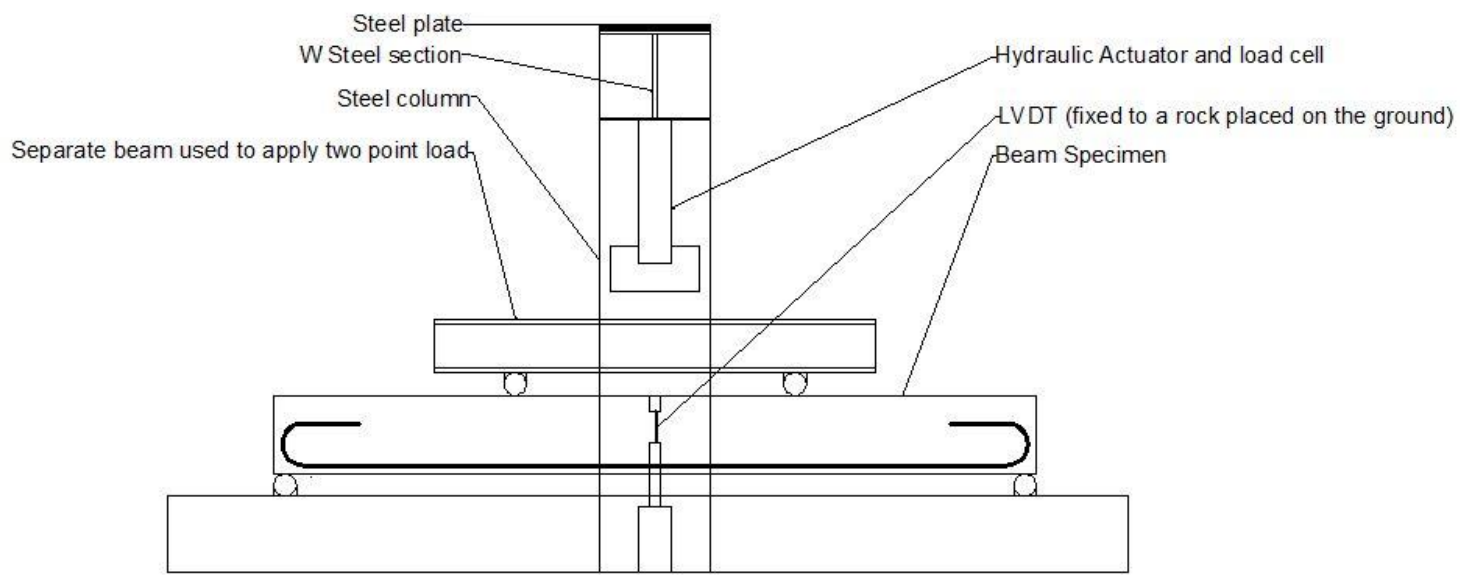

Figure 3-9 Beam test setup 


\subsection{Material Testing and Properties}

\subsubsection{Shear Reinforcement}

For shear reinforcement, a-steel wire of gage 7 was used as stirrups. The stress-strain relationship for this wire was obtained using direct tensile testing following the ASTM A370. Yield strength, ultimate strength, and other characteristics of this wire are shown in table 3-7. In addition, the stress-strain relationship is shown in figure 3-10.

Table 3-7 Diagonal shear reinforcement properties

\begin{tabular}{|c|c|c|c|}
\hline Wire type & Diameter & $\mathbf{F}_{\mathbf{y}}$ & $\mathbf{F u}_{\mathbf{u}}$ \\
& $(\mathbf{i n )}$ & $(\mathbf{k s i})$ & $\mathbf{( k s i )}$ \\
\hline Black Iron wire & 0.145 & 31.0 & 51.0 \\
\hline
\end{tabular}

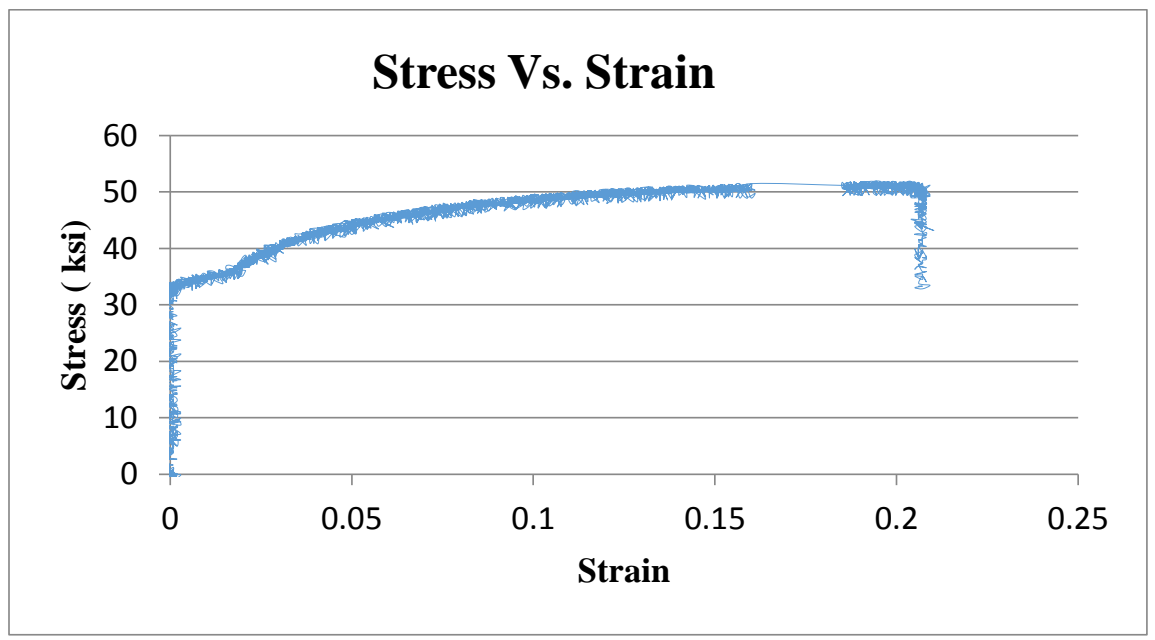

Figure 3-10 Stress-Strain relationship for diagonal shear reinforcement wire 


\section{Chapter 4: $\quad$ Result of the Experimental Program}

\subsection{Introduction}

This chapter is divided into two main parts. The first part focuses on the mechanical properties and behavior of the fiber reinforced concrete, which are compressive, tensile, toughness, and modules of elasticity. The second part provides a detailed analysis of the fiber reinforced concrete beams. Each is discussed separately to describe the behavior of the reinforced concrete beams by reviewing load versus deflection relationship, crack width, crack pattern, shear strength, and failure mode.

\subsection{Mechanical Properties of Fiber Reinforced Concrete}

\subsubsection{Compressive Strength of Fiber Reinforced Concrete}

At least two cylindrical specimens were tested on the same day of the beam testing, which was -twenty-eight days after casting. For beams reinforced with fibers, another two specimens were tested using ACCU-TEK 250 digital series compression tester following ASTM [44]. In addition, there were two cylinders used to determine the stress-strain diagram for plain and fiber reinforced concrete. Therefore, for each beam specimen there were at least five cylindrical specimens that were tested. The compressive test results are shown in figure 4-1. 
Table 4-1 Compressive strength and modulus of elasticity

\begin{tabular}{|c|c|c|c|c|c|c|c|c|c|c|c|c|}
\hline \multirow{3}{*}{ Beam } & \multirow{3}{*}{$\begin{array}{l}\text { Beam } \\
\text { Type }\end{array}$} & \multicolumn{10}{|c|}{$f^{\prime} c(\mathbf{p s i})$} & \multirow{3}{*}{$\begin{array}{l}\text { Modulus } \\
\text { of } \\
\text { Elasticity } \\
\text { (ksi) }\end{array}$} \\
\hline & & \multicolumn{5}{|c|}{ Plain Concrete } & \multicolumn{5}{|c|}{ Fiber reinforced concrete } & \\
\hline & & $\mathrm{C} 1$ & $\mathrm{C} 2$ & C3 & C4 & Ave & $\mathrm{C} 1$ & $\mathrm{C} 2$ & C3 & C4 & Ave & \\
\hline $\begin{array}{l}\text { B1- } \\
\text { MS }\end{array}$ & $\begin{array}{l}\text { Min. } \\
\text { renf. }\end{array}$ & 7253 & 7188 & 7188 & 7700 & 7332 & - & - & - & - & - & 4320 \\
\hline $\begin{array}{l}\text { B2- } \\
\text { HS }\end{array}$ & $\begin{array}{l}\text { Hook } \\
\text { steel }\end{array}$ & 7253 & 7188 & 7188 & 7700 & 7332 & 5823 & 6781 & 6374 & 7000 & 6495 & 5332 \\
\hline $\begin{array}{l}\text { B3- } \\
\text { CS }\end{array}$ & $\begin{array}{l}\text { Crimp } \\
\text { steel }\end{array}$ & 5805 & 6400 & - & - & 6102 & 5399 & 5753 & 6155 & 5723 & 5758 & 4180 \\
\hline $\begin{array}{l}\text { B4- } \\
\text { CPP }\end{array}$ & $\begin{array}{c}\text { Crimp } \\
\text { PPl }\end{array}$ & 6441 & 6981 & - & - & 6711 & 6649 & 6833 & 7046 & 7127 & 6914 & 4356 \\
\hline $\begin{array}{l}\text { B5- } \\
\text { NS }\end{array}$ & $\begin{array}{l}\text { No } \\
\text { reinf. }\end{array}$ & 6441 & 6981 & - & - & 6711 & - & - & - & - & - & - \\
\hline
\end{tabular}


It can be seen from the results represented in the Table 4-1 that both types of steel fiber reduced the compressive strength. For hooked-end steel fiber the reduction was $11 \%$. However, it was about $6 \%$ in case of the crimped-steel fiber. One of the reasons for the reduction in the compressive strength is the low amount of fine aggregate compared with coarse aggregate. In other words, the amount of fine aggregate that was used was not enough to fill all the additional voids created by the steel fiber. For example, one of the researches [47] used a fine aggregate to coarse aggregate ratio of $1.3 \%$ to obtain an increment in compressive strength up to $5.5 \%$. The polypropylene fiber did not have that significant of an effect on the compressive strength.

In addition to the compressive strength, stress-strain and modules of elasticity were determined. In this test, the strain was captured using 2.4" strain gauges. At least one strain gage was placed along the length of the cylindrical specimen. A pressure meter was used to determine the applied load. The data represented in figure 4-1 shows that the behavior of all specimens was similar up to the failure point, which occurred at strain of 0.003. However, the benefits of the fiber were determined after the failure by preventing the concrete from exploding, especially in the high strength concrete that occurred for the control specimens. This effect could not be determined using the stress-strain diagram because the strain gages split most of the time from the specimens when failure occurred. Figure 4-2 shows some photos of the tested specimens. 

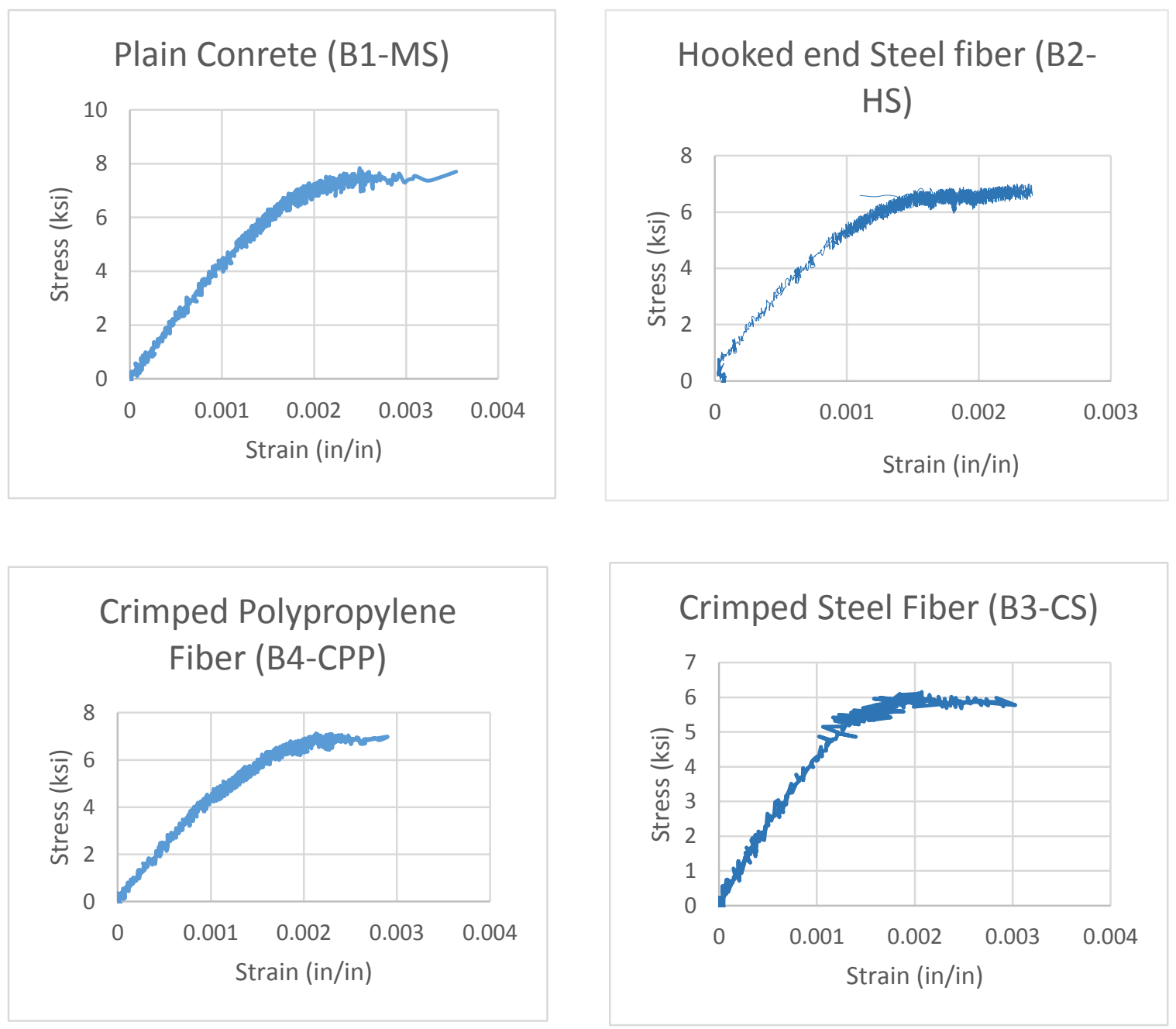

Figure 4-1 Stress-Strain curves 

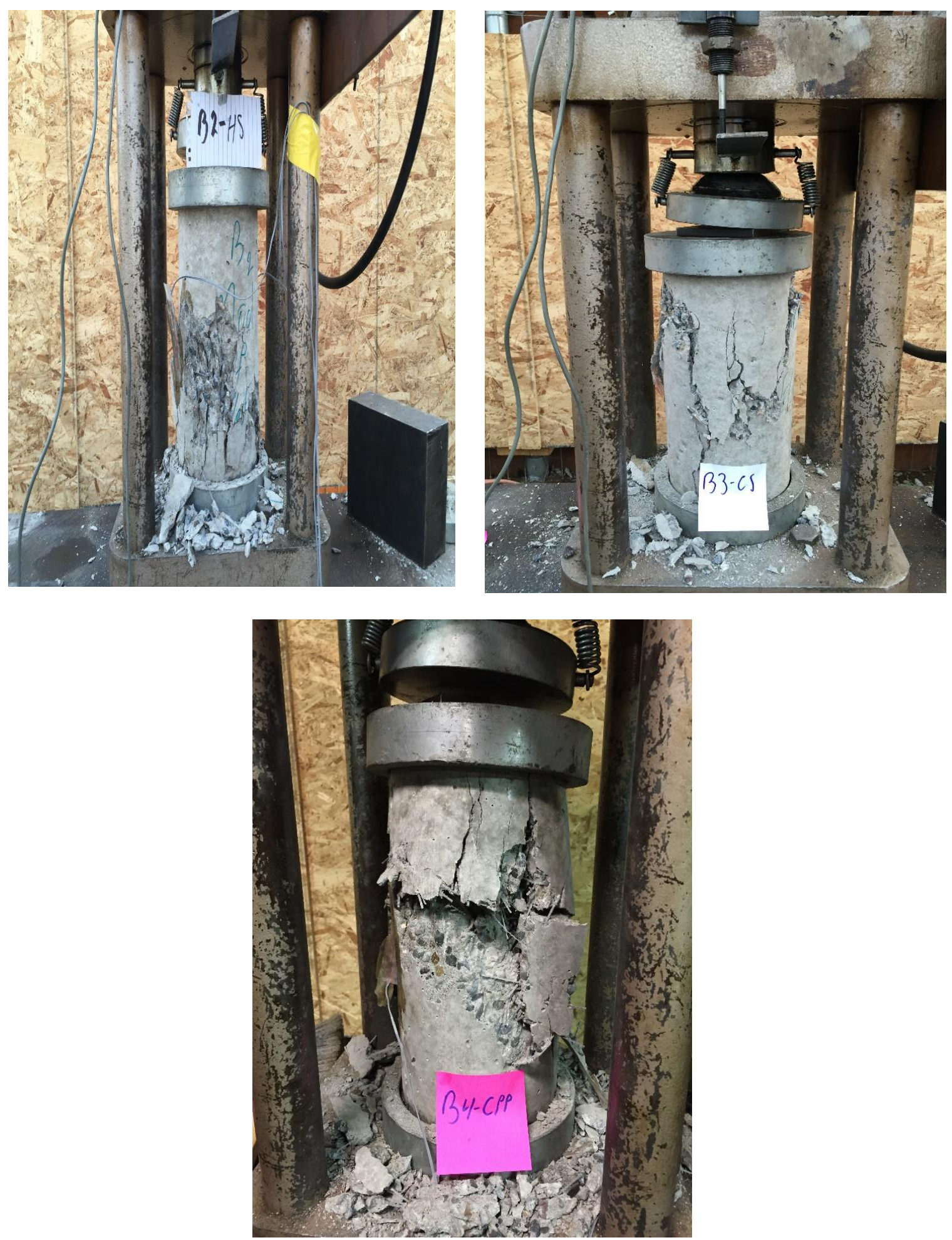

Figure 4-2 Cylinders failure pattern 


\subsubsection{Splitting Tensile Strength}

The tensile splitting strength for each type of specimen was calculated from the maximum recorded failure load. Figure 4-4 shows the loading system. The effect of plywood bearing strips was included in order to reduce the tolerance from the direct tensile test. The tensile strength was determined using the Tang [13] correction

$\sigma_{t}=\frac{2 P}{\pi D L}\left[1-\left(\frac{b}{D}\right)^{2}\right]^{\frac{2}{3}}$

Where $P$ is failure load, $D$ is specimen diameter, $L$ is specimen diameter, and $b$ is the bearing strip width.

The tensile stress-strain diagram was constructed for each type of the three fibers using at least one of the cylindrical specimens as shown in figure 4-3. Results showed that the tensile stain was increasing linearly as the applied load or the stress was increasing until the section was cracked. After the cracking point, failure was obtained in the control section which did not have any type of fiber. From its test name, it can be concluded that failure pattern was splitting the cylinders into two halves. At this point, the strain gage was either destroyed or it was reading the maximum strain, which was 0.02 inches/inches.

The interpretation of the stress-strain curve for the crimped-steel fiber would show a similar conclusion for the control one. However, this curve reflected the part of the test result up to the cracking stage where the developed crack was bigger than was captured by the strain gage. After cracking, the specimen kept preserving the applied load with 
little loss to the load. In other words, the strain beyond cracking was not captured because it was more than the strain gage capacity.
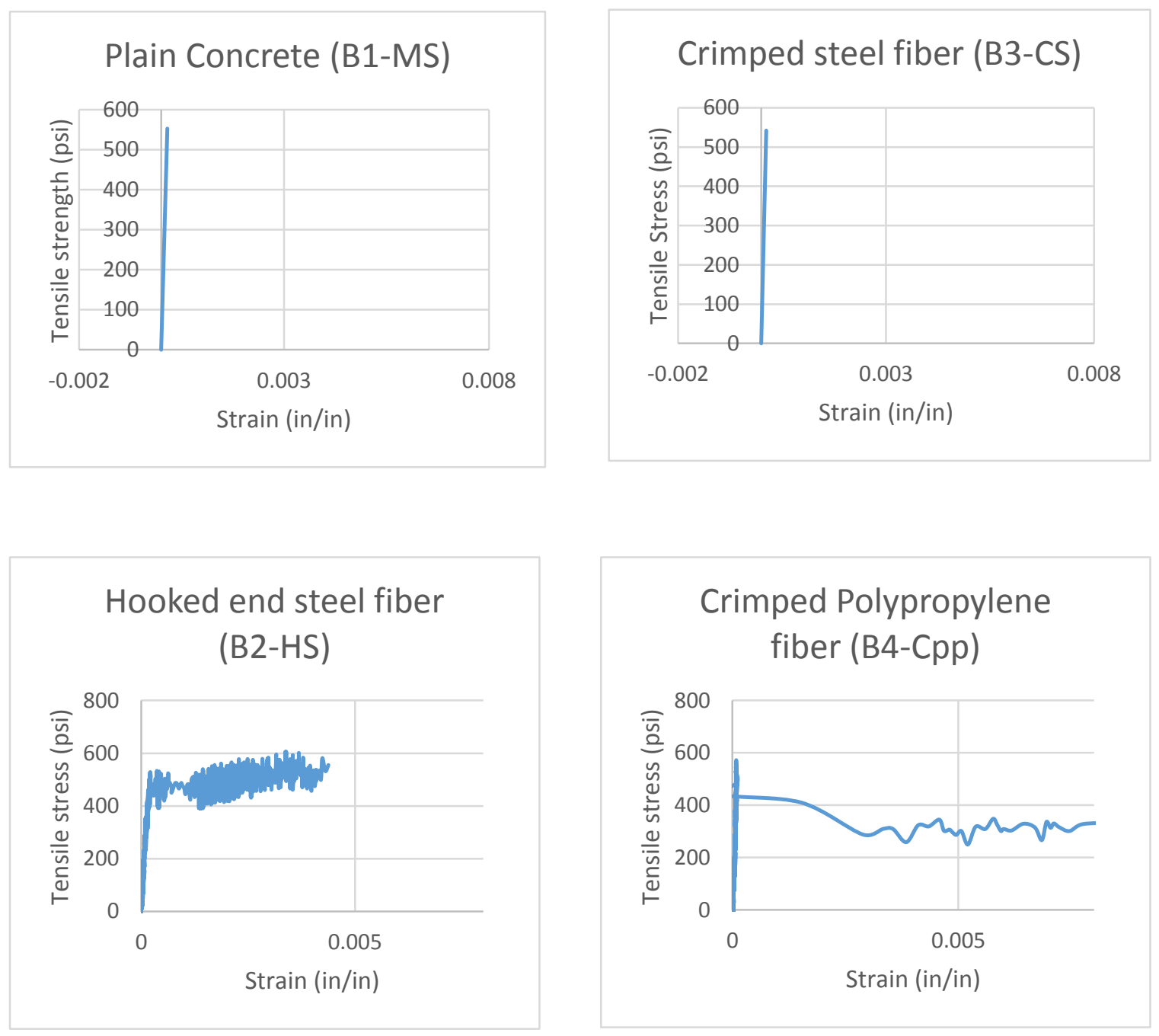

Figure 4-3 Tensile stress Vs Strain for splitting test 
For hooked-end steel fiber, the same linear effect was obtained until section was cracked. Since the developed crack was very small, the $\operatorname{strain}^{1}$ in term of the crack width could be captured by strain gages. From the stress-strain curve shown in Figure 4-3, it can be inferred that fiber prevents concrete failure by transferring stress through cracks. The test was stopped when cracks were propagated and exceed the strain gage limit. A similar conclusion can be inferred for the crimped-monofilament polypropylene fiber.

Nevertheless, the lost stress after section cracking was greater than hooked-end steel fiber.

It can be concluded from the results shown in table 4-2 that splitting tensile strength for fiber reinforced concrete is almost equal because the fiber enhanced the post-crack characteristics by transferring stress across the crack. Finally, figure 4-4 shows some of the failure pattern for some types of specimens.

${ }^{1}$ When concrete is cracked, the change in its dimension cannot be called strain anymore because it is resisted by the added material. 
Table 4-2 Splitting tensile strength

\begin{tabular}{|c|c|c|c|c|}
\hline Beam & Fiber type & $\begin{array}{l}\text { C1 } \\
\text { (psi) }\end{array}$ & $\begin{array}{l}\text { C2 } \\
\text { (psi) }\end{array}$ & $\begin{array}{c}\text { Average splitting strength } \\
\text { (psi) }\end{array}$ \\
\hline B1-TD & No Fiber & 597 & 553 & 575 \\
\hline B2-HS & Hooked end steel fiber & 605 & 581 & 593 \\
\hline B3-CS & Crimped steel fiber & 557 & 542 & 550 \\
\hline $\begin{array}{l}\text { B4- } \\
\text { CPP }\end{array}$ & $\begin{array}{c}\text { Crimped } \\
\text { polypropylene }\end{array}$ & 572 & 587 & 580 \\
\hline
\end{tabular}
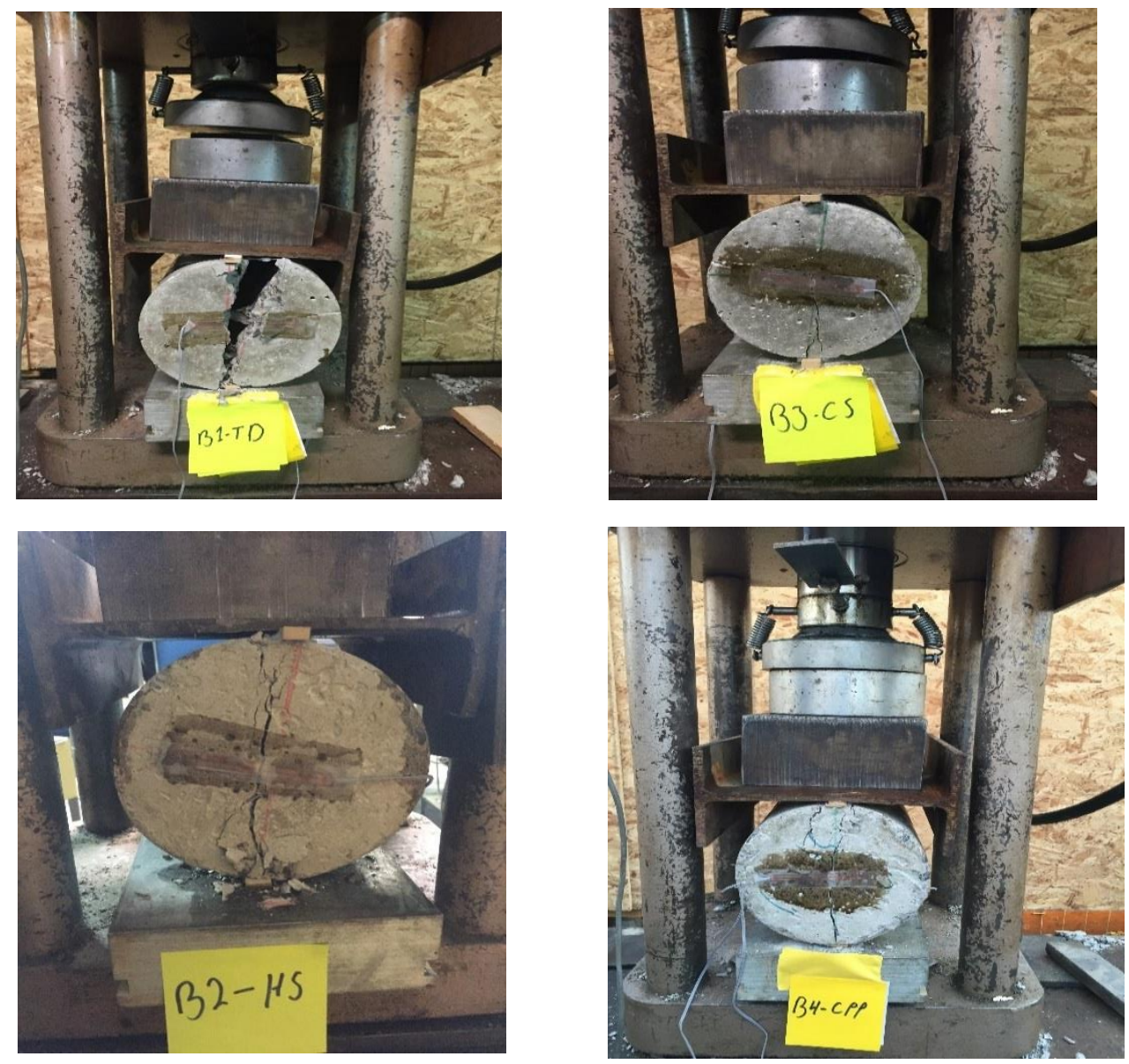

Figure 4-4 Splitting test 


\subsubsection{Flexural Strength}

For each type of fiber, three beam specimens that were 6" x 6"x 20" were sampled following the ASTM C172, and were left to be cured for twenty-eight days. The flexural strength of steel fiber reinforced concrete was determined based on the ASTM C1609 (2007). The four-point bending test set-up is shown in the figure 4-5. Since there was no displacement control machine in the lab, a load control base machine, ACCU-TEK 250 digital series compression tester, was used in this test. The specimens were loaded at a rate of $10 \mathrm{lb} / \mathrm{sec}$. depending on the obtained load-deflection curve, and in comparison with literature it was found that a load rate ranging from $10 \mathrm{lb} / \mathrm{sec}$ to $15 \mathrm{lb} / \mathrm{sec}(600$ $\mathrm{lb} / \mathrm{min}$ to $900 \mathrm{lb} / \mathrm{min}$ ) can simulate a loading rate of $0.005 \mathrm{in} / \mathrm{min}$, which is required by ASTM C1609. The test was stopped at a deflection of 0.12 inches at the mid-span, which is equivalent to $1 / 150$ of the span length (18in).
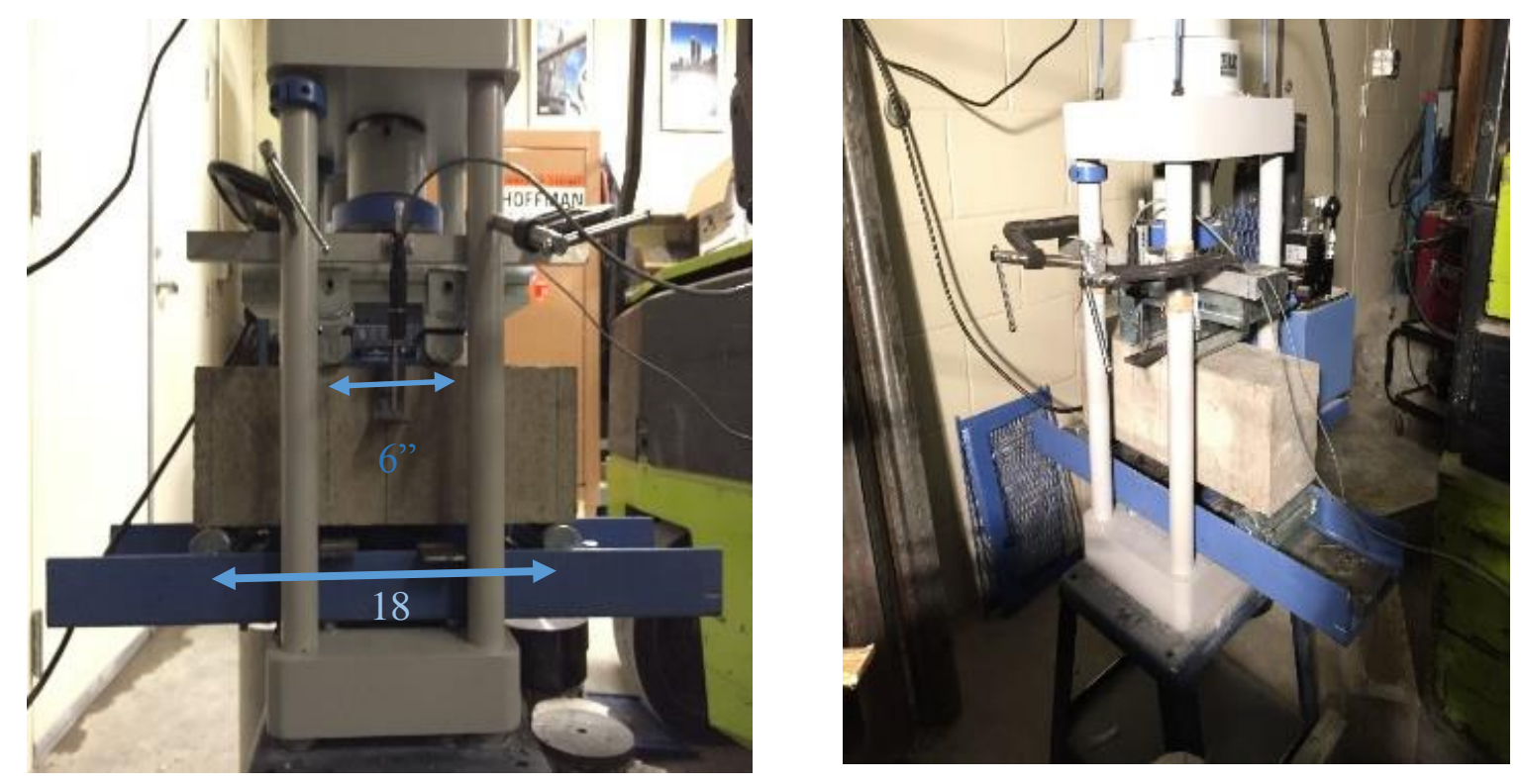

Figure 4-5 Flexural test setup 
When the test was terminated at a deflection of 0.12 inches, the largest distance from the closest support to the crack was reported as shown in table 4-3.

Table 4-3 Prism Test information

\begin{tabular}{|c|c|c|c|c|}
\hline Beam & Specimen No. & Fiber type & $\mathbf{V}_{\mathbf{f}}$ & a (in) \\
\hline \multirow{3}{*}{ B1-TD } & 1 & No fiber & $1 \%$ & 8.2 \\
\hline & 2 & No fiber & $1 \%$ & 8.8 \\
\hline & 3 & No fiber & $1 \%$ & 8.6 \\
\hline \multirow{3}{*}{ B2-HS } & 1 & Novocon 1050 & $1 \%$ & 10.5 \\
\hline & 2 & Novocon 1050 & $1 \%$ & 10 \\
\hline & 3 & Novocon 1050 & $1 \%$ & 9.5 \\
\hline \multirow{3}{*}{ B3-CS } & 1 & Novomesh $850 *$ & $1 \%$ & 7.5 \\
\hline & 2 & Novomesh $850^{*}$ & $1 \%$ & 8.2 \\
\hline & 3 & Novomesh $850 *$ & $1 \%$ & 9.2 \\
\hline \multirow{3}{*}{ B4-PP } & 1 & Novomesh $950 *$ & $1 \%$ & 7.8 \\
\hline & 2 & Novomesh $950 *$ & $1 \%$ & 8.5 \\
\hline & 3 & Novomesh $950 *$ & $1 \%$ & 8.0 \\
\hline
\end{tabular}

*For Novomesh 850 and Novomesh 950, The only mulfilment fiber were used in the test. 
The equivalent bending stress was determined based on the assumption of linear stress distribution along the section. Therefore, the maximum flexural stress will be at the extreme top and bottom faces.

$\sigma=\frac{M C}{I}=\frac{\left(\frac{P}{2} * l\right) \frac{h}{2}}{\frac{b h^{3}}{12}}=\frac{\left(\frac{P}{2} * 6\right) 3}{\frac{6^{4}}{12}}=\frac{P}{12}$

Where: $\sigma$ is flexural stress in psi; $P$ is the applied load in $l b ; 1$ is the distance distance from the support to the nearest applied load in inches; and $h$ and $b$ are the cross section dimension in inches.

The data represented in figure 4-6 shows that all three fibers increased the pre-cracking flexural strength. However, each one enhanced it with a different trend. Hooked-end steel fiber raised the flexural strength from 442 psi to 710 psi. In addition to increasing flexural strength, crimped- steel fiber increased the pre-cracking deflection. In other words, crimped fiber can increase the energy absorbed up to the first crack initiation. This feature was more obvious in polypropylene fiber when it shifted the first cracks initiation up to 0.064 inches in some of the tested specimens. 

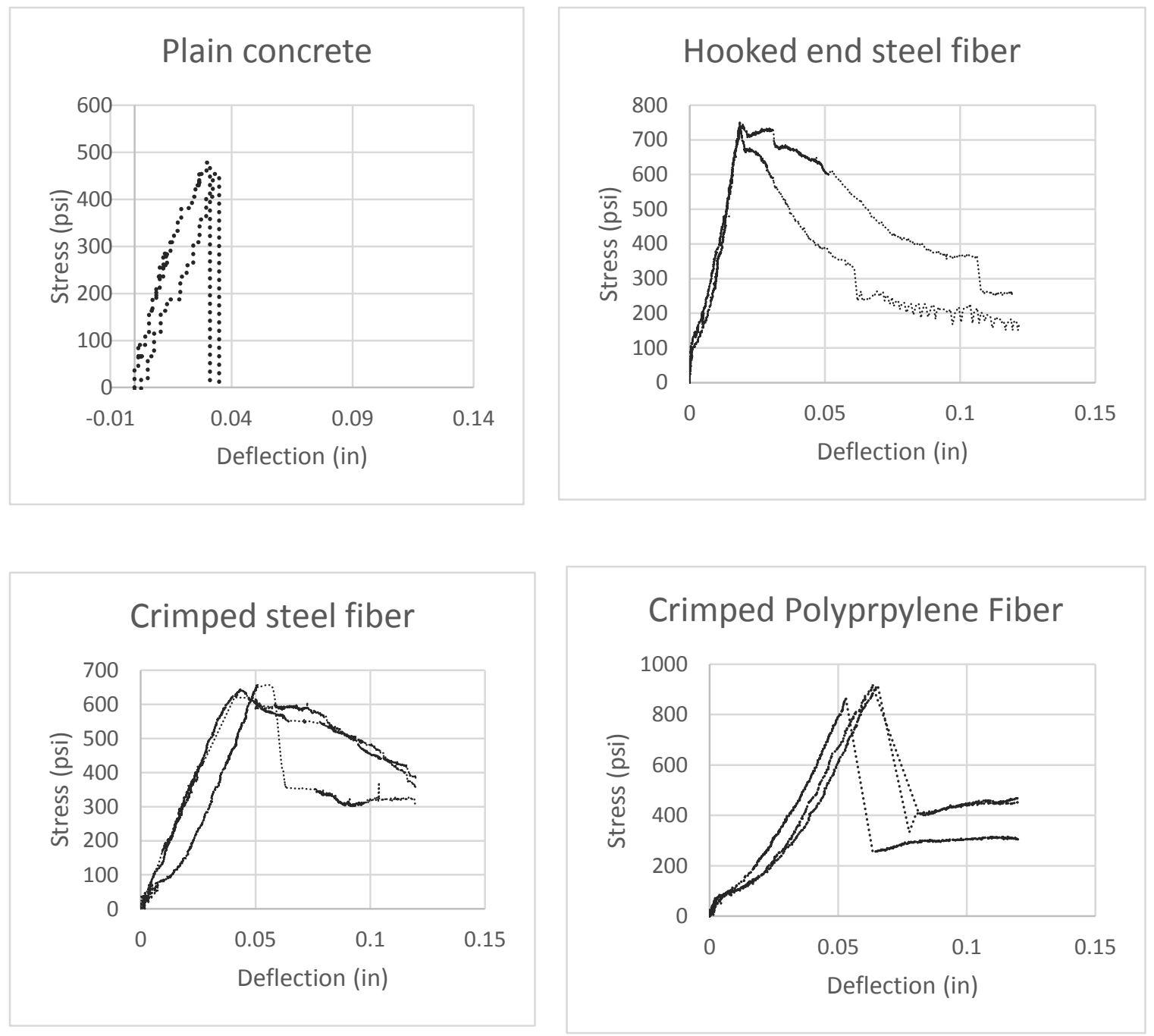

Figure 4-6 Flexural Stress Versus Deflection at midspan

It can be seen from figure 4-6 that the flexural strength of the specimens increased linearly up to the rapture point where strength drops rapidly or gradually, which will be explain in more detail in the section on toughness. Table 4-4 shows the maximum flexural stresses of each specimen $\sigma_{\mathrm{f}}$, deflection at that stress $\delta_{\mathrm{f}, \text {, and flexural strength at }}$ the end of the test. 
Table 4-4 Flexural test results

*For Novomesh 850, and Novomesh 950, only crimped steel fiber and crimped

\begin{tabular}{|c|c|c|c|c|c|c|c|}
\hline Beam & $\begin{array}{l}\text { Speci } \\
\text { men } \\
\text { No. }\end{array}$ & Fiber type & $\begin{array}{c}\text { Max } \\
\text { flexura } \\
\text { I stress } \\
\text { of }(\mathbf{p s i})\end{array}$ & $\begin{array}{l}\text { Deflection at } \\
\text { Max stress } \\
\text { in (inches) }\end{array}$ & $\begin{array}{c}\text { Stress } \\
\text { at } \\
0.06 \mathrm{in} \\
\text { (psi) }\end{array}$ & $\begin{array}{l}\text { Stress } \\
\text { at the } \\
\text { test end } \\
\text { (psi) }\end{array}$ & $\begin{array}{c}\text { Beams } \\
\text { Description }\end{array}$ \\
\hline \multirow[b]{2}{*}{ B1-MS } & 1 & No fiber & 477 & 0.031 & 0 & 0 & \multirow{2}{*}{$\begin{array}{l}\text { Min shear } \\
\text { reinforcement }\end{array}$} \\
\hline & 2 & No fiber & 453 & 0.035 & 0 & 0 & \\
\hline \multirow[b]{2}{*}{ B2-HS } & 1 & $\begin{array}{c}\text { Novocon } \\
1050\end{array}$ & 732 & 0.019 & 532 & 260 & \multirow{2}{*}{$\begin{array}{c}\text { Hooked-end } \\
\text { steel }\end{array}$} \\
\hline & 2 & $\begin{array}{c}\text { Novocon } \\
1050\end{array}$ & 742 & 0.0198 & 329 & 164 & \\
\hline \multirow{3}{*}{ B3-CS } & 1 & $\begin{array}{c}\text { Novomesh } \\
850 *\end{array}$ & 619 & 0.042 & 569 & 386 & \multirow{3}{*}{ Crimped-steel } \\
\hline & 2 & $\begin{array}{c}\text { Novomesh } \\
850^{*}\end{array}$ & 647 & 0.044 & 566 & 356 & \\
\hline & 3 & $\begin{array}{c}\text { Novomesh } \\
850^{*}\end{array}$ & 657 & 0.051 & 439 & 298 & \\
\hline \multirow{3}{*}{ B4-PP } & 1 & $\begin{array}{c}\text { Novomesh } \\
950^{*}\end{array}$ & 848 & 0.052 & 258 & 304 & \multirow{3}{*}{$\begin{array}{c}\text { Crimped } \\
\text { polypropylene }\end{array}$} \\
\hline & 2 & $\begin{array}{c}\text { Novomesh } \\
950^{*}\end{array}$ & 908 & 0.064 & - & 465 & \\
\hline & 3 & $\begin{array}{c}\text { Novomesh } \\
950 *\end{array}$ & 911 & 0.066 & - & 499 & \\
\hline
\end{tabular}

monofilament polypropylene fiber were used respectively. 


\section{- ACI Code Requirements to Use Steel Fiber as Shear Reinforcement}

ACI 318 in section 5.6.6.2 specified three conditions to accept steel fiber shear reinforcement. The weight of deformed steel fiber should not be less than $100 \mathrm{lb}$ per cubic yard $(3.7 \mathrm{lb} / \mathrm{cubic} \mathrm{ft})$. This requirement was satisfied since the amount that was used was about $5.0 \mathrm{lb} /$ cubic ft. The other two conditions were that the residual strength at deflection $1 / 300$ and $1 / 150$ (0.06 inches and 0.12 inches) of the span length is greater than $90 \%$ and $75 \%$ of the first peak strength, respectively. From the result shown in the table, it can be seen that neither the hooked-end steel fiber nor the crimped-steel fiber could pass these criteria. Polypropylene fiber shifted the first peak beyond the deflection of $1 / 300$ of the span length. Therefore, this eriteria criterion could not be applied to it. Nevertheless, polypropylene strength at deflection 1/150 of the span length was less than $75 \%$ at first peak strength. 


\subsubsection{Flexural Toughness}

As mentioned in the second chapter, toughness is the absorbed energy prior to the specimen separation, which is measured using toughness index. These indexes are $\mathrm{I}_{5}$, which is the ratio of the area under load-deflection curve at 3 times first-crack deflection to area under load-deflection curve at first crack, $\mathrm{I}_{10}$, measured at 5.5 times the firstcrack, and $\mathrm{I}_{30}$, measured at 15.5 times the first-crack deflection.

ASTM C1018 [18] is the specification that was used to determine the fiber reinforced concrete toughness. This standard was withdrawn in the 2007 publication because of lack of interest. This specification has the same testing procedure as described in ASTM C1609 [48]. Therefore, similar to the flexural strength test for each type of fiber, three beam specimens measuring 6" x 6" x 20" were sampled using the ASTM C172. The specimens were cured for twenty-eight days. The test was stopped at a deflection equal to 5.5 times the deflection at the first crack occurrence.

The first graph in figure 4-7 shows the load-deflection curve for the plain concrete. It can be seen that beam did not have any toughness. Thus, the toughness is zero. This result was expected since it is known that concrete is brittle material.

The second graph is the hooked-end steel fiber results. After reaching the maximum flexural strength, the section started cracking. However, unlike the plain concrete beam specimens, the steel fiber held the section allowing load transfer across the cracks. The post-cracking behavior of a specimen depends on number of factors such as volumetric ratio, aspect ratio, and fiber type. In this case, the post-cracking flexural strength showed 
a short hardening before it started decreasing gradually as the applied load increased giving the specimen good toughness behavior. The gradual decreasing in the flexural strength was caused by the bond failure of the steel fiber-concrete. This toughness is explained in the Form of Toughness Index in table 4-5.

The third graph in figure 4-7 belongs to the crimped-steel fibers. These types of fibers have less aspect ratio than the one discussed earlier. Despite the fact that the area under the load-deflection curve for the post-cracking phase at three times the cracking load of this fiber was greater than the previous fiber, the obtained toughness was still lower than hooked-end steel fiber. This result can be explained by the fact this fiber increased both areas for pre-cracking and post-cracking. In addition, it has a lower aspect ratio, which can cause an earlier bond failure.

The last type of fiber was the crimped-monofilament polypropylene fiber, which is shown in the fourth graph. It was mentioned in the previous section that this type of fiber had a good effect on the pre-cracking flexural strength. Nevertheless, once the section cracked there was a significant drop that sometimes exceeded $50 \%$ of the pre-cracking strength. Therefore, the toughness of this type of fiber was lower than the other two. 

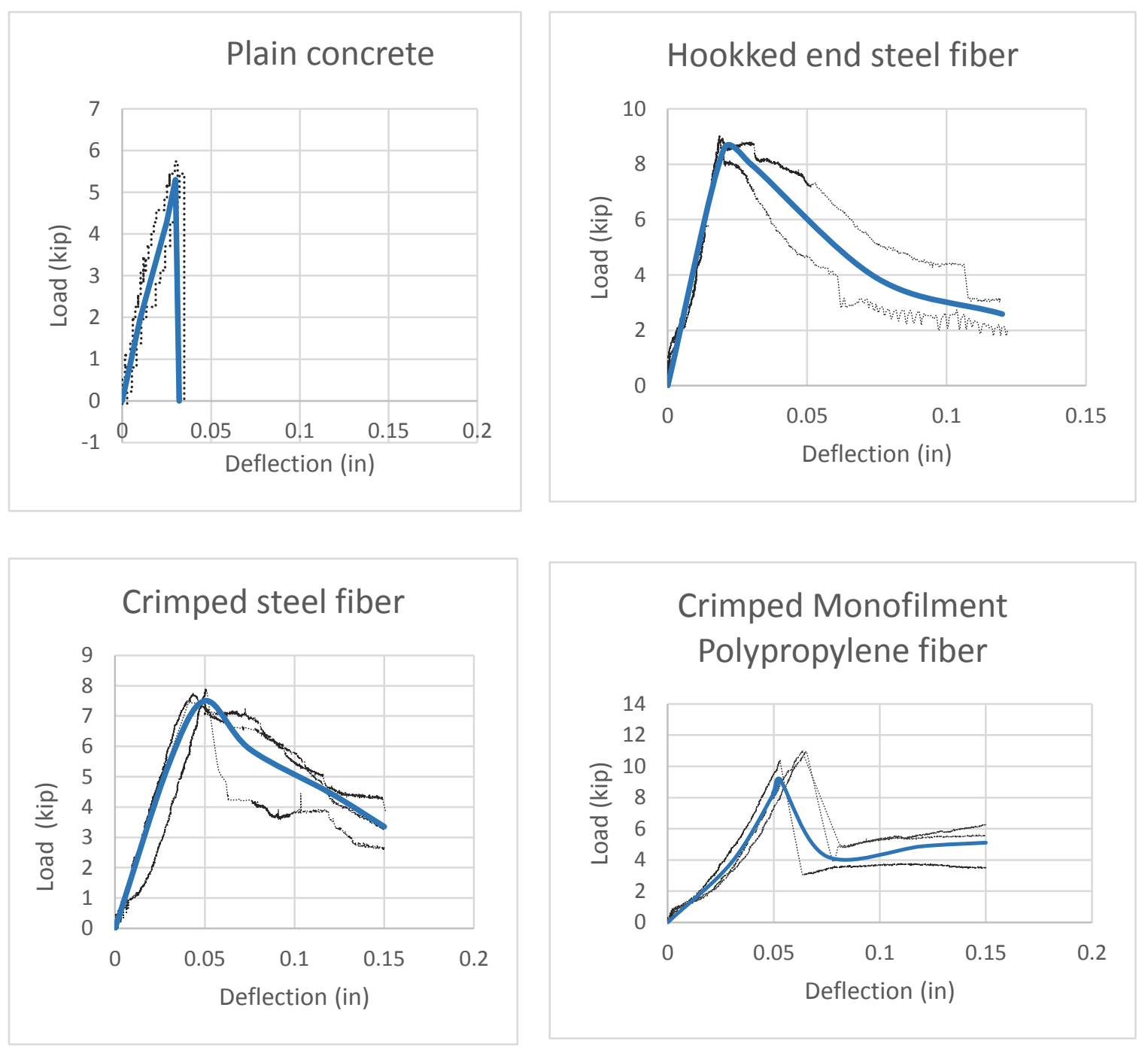

Figure 4-7 Flexural toughness of concrete prism ( The dashed lines represent the tested specimens and the solid line is the average of these specimen) 
Table 4-5 Flexural toughness index of fiber reinforced concrete

\begin{tabular}{|c|c|c|c|}
\hline Fiber Type & $\begin{array}{c}\text { Area under load } \\
\text { deflection curve up to } \\
\text { the first Crack (A) }\end{array}$ & $\begin{array}{c}\text { Area under load-deflection } \\
\text { curve at } 3 \text { times the } \\
\text { cracking deflection }\left(\mathbf{A}_{\mathbf{2}}\right)\end{array}$ & $\begin{array}{l}\boldsymbol{I}_{\mathbf{5}} \\
=\frac{\boldsymbol{A}_{\mathbf{2}}}{\boldsymbol{A}_{\mathbf{1}}}\end{array}$ \\
\hline Plain Concrete & 0.08 & 0 & 0 \\
\hline Hooked end steel & 0.085 & 0.27 & 3.17 \\
\hline $\begin{array}{c}\text { Crimped steel } \\
\text { fiber }\end{array}$ & 0.2 & 0.315 & 2.7 \\
\hline $\begin{array}{c}\text { Crimped } \\
\text { polypropylene }\end{array}$ & 0.48 & 0.488 & 1.02 \\
\hline
\end{tabular}

Figure 4-7 shows the flexural toughness index at three times the cracking deflection. The flexural toughness was summarized in figure 4-8. It can be concluded that hooked-end steel fiber can increase both stiffness and the toughness. This was the same result obtained by other researchers like Thomas and Ramaswamy [16]. Crimped-steel fiber significantly increased pre-cracking flexural strength and toughness. However, monofilament polypropylene fiber had a greater effect on the pre-cracking flexural strength. In addition, it had a lower toughness increment in comparison with steel fiber. Finally, figure 4-10 shows the areas used in the determination of flexural toughness index. 


\section{FLEXURAL TOUGHNESS}

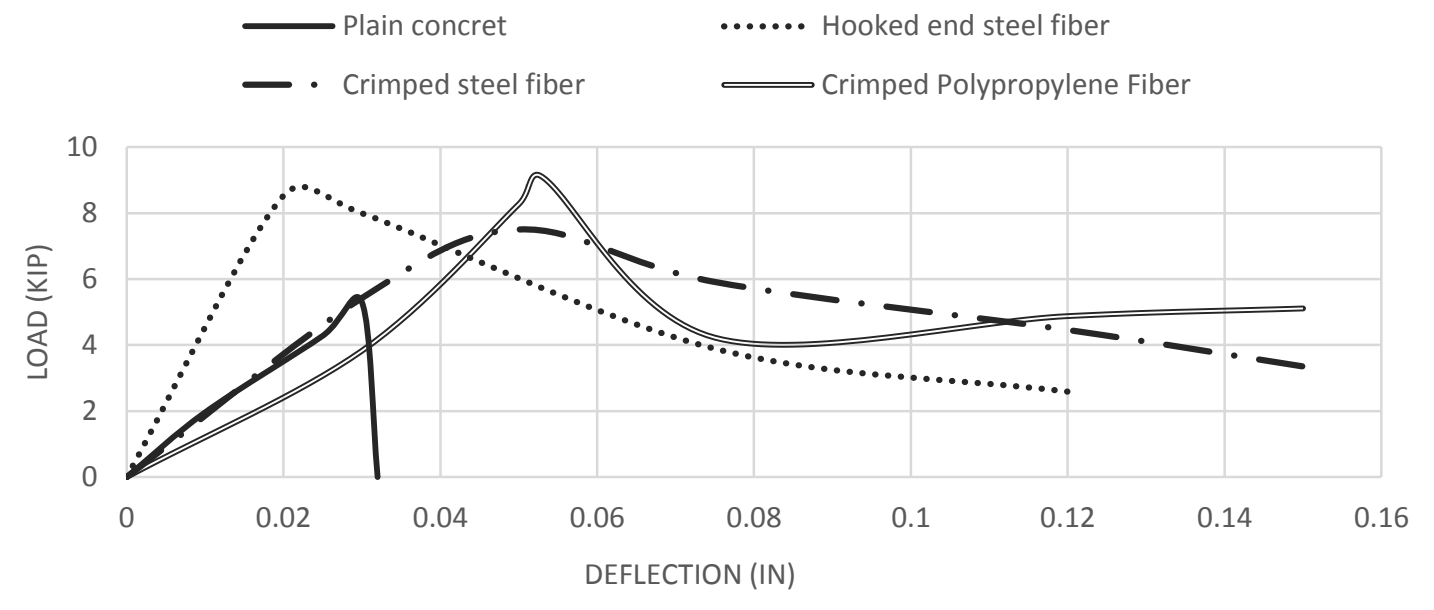

Figure 4-8 Comparison of the average flexural toughness index for the three used fiber.
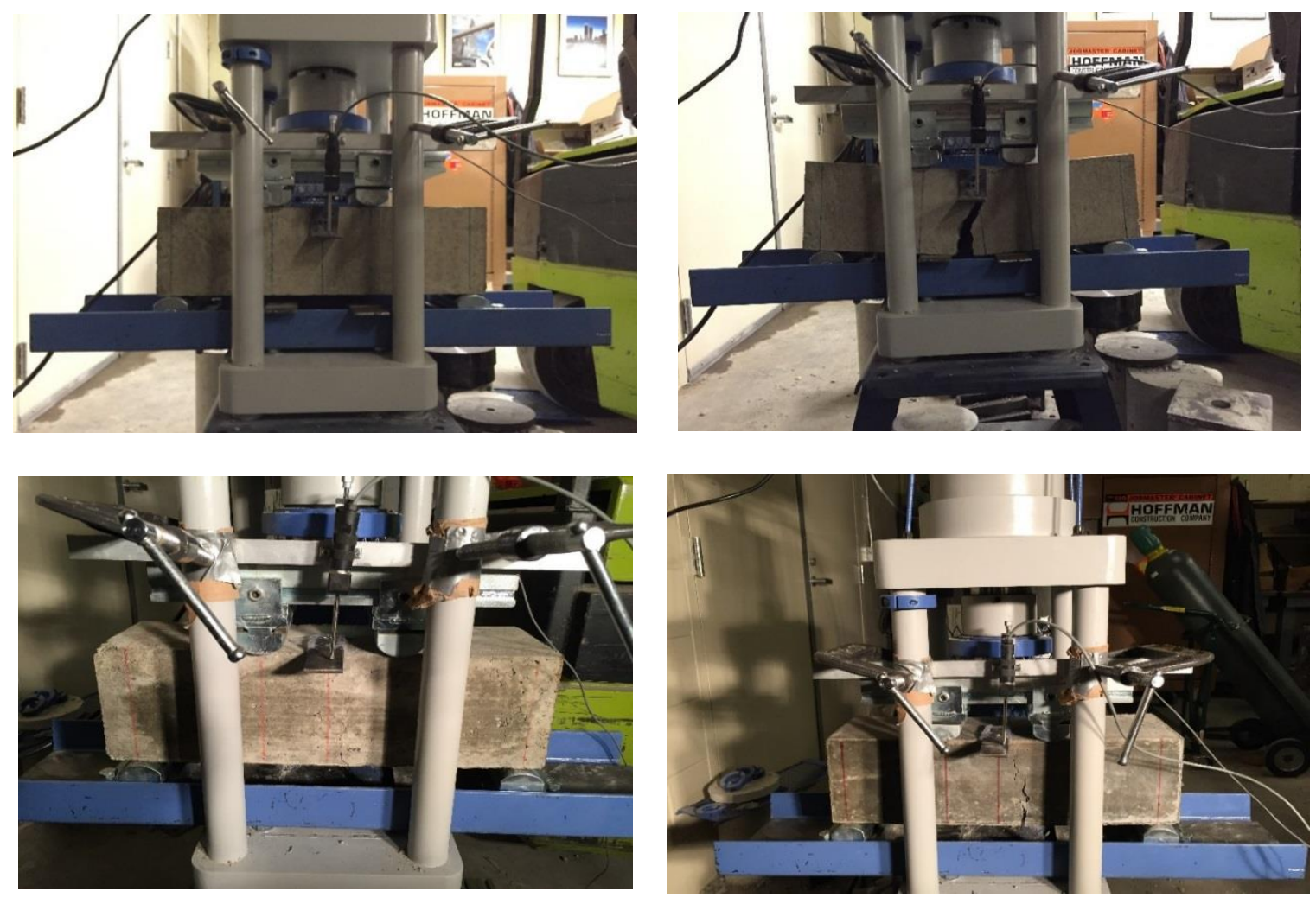

Figure 4-9 Failure stages of plain concrete 


\section{FLEXURAL TOUGHNESS INDEX}

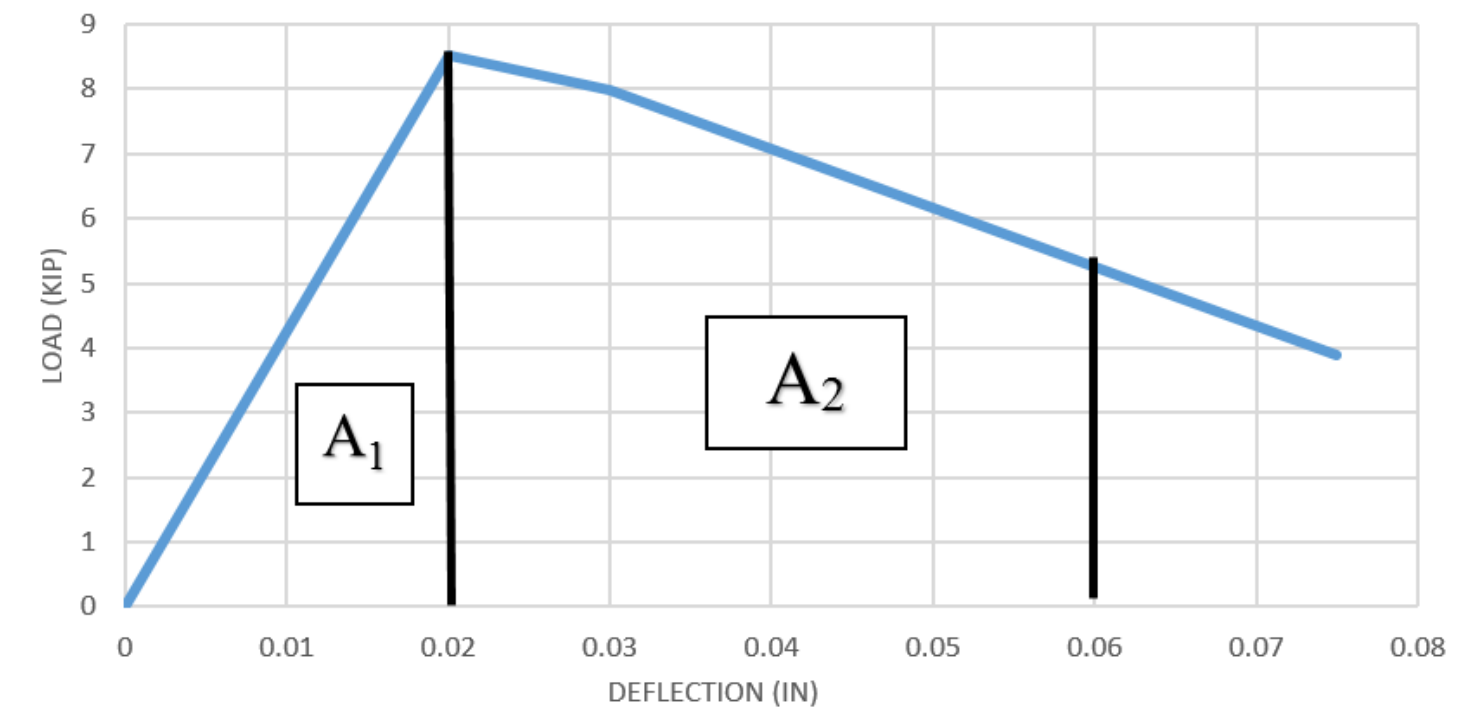

Figure 4-10 Areas used to determine flexural toughness index 


\subsection{Beams' Behavior and Discussion}

\subsubsection{Beam Without Any Shear Reinforcement (B5-NS)}

This beam had only two \#5 rebars located at 0.75 inches from the bottom face. Its compressive strength was estimated in section 4.2.1 to be $6711 \mathrm{psi}$. Therefore, its maximum theatrical shear capacity, which was determined in chapter 3, can be revised based on equation $11-3$ or $11-5$ in the ACI 318-08 [41]

$$
\begin{aligned}
& V_{c}=\left(1.9 \lambda \sqrt{f^{\prime} c}+2500 \rho_{w} \frac{V_{u} d}{M_{u}}\right) b_{w} d=\left(1.9 \lambda \sqrt{f^{\prime} c}+2500 \rho_{w} \frac{d}{a}\right) b_{w} d \\
& \mathrm{~V}_{\mathrm{c}}=4499 \mathrm{lb} \\
& \mathbf{Q}=\mathbf{2} \mathbf{V}_{\mathbf{c}}=\mathbf{8 9 9 7} \mathbf{l b} \sim \mathbf{9 . 0} \mathbf{k i p s} \\
& V_{c}=2 \lambda \sqrt{f^{\prime} c} b . d=2 \sqrt{6711}(4.5)(5.8)=4.28 \mathrm{kips} \\
& \therefore \mathbf{Q}=\mathbf{2} \mathbf{V}_{\mathbf{c}}=\mathbf{8 . 5 5} \mathbf{k i p s}
\end{aligned}
$$

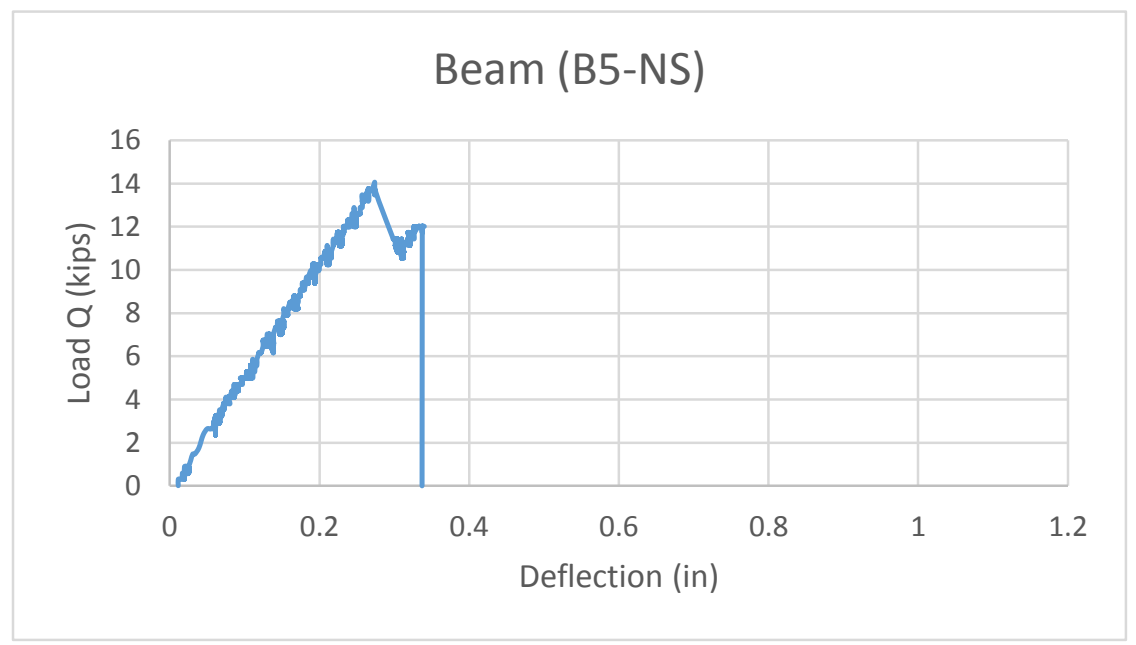

Figure 4-11 Experimental load versus deflection 
If the ultimate strength estimated by ACI 318 is compared with one determine in the test, it can be seen the measured strength was about $40 \%$ higher than predicted by ACI Code. This result was expected since ACI equation was derived based on a very large number of test results. Moreover, the beam contained a high amount of flexural steel, thus adding to the dowel action capacity.

This type of beam has a brittle failure. Therefore, the ductility after the ultimate load is zero.

Stiffness at service load $=k=\frac{Q / 2}{\delta}=\frac{7}{0.15}=46.7 \mathrm{k} / \mathrm{in}$

Stiffness at ultimate load $=14 / 0.27=52.2$

If the beam stiffness at the service load (estimated as about $50 \%$ of the ultimate load), which is 46.7 , is compared with one at the ultimate load, which is $52.2 \mathrm{k} / \mathrm{in}$, it can be concluded that the beam has nearly a linear behavior until ultimate load.

Figure 4-12 shows cracks propagation and widths, which were checked at every 1 kip load. First flexural cracks developed at the bottom fiber below the two point-loads. First cracks were developed at 6 kips with a width less than 0.004 in $(0.1 \mathrm{~mm})$. As the load was increased, more cracks developed extending away from the middle third reign, the reign of the pure flexural stress. These cracks are known as flexural-shear cracks. However, the dominant shear cracks were developed at 14 kips. At this stage, the beam could not sustain the load and load dropped to $12 \mathrm{kips}$. A little incremental increase in the load led to a brittle failure. The failure was created by diagonal tension. 

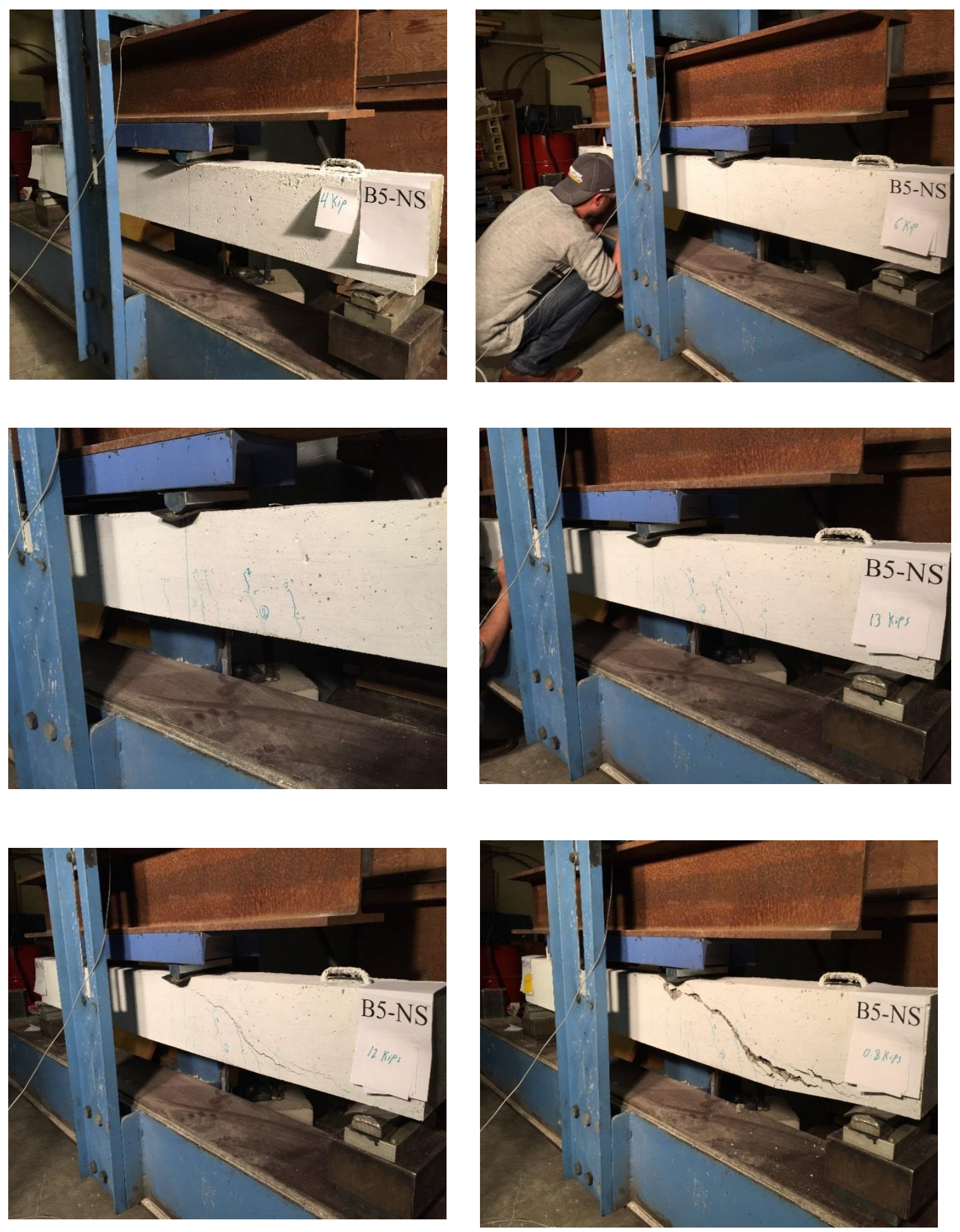

Figure 4-12 Cracks pattern and beam failure 


\subsubsection{Beam Reinforced with Minimum Shear Steel Reinforcement (B1-MS)}

Figure 4-13 shows load versus deflection for this beam specimen. It can be inferred that reinforcement increases both shear strength and ductility by transferring the load across the cracks. The shear strength estimated in section 3.3 was revised based on the average compressive strength presented in section 4.2.1. However, when shear strength was provided by a reinforcement placed at $\mathrm{d} / 2$, minimum shear reinforcement was not affected.

$$
\begin{aligned}
& V_{c}=\left(1.9 \lambda \sqrt{f^{\prime} c}+2500 \rho_{w} \frac{V_{u} d}{M_{u}}\right) b_{w} d=\left(1.9 \lambda \sqrt{f^{\prime} c}+2500 \rho_{w} \frac{d}{a}\right) b_{w} d \\
& \mathrm{~V}_{\mathrm{c}}=4682 \mathrm{lb}=4.4 \mathrm{kips} \\
& \mathrm{V}_{\mathrm{s}}=2.1 \mathrm{kips} \\
& \mathrm{V}_{\mathrm{u}}=\mathrm{V}_{\mathrm{n}}=4.6+2.1=6.7 \mathrm{kips} \\
& \mathrm{Q}=2(6.7)=13.4 \mathrm{kips}
\end{aligned}
$$

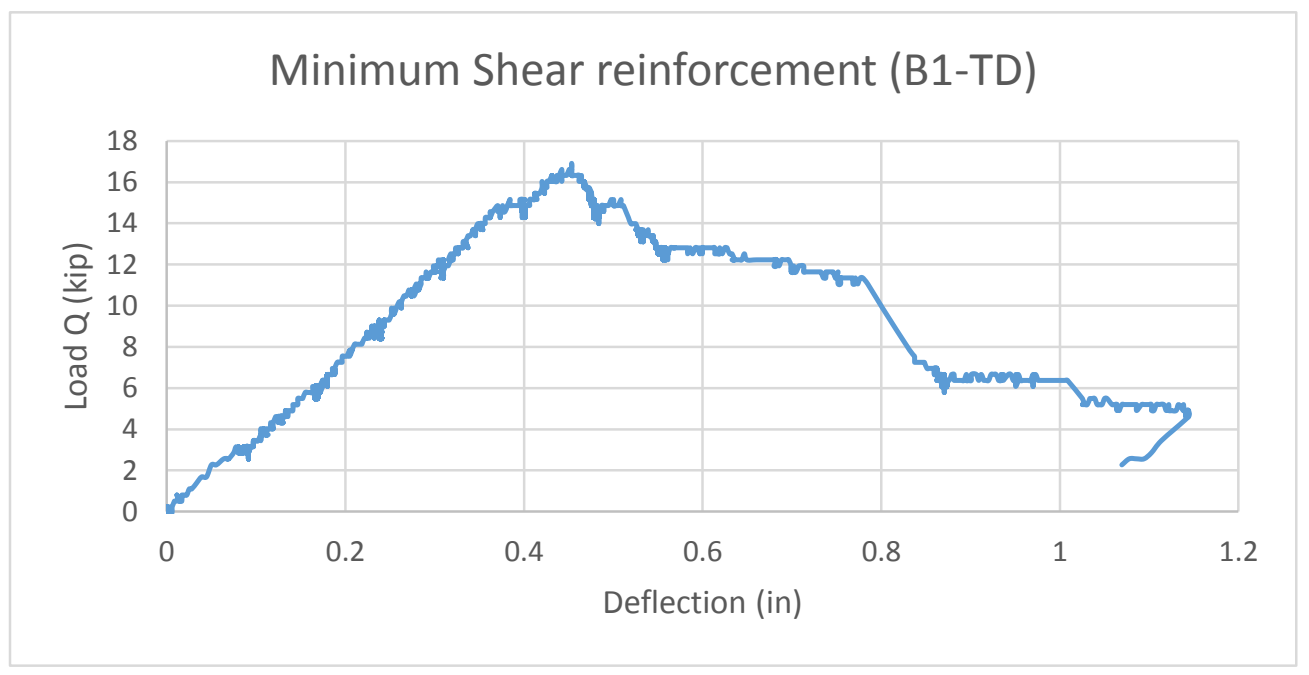

Figure 4-13 Load versus deflection for minimum shear reinforcement beam 
From figure 4-13 it can be seen that as the load increased, the beam's deflection was increasing. This deflection followed a linear behavior until the ultimate load was reached, at which point the beam stiffness was determined. After reaching the ultimate load, the beam strength started decreasing gradually giving a good ductility for the beam. This ductility was provided by shear reinforcement. The ductility of the beam was determined after dropping the beam strength to the service limit, which is estimated as about $50 \%$ of the ultimate strength.

Stiffness at service load $=k=\frac{Q / 2}{\delta}=\frac{8.13}{0.21}=38.7 \mathrm{k} / \mathrm{in}$

Ductility $=\mu=\frac{4.71}{2.93}=1.61$

Ductility is the ratio of the absorbed energy by the plastic deformation when load dropped to the service limit to the energy absorbed under elastic deformation. In other words, it the ratio of area under load deflection curve when load dropped from peak value to the service limit to the area when load increased from zero the peak value.

The nominal strength of each system was determined in terms of $\sqrt{f^{\prime} c}$. This nominal shear strength was referred to as $\mathrm{V}_{\mathrm{c}}$ for the purpose of comparsion with specimen that did not have any shear reinforcement.

$$
\begin{aligned}
& V_{C}=x \sqrt{f^{\prime} c} b_{w} \cdot d \rightarrow \frac{16.6}{2}=x \frac{\sqrt{7332}}{1000} \\
& \mathrm{X}=3.71 \\
& \therefore V_{C}=3.71 \sqrt{f^{\prime} c} b_{w} \cdot d
\end{aligned}
$$


Figure 4-14 shows the cracks pattern. Flexural cracks were initiated under 3 kips at the bottom face. The width of the cracks at this stage was less than $0.1 \mathrm{~mm}$. The width of the cracks increased to $0.1 \mathrm{~mm}$ under 6 kips. At 9 kips, more cracks were initiated. However, old cracks preserved their width. Shear cracks of 0.004 in $(0.1 \mathrm{~mm})$ width were developed under 12 kips. As the load increased to $15 \mathrm{kips}$, shear cracks widened to 0.013 in $(0.33 \mathrm{~mm})$. Nevertheless, flexural cracks stopped propagating at this stage. Shear crack width at the ultimate load was 0.05 in $(1.25 \mathrm{~mm})$. After this stage, the shear cracks started widening as the load was increased until diagonal tensile failure occurred. 

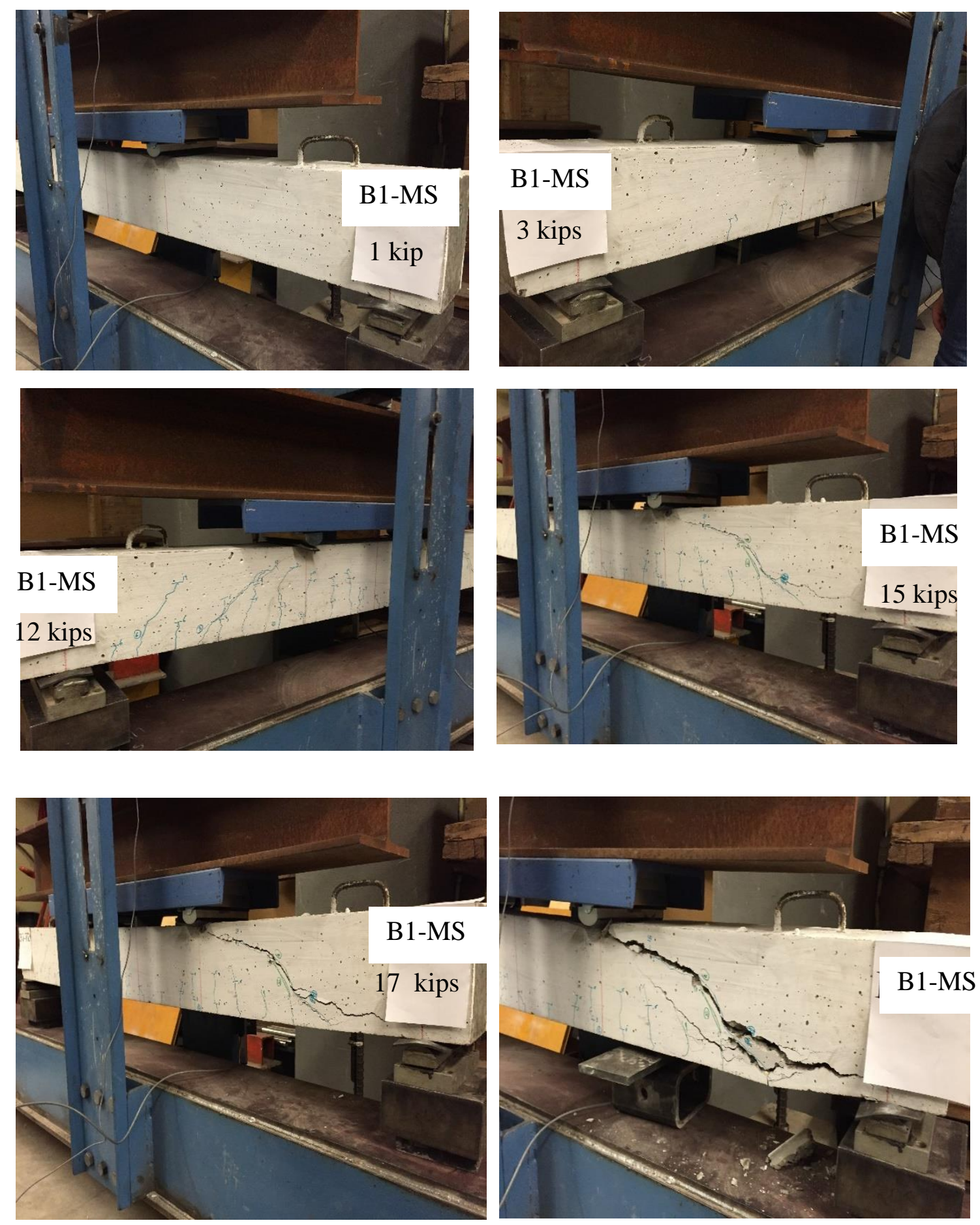

Figure 4-14 Cracks propagation and failure pattern for minimum shear reinforcement specimen 


\subsubsection{Beam Reinforced with Hooked-End Steel Fiber (B2-HS)}

Similar to the other two specimens, using a $1 \%$ volumetric ratio of hooked-end steel fiber did not change the linear behavior of stiffness up to peak strength. However, when this beam reached the ultimate strength, its strength did not drop like the control specimens. The hooked-end steel fiber bridged the cracks and transferred the stress along them. Therefore, the specimen sustained the applied load, but its strength started dropping when the concrete on the top surface started to crush.Figure 4-15 shows that hooked-end steel fiber provided a very good ductility for this system. In other words, as the deflection was increasing, the beam sustained the same ultimate load. After this stage, the load started decreasing gradually.

Stiffness at service load $=k=\frac{Q / 2}{\delta}=\frac{11.3}{0.25}=45.2 \mathrm{k} / \mathrm{in}$

Stiffness at ultimate load $=k=\frac{Q / 2}{\delta}=\frac{23.4}{0.57}=41.1 k /$ in

Ductility was determined using same method in section 4.3.2 $=\mu=\frac{10.24}{5.15}=2.0$

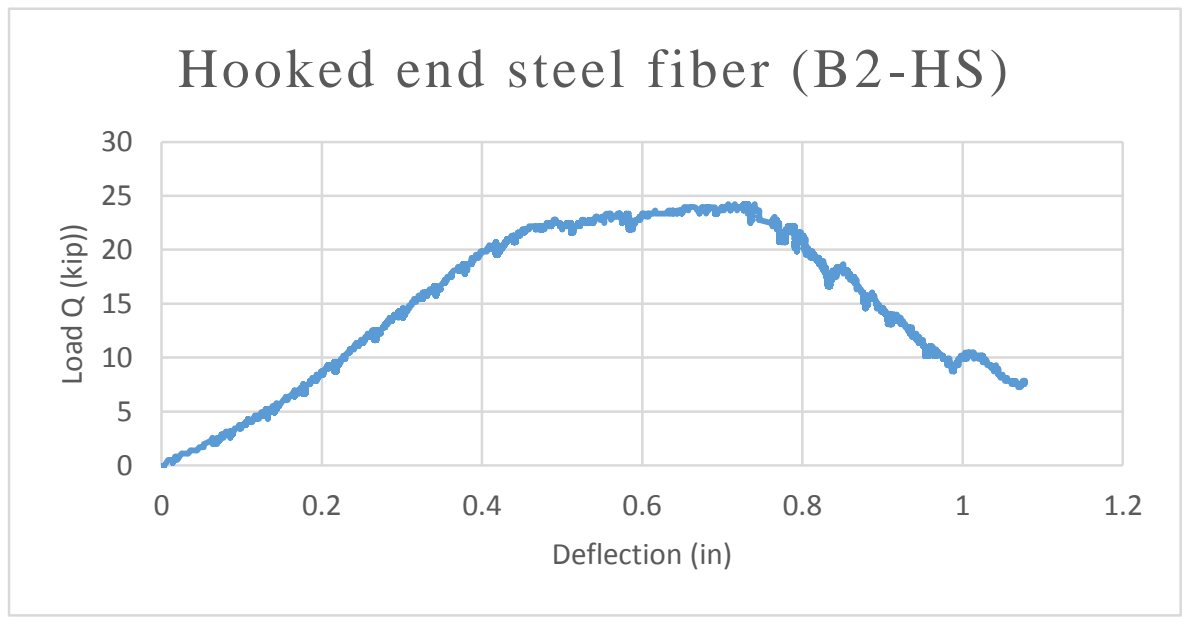

Figure 4-15 Load Vs deflection for hooked end steel fiber 
The ultimate strength was estimated based on Parra-Montesinos (2006) and ACI 318-11, and was revised by using actual compressive strength of the beam.

$V_{C}=3.5 \sqrt{f^{\prime} c} b_{w} . d \rightarrow V_{c}=3.5 \sqrt{6495}(4.5)(5.8)$

$\mathrm{V}_{\mathrm{c}}=7362 \mathrm{lb}=7.4 \mathrm{kips}$

$\mathrm{Q}=2 \mathrm{~V}_{\mathrm{c}}=2(7.4)=14.8 \mathrm{kips}$

It can be seen that the estimated strength is much lower than one determined in the test. Therefore, based on the test result the shear strength of can be estimated with respect $\operatorname{to} \sqrt{f^{\prime} c}$

$V_{C}=x \sqrt{f^{\prime} c} b_{w} \cdot d \rightarrow \frac{24.0}{2}=x \frac{\sqrt{6495}}{1000}$

$\therefore \mathrm{X}=\mathbf{5 . 7}$

$V_{C}=5.7 \sqrt{f^{\prime} c} b_{w} \cdot d$

Flexural cracks with a width less than 0.004 in $(0.1 \mathrm{~mm})$ first developed at 5 kips. As the load was increased, more cracks developed out of the middle third of the beam. Flexural shear cracks were developed at 7 kips. At 9 kips, the biggest crack width was 0.008 in $(0.2 \mathrm{~mm})$. The first shear crack was initiated at $16 \mathrm{kips}$. At this level, the biggest crack width was 0.016 in $(0.4 \mathrm{~mm})$. It can be seen from figure $4-16$ that this beam developed a greater number of cracks than the control specimens. This result reflects a good redistribution of the stresses. When the load was increased, the cracks widened. However, it was bridged by fibers. The maximum crack width at the ultimate load, which was 24 
kips, was 0.07 in $(1.8 \mathrm{~mm})$. Compression failure occurred by crushing the concrete in the middle third of the top face.
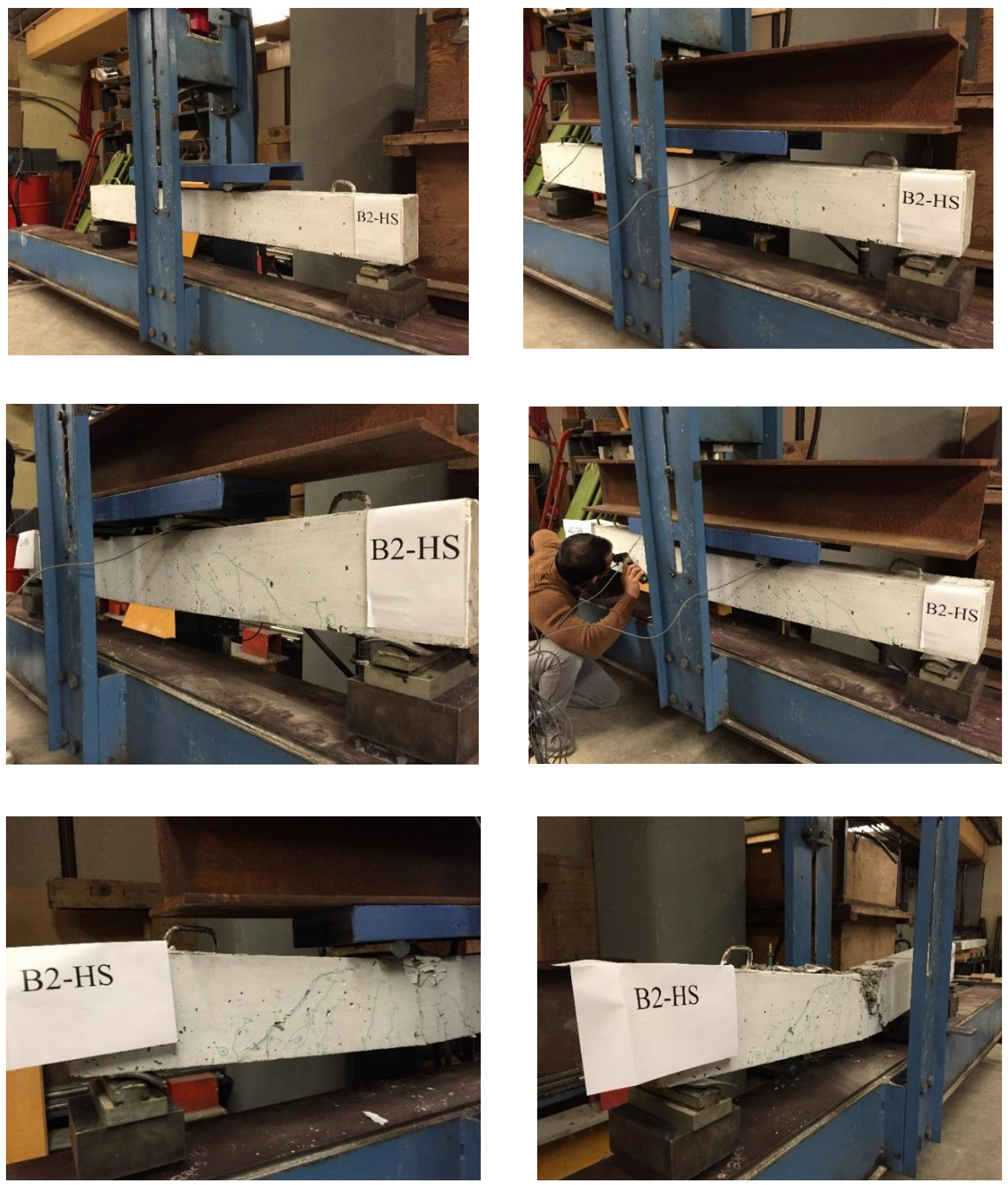

Figure 4-16 Cracks propagation and failure pattern for hooked end steel fiber 


\subsubsection{Beam Reinforced with Crimped-Steel Fiber (B3-CS)}

Similar to the previous beam, using a $1 \%$ of crimped-steel fiber increased the shear strength of the beam. It can be seen from figure 4-17 that the shear strength increased linearly up to the ultimate strength, at which point the curve started flatting. In other words, at the ultimate load, the beam stiffness dropped due to the amount of the cracks that developed.

AIt can be seen that fiber significantly enhanced the ductility of the concrete beam. Bond failure between fibers and concrete was observed due to increasing the load beyond the ultimate strength. At this level, beam strength started dropping due to a shear failure followed by a compression failure.

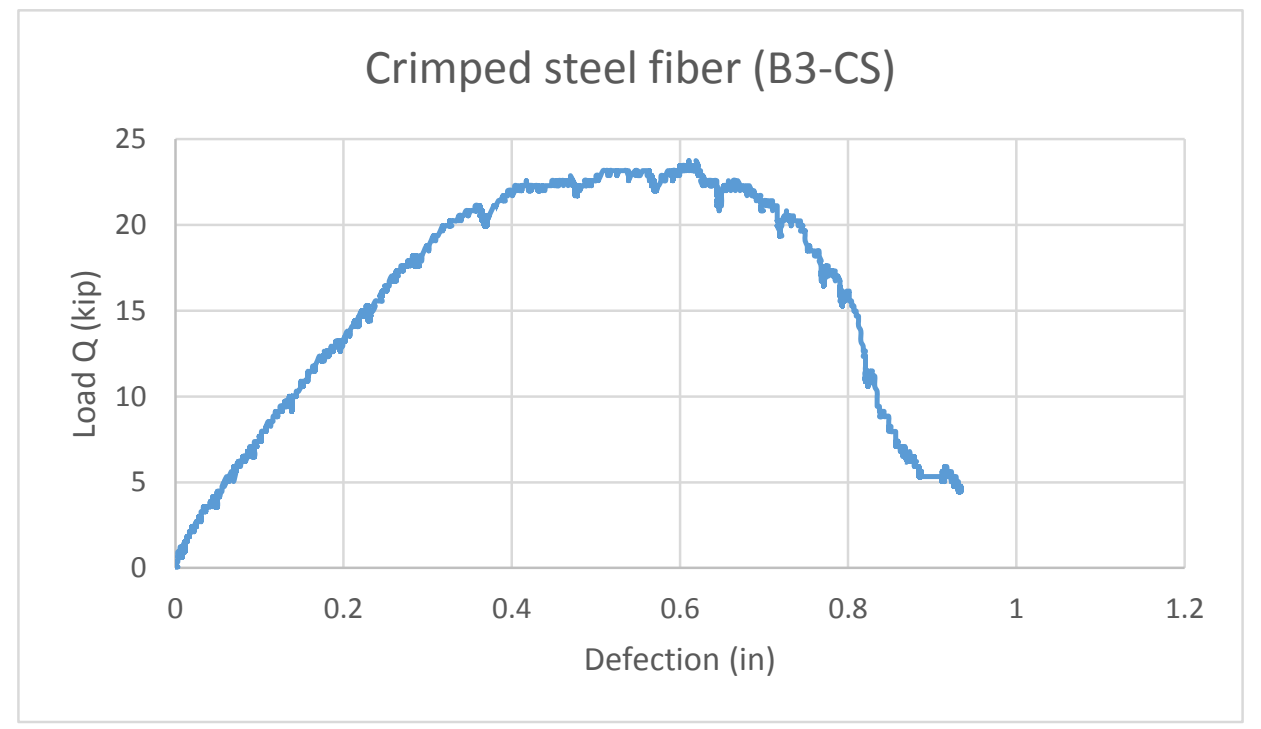

Figure 4-17 Load vs deflection for crimped steel fiber 
Stiffness at service load $=k=\frac{Q / 2}{\delta}=\frac{11.5}{0.17}=64.7 \mathrm{k} / \mathrm{in}$

Stiffness at ultimate load $=k=\frac{Q}{\delta}=\frac{22.9}{0.57}=40.2 \mathrm{k} / \mathrm{in}$

Ductility to a point when strength dropped to the service load $=\mu=\frac{8.87}{4.4}=2.0$

The estimated shear strength based on the actual compressive strength is

$V_{C}=3.5 \sqrt{f^{\prime} c} b_{w} . d \rightarrow V_{c}=3.5 \sqrt{5758}(4.5)(5.8)$

$V_{c}=6931 \mathrm{lb}=6.9 \mathrm{kips}$

$2 \mathrm{P}=2 \mathrm{~V}_{\mathrm{c}}=2(6.9)=13.9 \mathrm{kips}<$ less than actual strength determined in the test

Therefore the actual strength can be determine with respect to $\sqrt{f^{\prime} c}$

$V_{C}=x \sqrt{f^{\prime} c} b_{w} \cdot d \rightarrow \frac{23.6}{2}=x \frac{\sqrt{5758}}{1000}(4.5)(5.8)$

$\therefore \mathbf{X}=\mathbf{6 . 0}$

$V_{C}=6.0 \sqrt{f^{\prime} c} b_{w} \cdot d$

Visible flexural cracks with a width less than $0.1 \mathrm{~mm}$ were initiated at the middle third of the beam at 6 kips. The cracks' width was not effected when the applied load was increased to 9 kips. However, a few other cracks formed, which refers to a good stress redistribution. At 12 kips some of the cracks widened to 0.004 in $(0.1 \mathrm{~mm})$. The first shear crack with a width less than 0.004 in $(0.1 \mathrm{~mm})$ was initiated at 15 kips. At this stage, some of the flexural cracks widened to 0.008 in $(0.2 \mathrm{~mm})$. Crimped-steel fiber prevented 
the cracks from propagating, and transferred the load across them. When the applied load reached 22 kips, cracks were initiated and some of the old ones widened. As the load was increased, most of the fibers had a bond failure or fracture failure. At this stage, the maximum crack width was 0.028 in $(0.7 \mathrm{~mm})$. As shown in figure $4-18$, after the maximum crack was reached, the beam strength decreased gradually as the load was increased. Due to shear failure that was later companied by compression failure, a brittle failure occurred.
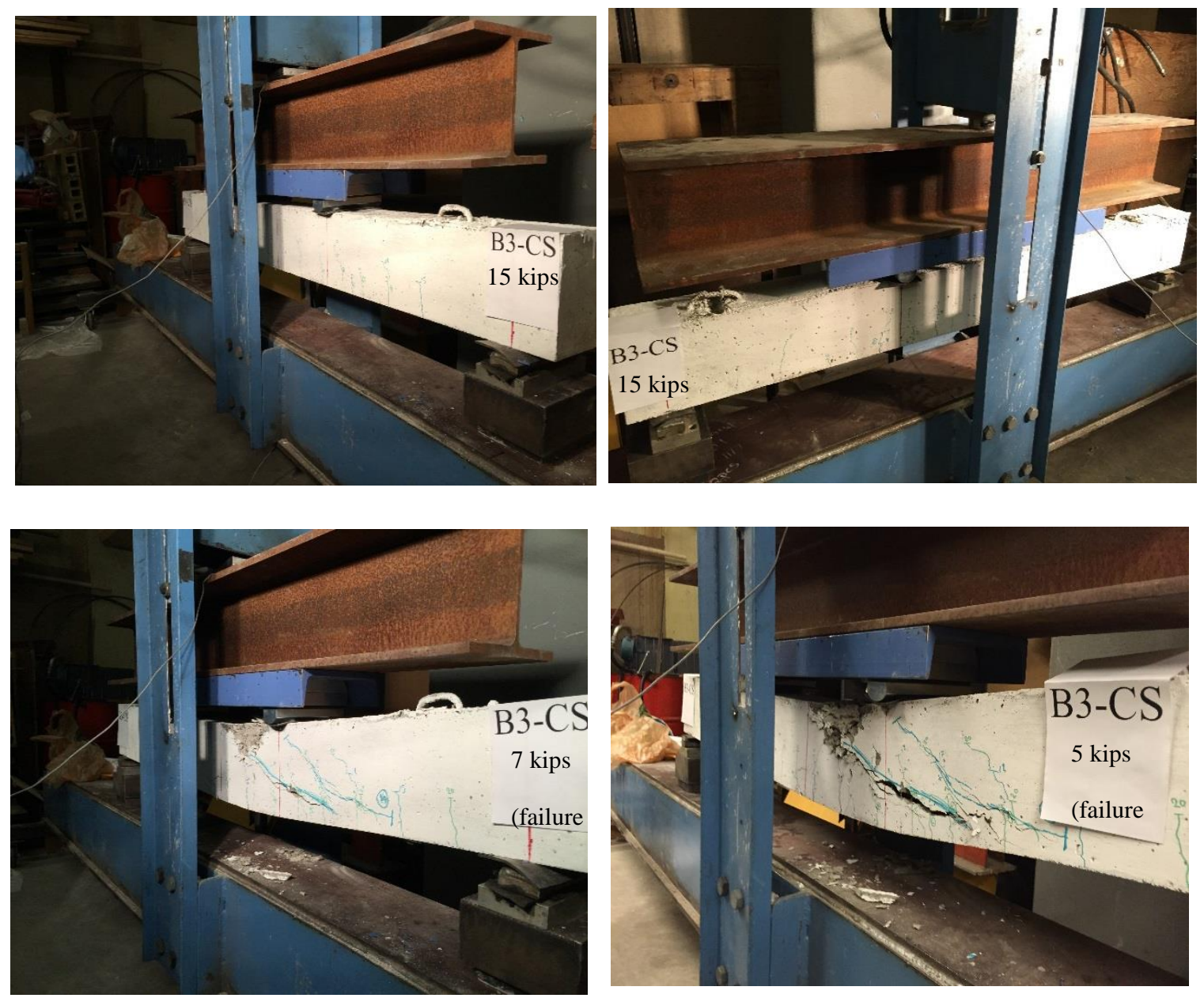

Figure 4-18 Cracks propagation and failure pattern for crimped steel fiber 


\subsubsection{Beam Reinforced with Monofilament-Crimped Polypropylene Fiber (B4-CPP)}

Figure 4-19 shows the load versus deflection for the crimped-monofilament polypropylene fiber. The stiffness of this beam increased linearly up to the ultimate strength when a brittle shear failure occurred. In comparison with the other control specimens, polypropylene fiber boosted the beam strength by bridging micro cracks.

Nevertheless, when the stress was increased and cracks began to propagate, most of the fibers fractured causing beam failure.

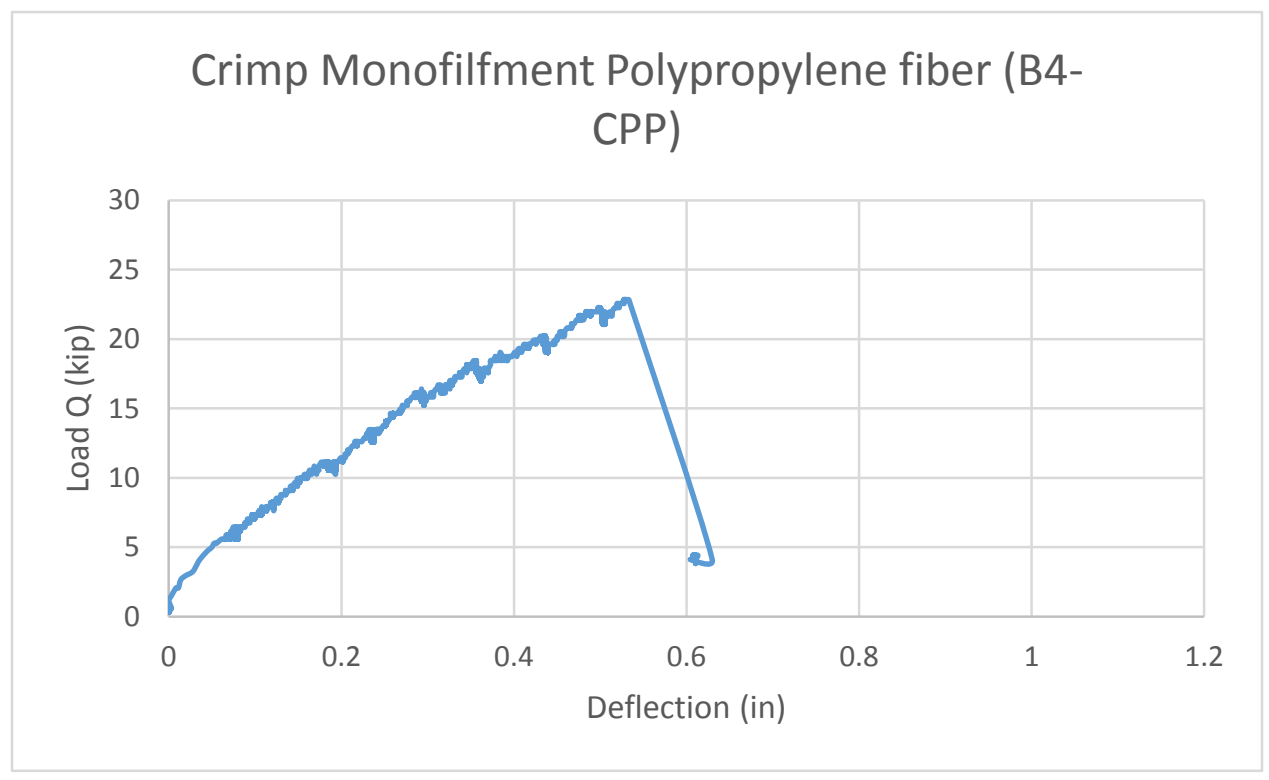

Figure 4-19 Load vs deflection for crimped monofilament polypropylene fiber

Stiffness at service load $=k=\frac{Q / 2}{\delta}=\frac{11.4}{0.2}=57 \mathrm{k} / \mathrm{in}$

$V_{C}=3.5 \sqrt{f^{\prime} c} b_{w} . d \rightarrow V_{c}=3.5 \sqrt{6914}(4.5)(5.8)$ 
$V_{c}=7596 \mathrm{lb}=7.6 \mathrm{kips}$

$\mathrm{Q}=2 \mathrm{~V}_{\mathrm{c}}=2(7.6)=15.2 \mathrm{kips}$

Based on earlier research [42] and ACI 318-11 tests, it can be seen that the estimated strength was less than the strength determined in this test. Therefore, shear strength can be determined as a function of $\sqrt{f^{\prime} c}$

$V_{C}=x \sqrt{f^{\prime} c} b_{w} . d \rightarrow \frac{22.8}{2}=x \frac{\sqrt{6914}}{1000}$

$\therefore \mathrm{X}=\mathbf{5 . 2 5}$

$V_{C}=5.25 \sqrt{f^{\prime} c} b_{w} \cdot d$

Similar to the previous beam, flexural cracks were first initiated at a load of 6 kips. At a load of 8 kips, additional two cracks were initiated. The maximum crack width at this stage was less than $0.1 \mathrm{~mm}$. while few other cracks developed at $11 \mathrm{kips}$. The overall amount of cracks was less than the beam specimen reinforced with steel fiber. Therefore, it can be concluded that polypropylene inhibited micro-crack propagation. As the load increased, cracks propagated and the polypropylene fibers fractured. Shear cracks developed at 13.5 kips with a width of $0.1 \mathrm{~mm}$. At 16.4 kips, shear cracks width was $0.2 \mathrm{~mm}$. As the load was increased, the cracks widened. In addition, few other cracks developed. The maximum crack width at $22.2 \mathrm{kips}$, which was close to the failure load, was $1.6 \mathrm{~mm}$. After this stage, a brittle shear failure developed and the beam strength dropped to almost zero as shown in figure 4-20. 

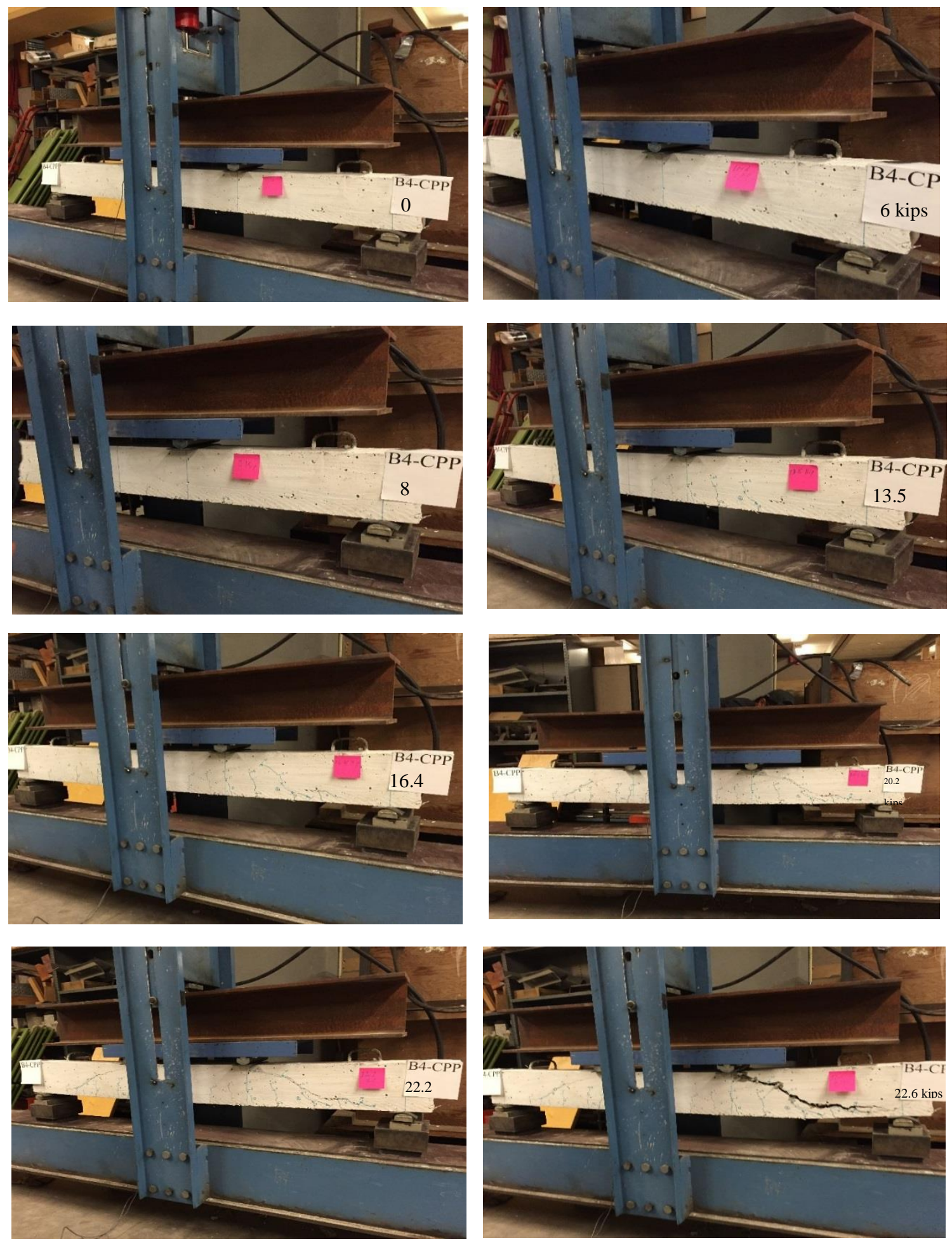

Figure 4-20 Cracks propagation and failure pattern for monofilament crimped polypropylene fiber 


\subsection{Summary of the Beams Tests}

\subsubsection{Ultimate Shear Stress and Normalize Shear Stress}

The ultimate shear strength of the beam specimens, $v_{u}$, was determined from the peak applied load, $Q / 2$, shear span, $a$, and the beam cross section. The table shows the normalize shear-stress for each of the beam specimens.

$v_{u}=\frac{Q}{2 b \cdot d}$

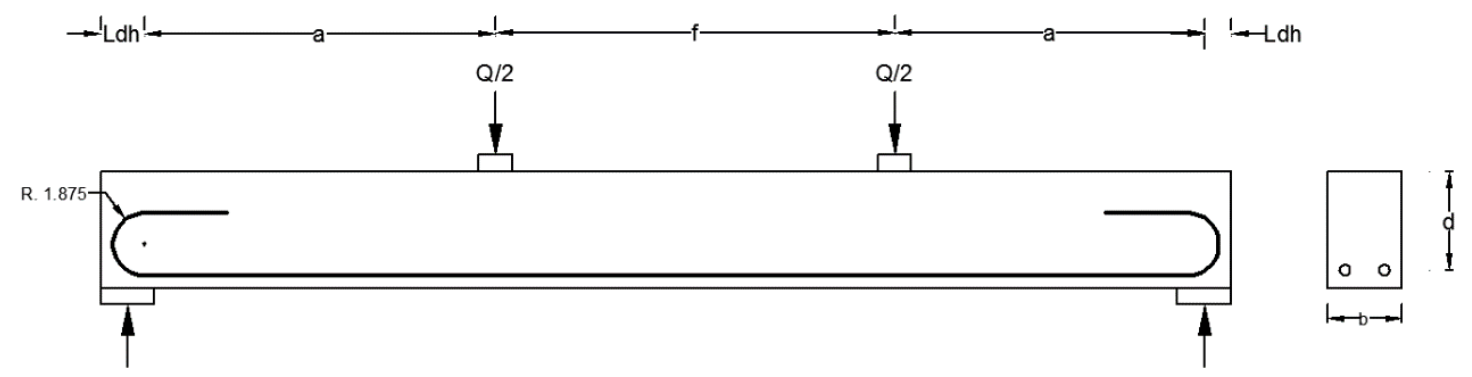

Figure 4-21 Shear forces in the tested beams 
Table 4-6 Normalized ultimate shear stress in term of $\sqrt{f^{\prime} c}$

\begin{tabular}{|c|c|c|c|c|c|c|}
\hline Beam & $\begin{array}{c}\text { Beams } \\
\text { description }\end{array}$ & $\begin{array}{c}\mathbf{Q} / \mathbf{2} \\
(\mathbf{k i p s})\end{array}$ & $\begin{array}{c}\boldsymbol{v}_{\boldsymbol{u}} \\
(\mathbf{p s i})\end{array}$ & $\frac{\boldsymbol{v}_{\boldsymbol{u}}}{\sqrt{\boldsymbol{f}^{\prime} \boldsymbol{c}}}$ & Ductility & Failure mode \\
\hline B5-NS & $\begin{array}{c}\text { (No Shear } \\
\text { Reinforcement) }\end{array}$ & 7.0 & 287 & 3.5 & 0 & Diagonal tension \\
\hline B1- MS & (Min Steel) & 8.3 & 318 & 3.7 & 1.61 & Diagonal tension \\
\hline B2-HS & $\begin{array}{c}\text { (Hooked Steel) } \\
\text { B3-CS }\end{array}$ & 11.8 & 452 & 5.7 & 2.0 & $\begin{array}{c}\text { Compression } \\
\text { failure }\end{array}$ \\
\hline (Crimpled Steel) & 11.9 & 455 & 6.0 & 2.0 & Compression- \\
shear failure
\end{tabular}

It can be seen from table 4-6 that minimum normalized shear-stress for the fiber reinforced concrete beam is $5.25 \sqrt{f^{\prime} c}$. This value is greater than the normalized value for the beam specimen reinforced with minimum shear reinforcement. In addition, it is more than the value estimated in ACI $318,3.5 \sqrt{f^{\prime} c}$. 
In order to compare shear strength and the behavior of fiber reinforced concrete beams, the beam reinforced with minimum shear reinforcement was used as a base line for normalizing the strength of other specimens. Table 4-7 shows the normalized ultimate shear strength for the beam specimens.

Table 4-7 Normalized shear strength of the beams to the one with minimum shear reinforcement

\begin{tabular}{|c|c|c|c|}
\hline Beam & Beams description & $\begin{array}{c}\text { Q/2 } \\
\text { (kips) }\end{array}$ & $\begin{array}{c}\text { Shear strength normalize to min. } \\
\text { shear reinforced beam (B1-MS) }\end{array}$ \\
\hline B5-NS & (No Shear & 7.0 & 0.84 \\
\hline B1- MS & (Min Steel) & 8.3 & 1.0 \\
\hline B2-HS & (Hooked Steel) & 12 & 1.46 \\
\hline B3-CS & (Crimpled Steel) & 11.8 & 1.42 \\
\hline B4-Cpp & (crimped & 11.4 & \\
\hline
\end{tabular}




\subsubsection{Crack Width, Pattern and Failure Mode}

From test results, it was observed that all of the beams developed a number of cracks. However, the amount that was developed in the fiber-reinforced specimens, especially for steel fiber specimens, was more than other specimens. This phenomenon indicates a better behavior in stress redistribution.

A maximum crack width of 0.071 in $(1.8 \mathrm{~mm})$ was observed in the beam specimen reinforced with hooked-end steel fiber. For crimped-steel fiber, the maximum crack width was $0.028 \mathrm{in}(0.7 \mathrm{~mm})$. The polypropylene fiber specimen developed a wider crack with a width of 0.063 in $(1.6 \mathrm{~mm})$. For the control specimen with minimum shear reinforcement and plain concrete, cracks of $0.049 \mathrm{in}(1.25 \mathrm{~mm})$ and 0.004 in $(0.1 \mathrm{~mm})$ respectively were observed. Regarding cracks, the previous results showed that fiber reinforced concrete specimens can provide behavior similar to, if not better than, a beam with minimum shear reinforcement.

Table 4-6 lists three types of failure. The first type of failure is diagonal tension, which was observed in the control specimen and specimen reinforced with polypropylene fiber. In this type of failure, a diagonal tension crack developed that widened and led to failure. The second type of failure was compression failure, which occurred at the top compression fiber of concrete in the middle third of the beam. This type of failure was observed in the beam reinforced with hooked-end steel fiber. The last type of failure was started by the bond failure between the concrete and the fiber in the diagonal crack that was followed by crushing of the concrete at the top fiber. This failure was obtained in the beam specimen reinforced with crimped-steel fiber. 


\subsubsection{Prediction of Shear Strength Based on Previous Research.}

As described in section 2.4, a number of researchers have proposed expressions to predict the shear strength of steel fiber reinforced concrete beams. These expressions are used in this section to compute shear strength values, and to compare them with measured shear strength to find the closest estimation. It is should be noted that these expressions were derived for steel fibers. However, when it was used for the polypropylene fiber, it gave a very close estimation.

Table 4-8 Prediction shear strength of SFC

\begin{tabular}{|c|c|c|c|c|c|c|}
\hline Beam & $\begin{array}{l}\text { Shear } \\
\text { strength } \\
\text { from the } \\
\text { test (psi) }\end{array}$ & $\begin{array}{c}\text { Shear } \\
\text { strength } \\
\text { based on } \\
\text { Sharma } \\
\text { (psi) }\end{array}$ & $\begin{array}{c}\text { Shear } \\
\text { strength } \\
\text { based on } \\
\text { Narayanan } \\
\text { \& Darwish } \\
\text { (psi) }\end{array}$ & $\begin{array}{c}\text { Shear } \\
\text { strength } \\
\text { based on } \\
\text { Al-Ta'an } \\
\text { (psi) }\end{array}$ & $\begin{array}{l}\text { Shear } \\
\text { strength } \\
\text { based on } \\
\text { Khuntia, } \\
\text { (psi) }\end{array}$ & $\begin{array}{c}\text { Variation } \\
\text { from the } \\
\text { closest } \\
\text { estimation }\end{array}$ \\
\hline $\begin{array}{l}\text { B2- } \\
\text { HS }\end{array}$ & 452 & 287 & 311 & 320 & 253 & $29 \%$ \\
\hline $\begin{array}{l}\text { B3- } \\
\text { CS }\end{array}$ & 455 & 266 & 284 & 292 & 175 & $36 \%$ \\
\hline $\begin{array}{l}\text { B4- } \\
\text { CPP }\end{array}$ & 437 & 280 & 336 & 359 & 238 & $17 \%$ \\
\hline
\end{tabular}




\subsubsection{Replacement of Minimum Shear Reinforcement}

Results presented in table 4-6 show that the normalized ultimate shear-stress for the fiber reinforced concrete was more than the one reinforced with steel reinforcement. In addition, Figure 4-22 shows that the beam specimen reinforced with steel fiber exhibited ductility better than the control specimen. Therefore, both types of steel fiber appear to have the potential to replace traditional reinforcement for minimum shear reinforcement.

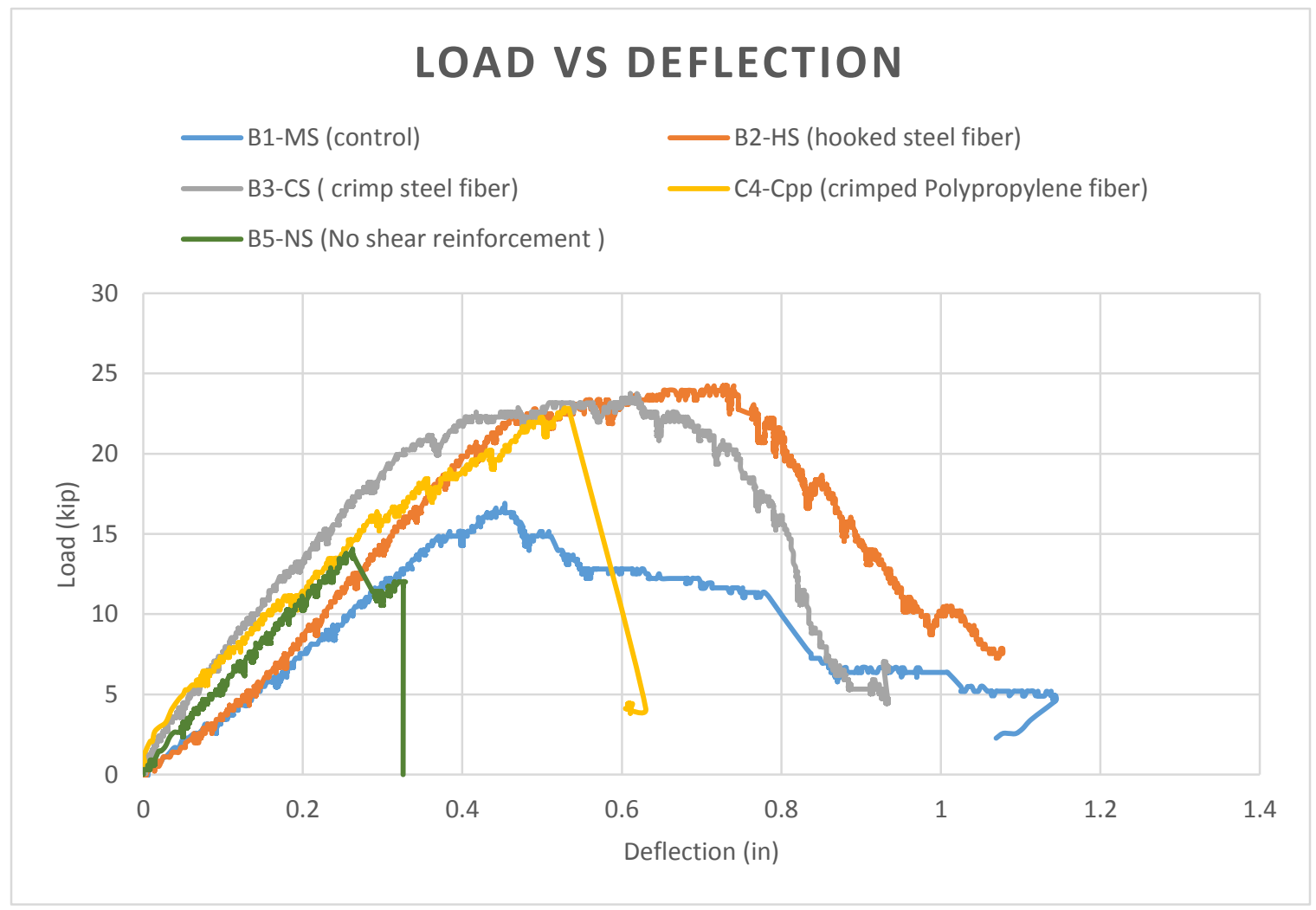

Figure 4-22 comparison load versus deflection for the tested beam specimens. 
In order to compare the effect of fibers on the shear strength, all load-deflection relationships for specimens were normalized to the one reinforced with minimum shear reinforcement as shown in figure 4-23.

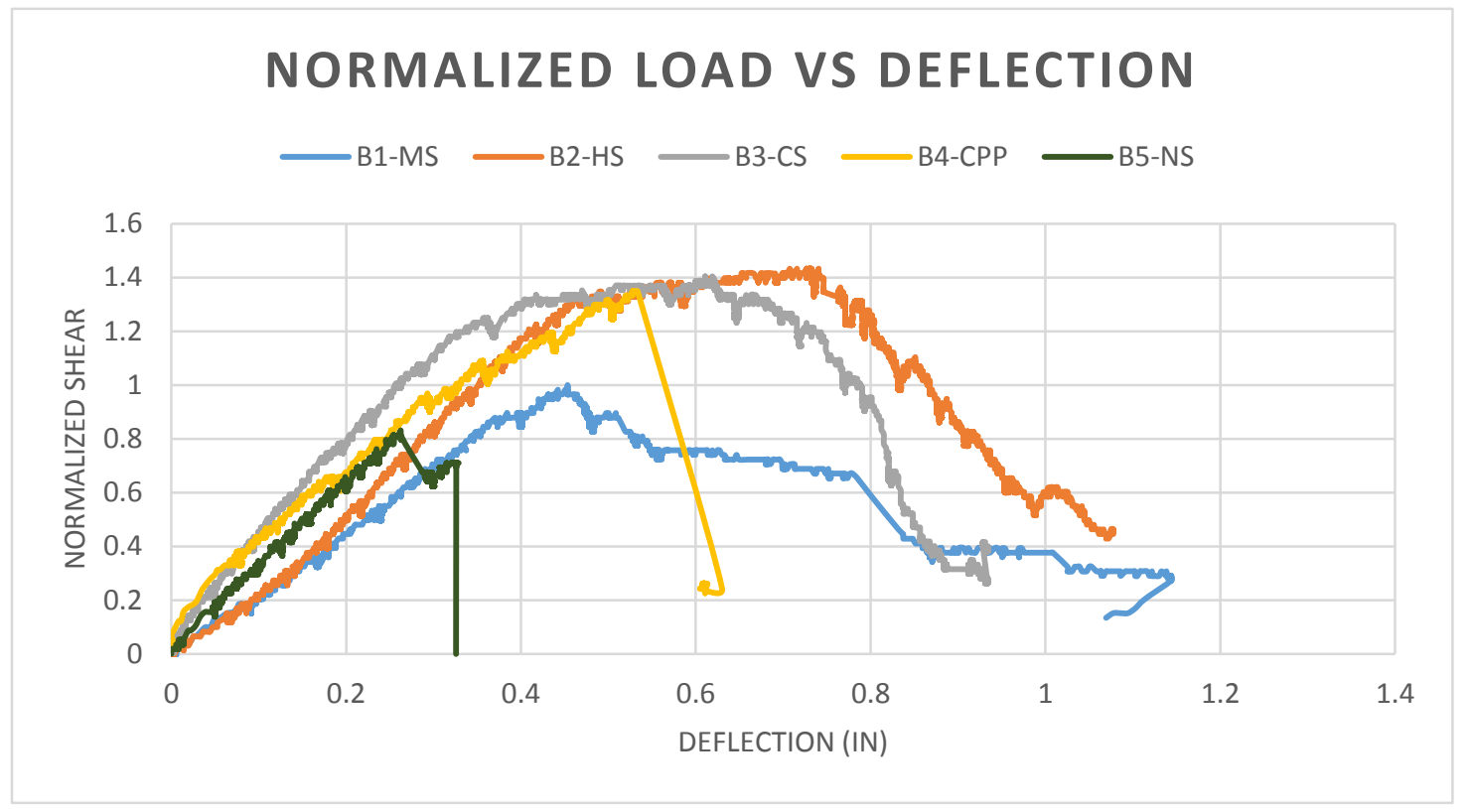

Figure 4-23 Normalized Shear strength 


\section{Chapter 5: Summary, Conclusions and Recommendations for Further Research}

\subsection{Summary}

The experimental program consisted of five approximately one-third scale beam specimens. Three specimens were reinforced with hooked-end steel, crimped-steel and crimped-monofilament polypropylene fibers. The other two were control beam specimens. One was reinforced with steel wire stirrups placed at maximum spacing specified by ACI 318. The other control beam did not have any shear reinforcement. These beams had a moderate slenderness ratio of effective shear span-to-depth ratio of 3.6. The concrete compressive strength varied from 5758 psi to 7332 psi. In order to avoid flexural failure and ensure a shear failure, a longitudinal reinforcement ratio of $2.42 \%$ was selected. In addition to the beam specimens, twelve prisms measuring $6 " \mathrm{x} 6$ " x 18 " were made to determine flexural strength and flexural toughness of each type of fiber. The effect of fibers on the compressive strength of concrete were determined by testing standard 6"x12" cylinders. The effect of fibers on the tensile strength of concrete were determined by testing eight cylinders, $6 " \mathrm{x} 12$ ", using the splitting tensile test.

The aim of this research was to compare the effect of the fiber on the compressive strength, tensile strength, crack pattern, flexural strength, and the flexural toughness of FRC. Moreover, the effect of the type of fiber on the shear strength was studied. Finally, this research investigated the possibility replacing minimum shear reinforcement specified by ACI 318 by a $1 \%$ volumetric amount of fiber. 
The fibers used were manufactured by Propex, namely by Novomesh 850, Novomesh 950 and Novocon 1050. It should be noted that for Novomesh 850, and Novomesh 950 fibrillated polypropylene fiber was not investigated for the purpose of consistency in this research. In the other, only crimped-steel and crimped-polypropylene were investigated. The aspect ratio of the fiber was 34 for the crimped-steel, 55 for the crimpedpolypropylene, and 55 for the hooked-end steel fiber. The volumetric ratio was $1 \%$ for the three fibers.

\subsection{Conclusions}

1- Using $1 \%$ of the crimped-polypropylene fiber increased the pre-cracking flexural strength by bridging the micro-cracks. However, this effect diminished in the case of crimped-steel fiber and vanished for hooked-end steel fiber.

2- Using a $1 \%$ volumetric ratio of the hooked-end steel fiber greatly enhanced the post-cracking characteristics or flexural toughness. This effect was slightly decreased when crimped-steel fiber used. However, in the case of crimpedpolypropylene fiber, flexural toughness was greatly decreased.

3- For the beam specimens, all three types of fibers increased the number of cracks, especially in case of the steel fibers. Beams reinforced with steel fibers developed more cracks than the controls beams, which points to a better stress redistribution. In addition, hooked-end steel fiber shifted the failure mode from diagonal tension, which was observed in the control specimens and the beam reinforced with crimped polypropylene fiber, to compression failure and pure flexural 
failure. The mode of failure in case of crimped-steel fiber was a combination of compression failure and shear failure.

4- The results showed that the three types of the fibers could increase the shear strength of the beams more than the one reinforced with traditional shear reinforcement based on minimum reinforcement specified in the ACI 318. All three types of the fiber showed an increase in the shear strength up to $5.0 \sqrt{f^{\prime} c}$.

5- Both types of steel fibers enhanced the ductility of the beam beyond the ductility of the beam with minimum shear reinforcement. Therefore, it is observed that a $1 \%$ volumetric ratio of steel fiber is able to replace minimum traditional shear reinforcement.

\subsection{Recommendations for Further Research}

Fiber industry is a developing industryand a variety of types of fiberare being introduced such as arched-hooked end steel fibers. These newer types of fiber should be investigated. Another promising field of study is using hybrid fibers. Hybrid fiber can be obtained by mixing fibers made of different materials such as mixing steel fiber with polypropylene fiber to enhance both fresh and hardened concrete characteristics. Another form of hybrid fiber is mixing fibers of different size or shape. 


\section{References}

[1] ACI 544, "Design Concsiderations for Steel Fiber Reinforced Concrete," ACU Jornl Proceedings, vol. 1, no. 2003, pp. 1-23, 2003.

[2] E. Nawy, Fundmentals of High-performance Concrete 2nd ed., New York: John Wiley\& Sons, 2001.

[3] A. E. Naaman and H. Najm, "Bond-Slip Mechanisms of Steel Fibers in Concrete Beam," ACI Materials Journal, vol. 2, no. 88, pp. 135-145, 1991.

[4] N. Banthia and J. F. Trottier, "Concrete Reinforced with Deforemed Steel Fibers, Part I: Bond -Slip Mechanisms," ACI Mterials Journal, vol. 5, no. 91, pp. 435-446, 1994.

[5] D. J. Hannant, "Fiber Cements and Fiber Concretes," John Wily and Sons Ltd, 1978.

[6] H. H. Dinh, "SHEAR BEHAVIOR OF STEEL FIBER REINFORCED COCNRETE BEAMS WITOUT STIRUP REINFORCEMENT," Doctoral Disssertation, pp. 1-277, 2009.

[7] A. E. Naaman and H. W. Reinhardt, "Characterization of High Performance," in Proceedings of the Second International Workshop ' High Performance Fiber Reinforced Cement Composites, Ann Arbor, USA, 1995. 
[8] Z. P. Bazant, "Concrete fracture models: testing and practice," Engineering fracture mechanics, vol. 69, no. 2, pp. 165-205, 2002.

[9] S. Shah and B. V. Rangan, "Fiber Reinforced Concrete Properties," ACI Journal Proceedings, vol. 2, no. 68, pp. 126-135, 1971.

[10] K. Noghabai, "Beams of Fibours Concrete in Shear and Bending: Experment and Model," ASCE Journal of Structural Engineering , vol. 2, no. 126, pp. 243-251, 2000.

[11] D. Denneman, E. Kearsley and A. Visser, "Spliting tensile test of fiber reinforced cocnrete".

[12] J. Oleson, L. Ostergaared and H. Stang, "Nonlinear frccture mechancis and Plsticity of split tensile test," Material and Structures 39, pp. 421-432, 2006.

[13] T. Tang, "Effect of load-distribution width on splitting tesnsion unnotched and cotched cylincderical specimens," Journal of Testing anf Evaluation, no. 22, pp. 401-409, 1994.

[14] C. Recco, G. Guinea, J. Planas and M. Elices, "Size effect and boundary cocndition in the Brazilian test : Therotical verfication," Material and Structures , no. 32, pp. 210-217, 1999. 
[15] P. S. Song and Hwang, "Mechanicl properties of high-strength steel fiber rienforced cocnrete," Construction and Building Materials, vol. 0, no. 18, pp. 669$673,2004$.

[16] J. Thomas and A. Ramaswmy, "Mechanical Properties of Steel Fiber Reinforced Concrete," ASCE Journal of Materils in Civil Engineering , vol. 5, no. 19, pp. 385$392,2007$.

[17] C. D. Johnston, "Properties of Steel Fiber Reinforced Mortar and Concrete," in Interntional Symposium on Fibrous Concrete, Lancaster, 1980.

[18] ASTM. C1018, Standard Test Method for Flexural Toughness of Fiber Reinforced Concrete (Using Beam with Third-Point Loading), West Conshohocken: ASTM International , 2006.

[19] ACI. 544.4R, Design Considerations for Steel Fiber Reinforced Concrete, Farmington Hills, Michigan: ACI, 2009.

[20] v. Ramakarish , T. Brandshaug, W. V. Coy and E. K. Schrder, "Comparative Evaluation of Concrete Reinforced with Straight Steel Fibers and Fibers with Deforemed Ends Glued Together into Bundles," ACI Journal, vol. 3, no. 77, pp. 135-143, 1980. 
[21] P. Sorounshian and Z. Bayasi, "Fiber Type Effects on the Performance of Steel Fiber Reinforced Concrete," ACI Materials Journal , vol. 2, no. 88, pp. 129-134, 1991.

[22] A. R. Khaloo and N. Kim, "Mechanical Properties of Normal to High-Strength Steel Fiber-Reinforced Concrete," Concrete and Aggregates, vol. 2, no. 18, pp. $92-$ 97, 1996.

[23] S. Ahmed, I. A. Bukhari, J. I. Siddiqui and S. A. Qureshi, "A STUDY ON PROPERTIES OF POLYPROPYLENE FIBER REINFORCED COCNRETE," 2006.

[24] R. Zollo, "Collated Fibrillated Polypropylene Fibers in FRC," American Concrete Institute, no. 81, pp. 397-409, 1984.

[25] V. Ramakrish, S. Gollapudi and R. Zellers, "Performance Characteristics and Fatigue of Polypropylene Fiber Reinforced Concrete," American Concrete Institute , pp. 159-177, 1987.

[26] V. Ramakrish , G. Y. Wu and G. Hosalli, "Flexural Fatigue Strength Endurance Limit and Impact Strength of Fiber Reinforced Concrete," Transportation Reserch Record 1226, pp. 17-24, 1989. 
[27] M. Grzybowski and S. P. Shah, "Restrained Shrinkge Test with PP-Fiber Reinforced Concrete," Fiber Reinforced Concrete Properties and Applications, pp. 141-158, 1987.

[28] R. F. Zollo, J. A. IIter and G. B. Bouchaacourt, "Plastic and Drying Shrinkage in Concrete Contining Fibrillted Polypropylene Fiber," in Therid Unternational Symposium on Development in Fiber Reinforced Cement and Concrete , 1986.

[29] P. Vinu, R. Ankur and I. P. I, "Shear Strength of polypropylene fiber reinforced cocnrete moderate deep beams without stirrups," Journal of Structural Engineering , vol. 5, no. 37, pp. 364-368, 2010.

[30] E. Nawy, REINFORED CONCRETE FUNDMENTAL APPROACH, New Jersey: Pearson Education, 2009.

[31] Richart, An Investigstion of Web Stresses in Reinforced Concrete Mebers, University of Illinois Experment Station, 1927.

[32] O. Moretto, "An Investigtion of the Strength of Welded Strirrups in REinforced Concrete Beam," ACI Material Journal, vol. 11, no. 42, pp. 141-162, 1945.

[33] C. Cucchiara, L. Mendola and M. Papia, "Effectiveness of stirrups and steel fibers as shear reinforcement," Cement and Concrete Composite , 2002.

[34] K. Jain, "Steel fiber s minimum shear reinforcement in reinforced concrete beams," Magazine of Concrete Research, vol. 2, no. 18, pp. 92-97, 2013. 
[35] A. K. Sharm, "Shear Strength of Steel Fiber Reinforced Concrete Beams," ACI Journal, pp. 624-628, 1986.

[36] R. Narayanan and I. Y. Darwish , "Use of Steel Fibers as Shear Reinforcement," ACI Structural Journl, vol. 3, no. 84, pp. 216-227, 1987.

[37] J. P. Romualdi and G. B. Batson, "Mechnics of Crack Arrest in Concrete," ASCE Journal of the Engineering Mechanics , pp. 147-168, 1963.

[38] R. N. Swamy and P. S. Mangat, "THeory for the Flexural Strength of Steel Fiber Reinforced Concrete," Cement and Concrete Research, vol. 2, no. 4, pp. 313-325, 1974.

[39] S. A. Al-Ta'an and J. R. Al-Feel, "Evaluation of Shear Strength of fiberReainforcded Concrete Beams," Cement \&Concrete Composites, vol. 5, no. 85, pp. 87-94, 1990.

[40] M. Khuntia, B. Stojadinovic and S. C. Goel, "Shear STrength of Normal and Highstrength Fiber REinforced Concrete Beams without Stirrups," ACI STructural Journl, vol. @, no. 18, pp. 282-289, 1999.

[41] ACI. C. 318, Building Code Requirments for Structural Concrete and Commentary, Farmington Hills , 2008.

[42] G. J. Parra-Montesinos, "Shear Strength of Beams with Deformed Steel Fibers.," Concrete International, vol. 11, no. 28, pp. 57-66, 2006. 
[43] ASTM. C172, Standard Practice for Sampling Freshly Mixed Concrete., West Conshohocken, PA.: ASTM International, 1999.

[44] ASTM. C39/C39M, Standard Test Method for Compressive Strength of, West Conshohocken, PA.: ASTM, 2003.

[45] ASTM. C31/C31M, Standard Practice for Making and Curing Concrete Test, West Conshohocken, PA.: ASTM International, 2003.

[46] ASTM. C496, Standard Test Method For Splitting Tensile Strength of Cylinderical Concrete Specimens, West Conshohocken: ASTM, 2007.

[47] A. Sivakumar and Manu Santhanam, "Mechanical properties of high strength concrete reinforced with metallic and non-metallic fibres," Cement and Concrete Composites, vol. 29, pp. 603-608., 2007.

[48] ASTM. C1609, Standard Test Method for Flexural Performance of FiberReinforced Concrete (Using Beam With Third-Point Loading), Michigan : ASTM, 2007.

[49] ASTM. C1018, Standard Test Methods for Flexural Toughness and First-Crack Strength of Fiber-Reiforced Concrete, West Conshohocken: ASTM, 1997.

[50] ASTM. 370, Standard Test Methods and Definitions for Mechanical Testing of, West Conshohocken, PA.: ASTM, 2003. 